San Jose State University

SJSU ScholarWorks

Mineta Transportation Institute Publications

8-2021

\title{
Spatio-Temporal Analysis of the Roadside Transportation Related Air Quality (STARTRAQ) and Neighborhood Characterization
}

Jaymin Kwon

California State University, Fresno

Yushin Ahn

California State University, Fresno

Steve Chung

California State University, Fresno

Follow this and additional works at: https://scholarworks.sjsu.edu/mti_publications

Part of the Health Policy Commons, and the Transportation Commons

\section{Recommended Citation}

Jaymin Kwon, Yushin Ahn, and Steve Chung. "Spatio-Temporal Analysis of the Roadside Transportation Related Air Quality (STARTRAQ) and Neighborhood Characterization" Mineta Transportation Institute Publications (2021). https://doi.org/10.31979/mti.2021.2010

This Report is brought to you for free and open access by SJSU ScholarWorks. It has been accepted for inclusion in Mineta Transportation Institute Publications by an authorized administrator of SJSU ScholarWorks. For more information, please contact scholarworks@sjsu.edu. 


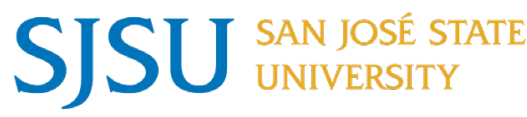

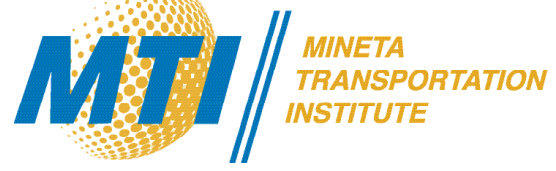

Spatio-Temporal Analysis of the Roadside Transportation Related Air Quality (STARTRAQ) and Neighborhood Characterization

Jaymin Kwon

Yushin Ahn

Steve Chung

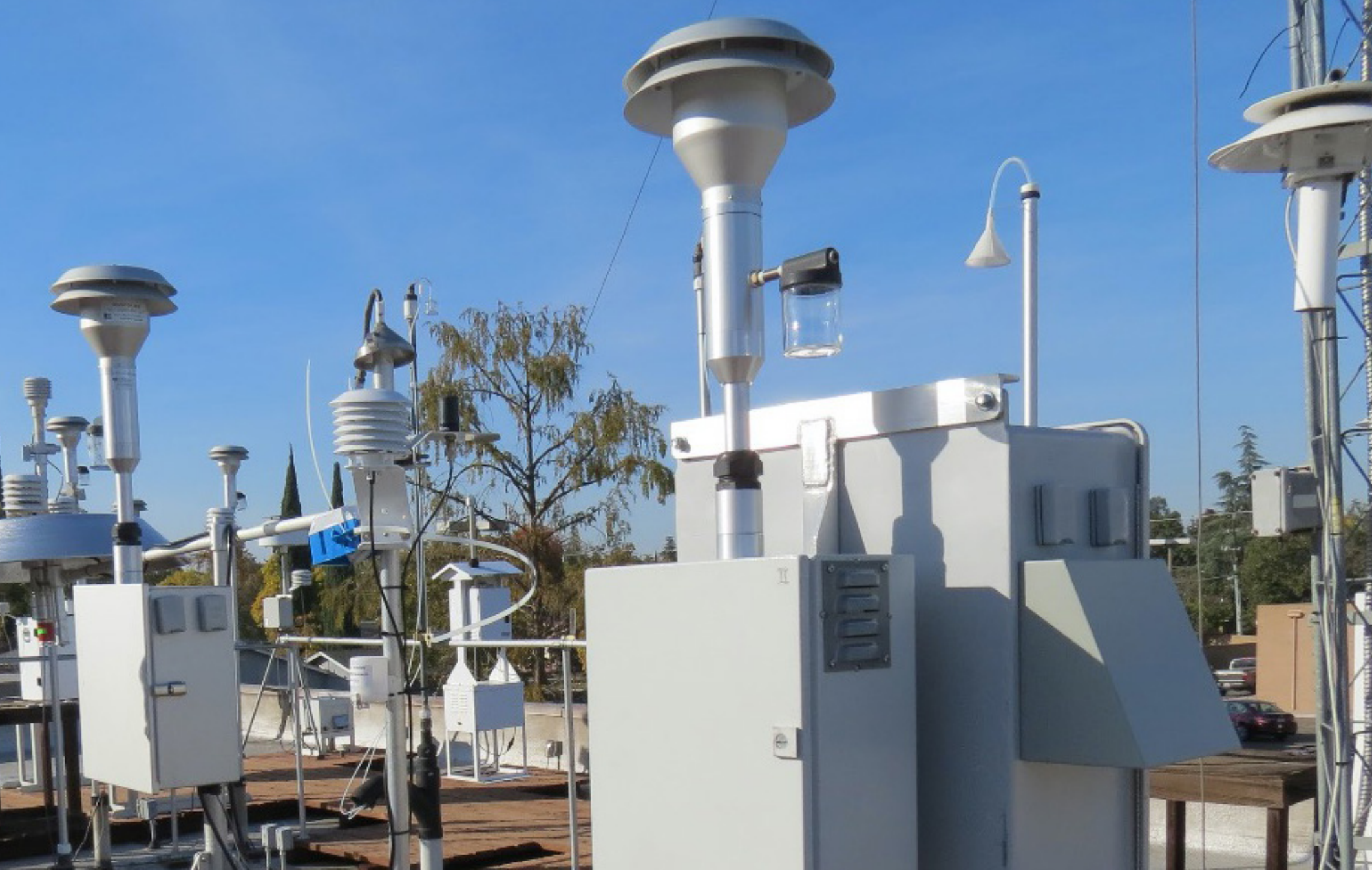

California State University
Transportation Consortium

CALIFORNIA STATE UNIVERSITY LONG BEACH 


\section{Mineta Transportation Institute}

Founded in 1991, the Mineta Transportation Institute (MTI), an organized research and training unit in partnership with the Lucas College and Graduate School of Business at San José State University (SJSU), increases mobility for all by improving the safety, efficiency, accessibility, and convenience of our nation's transportation system. Through research, education, workforce development, and technology transfer, we help create a connected world. MTI leads the Mineta Consortium for Transportation Mobility (MCTM) funded by the U.S. Department of Transportation and the California State University Transportation Consortium (CSUTC) funded by the State of California through Senate Bill 1. MTI focuses on three primary responsibilities:

\section{Research}

MTI conducts multi-disciplinary research focused on surface transportation that contributes to effective decision making. Research areas include: active transportation; planning and policy; security and counterterrorism; sustainable transportation and land use; transit and passenger rail; transportation engineering; transportation finance; transportation technology; and workforce and labor. MTI research publications undergo expert peer review to ensure the quality of the research.

\section{Education and Workforce}

To ensure the efficient movement of people and products, we must prepare a new cohort of transportation professionals who are ready to lead a more diverse, inclusive, and equitable transportation industry. To help achieve this, MTI sponsors a suite of workforce development and education opportunities. The Institute supports educational programs offered by the Lucas Graduate School of Business: a
Master of Science in Transportation Management, plus graduate certificates that include High-Speed and Intercity Rail Management and Transportation Security Management. These flexible programs offer live online classes so that working transportation professionals can pursue an advanced degree regardless of their location.

\section{Information and Technology Transfer}

MTI utilizes a diverse array of dissemination methods and media to ensure research results reach those responsible for managing change. These methods include publication, seminars, workshops, websites, social media, webinars, and other technology transfer mechanisms. Additionally, MTI promotes the availability of completed research to professional organizations and works to integrate the research findings into the graduate education program. MTI's extensive collection of transportation-related publications is integrated into San José State University's world-class Martin Luther King, Jr. Library.

\section{Disclaimer}

The contents of this report reflect the views of the authors, who are responsible for the facts and accuracy of the information presented herein. This document is disseminated in the interest of information exchange. MTI's research is funded, partially or entirely, by grants from the California Department of Transportation, the California State University Office of the Chancellor, the U.S. Department of Homeland Security, and the U.S. Department of Transportation, who assume no liability for the contents or use thereof. This report does not constitute a standard specification, design standard, or regulation. 
Report 21-22

\section{Spatio-Temporal Analysis of the Roadside Transportation Related Air Quality (STARTRAQ) and Neighborhood Characterization}

Jaymin Kwon

Yushin Ahn

Steve Chung

July 2021
A publication of the

Mineta Transportation Institute

Created by Congress in 1991

College of Business

San José State University

San José, CA 95192-0219 


\section{TECHNICAL REPORT \\ DOCUMENTATION PAGE}

\begin{tabular}{|c|c|c|c|}
\hline $\begin{array}{l}\text { 1. Report No. } \\
\text { 21-22 }\end{array}$ & 2. Government Accession No. & \multicolumn{2}{|c|}{ 3. Recipient's Catalog No. } \\
\hline \multirow{2}{*}{\multicolumn{2}{|c|}{$\begin{array}{l}\text { 4. Title and Subtitle } \\
\text { Spatio-Temporal Analysis of the Roadside Transportation Related Air Quality } \\
\text { (STARTRAQ) and Neighborhood Characterization }\end{array}$}} & \multicolumn{2}{|l|}{$\begin{array}{l}\text { 5. Report Date } \\
\text { July } 2021\end{array}$} \\
\hline & & \multicolumn{2}{|c|}{ 6. Performing Organization Code } \\
\hline \multicolumn{2}{|l|}{$\begin{array}{l}\text { 7. Authors } \\
\text { Jaymin Kwon: 0000-0002-4365-6902 } \\
\text { Yushin Ahn: 0000-0002-5305-6396 } \\
\text { Steve Chung: 0000-0001-7255-7244 }\end{array}$} & \multicolumn{2}{|c|}{$\begin{array}{l}\text { 8. Performing Organization Report } \\
\text { CA-MTI-2010 }\end{array}$} \\
\hline \multirow{2}{*}{\multicolumn{2}{|c|}{$\begin{array}{l}\text { 9. Performing Organization Name and Address } \\
\text { Mineta Transportation Institute } \\
\text { College of Business } \\
\text { San José State University } \\
\text { San José, CA 95192-0219 }\end{array}$}} & \multicolumn{2}{|c|}{ 10. Work Unit No. } \\
\hline & & \multicolumn{2}{|c|}{$\begin{array}{l}\text { 11. Contract or Grant No. } \\
\text { ZSB12017-SJAUX }\end{array}$} \\
\hline \multirow{2}{*}{\multicolumn{2}{|c|}{$\begin{array}{l}\text { 12. Sponsoring Agency Name and Address } \\
\text { State of California SB1 2017/2018 } \\
\text { Trustees of the California State University } \\
\text { Sponsored Programs Administration } \\
\text { 401 Golden Shore, 5th Floor } \\
\text { Long Beach, CA } 90802 \\
\end{array}$}} & \multicolumn{2}{|c|}{ 13. Type of Report and Period Covered } \\
\hline & & \multicolumn{2}{|c|}{ 14. Sponsoring Agency Code } \\
\hline \multicolumn{4}{|l|}{ 15. Supplemental Notes } \\
\hline \multicolumn{4}{|c|}{$\begin{array}{l}\text { 16. Abstract } \\
\text { To promote active transportation modes (such as bike ride and walking), and to create safer communities for easier access } \\
\text { to transit, it is essential to provide consolidated data-driven transportation information to the public. The relevant and } \\
\text { timely information from data facilitates the improvement of decision-making processes for the establishment of public } \\
\text { policy and urban planning for sustainable growth, and for promoting public health in the region. For the characterization } \\
\text { of the spatial variation of transportation-emitted air pollution in the Fresno/Clovis neighborhood in California, various } \\
\text { species of particulate matters emitted from traffic sources were measured using real-time monitors and GPS loggers at } \\
\text { over } 100 \text { neighborhood walking routes within } 58 \text { census tracts from the previous research, Children's Health to Air } \\
\text { Pollution Study - San Joaquin Valley (CHAPS-SJV). } \\
\text { Roadside air pollution data show that PM2.5, black carbon, and PAHs were significantly elevated in the } \\
\text { neighborhood walking air samples compared to indoor air or the ambient monitoring station in the Central Fresno area } \\
\text { due to the immediate source proximity. The simultaneous parallel measurements in two neighborhoods which are } \\
\text { distinctively different areas (High diesel High poverty vs. Low diesel Low poverty) showed that the higher pollution levels } \\
\text { were observed when more frequent vehicular activities were occurring around the neighborhoods. Elevated PM2.5 } \\
\text { concentrations near the roadways were evident with a high volume of traffic and in regions with more unpaved areas. } \\
\text { Neighborhood walking air samples were influenced by immediate roadway traffic conditions, such as encounters with } \\
\text { diesel trucks, approaching in close proximity to freeways and/or busy roadways, passing cigarette smokers, and gardening } \\
\text { activity. The elevated black carbon concentrations occur near the highway corridors and regions with high diesel traffic } \\
\text { and high industry. } \\
\text { This project provides consolidated data-driven transportation information to the public including: } \\
\text { 1. Transportation-related particle pollution data } \\
\text { 2. Spatial analyses of geocoded vehicle emissions } \\
\text { 3. Neighborhood characterization for the built environment such as cities, buildings, roads, parks, walkways, etc.. }\end{array}$} \\
\hline $\begin{array}{l}\text { 17. Key Words } \\
\text { Air pollution, built environment, } \\
\text { environmental monitoring, } \\
\text { nonmotorized transportation, public } \\
\text { health }\end{array}$ & $\begin{array}{l}\text { 18. Distribution Statement } \\
\text { No restrictions. This document is a } \\
\text { Technical Information Service, Spri }\end{array}$ & $\begin{array}{l}\text { lable to the public } \\
\text { field, VA } 22161 \text {. }\end{array}$ & ugh The National \\
\hline $\begin{array}{l}\text { 19. Security Classif. (of this report) } \\
\text { Unclassified }\end{array}$ & $\begin{array}{l}\text { 20. Security Classif. (of this page) } \\
\text { Unclassified }\end{array}$ & $\begin{array}{l}\text { 21. No. of Pages } \\
49\end{array}$ & 22. Price \\
\hline
\end{tabular}

Form DOT F 1700.7 (8-72) 
Copyright (c) 2021

\title{
by Mineta Transportation Institute
}

All rights reserved.

DOI: $10.31979 / \mathrm{mti} .2021 .2010$

\author{
Mineta Transportation Institute \\ College of Business \\ San José State University \\ San José, CA 95192-0219 \\ Tel: (408) 924-7560 \\ Fax: (408) 924-7565 \\ Email: mineta-institute@sjsu.edu
}

transweb.sjsu.edu/research/2010 


\section{CONTENTS}

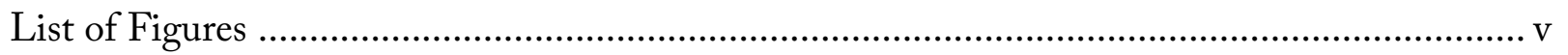

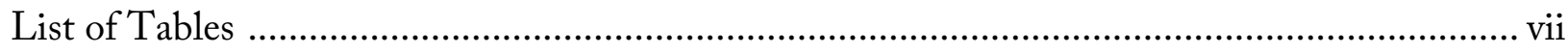

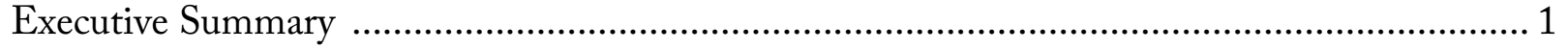

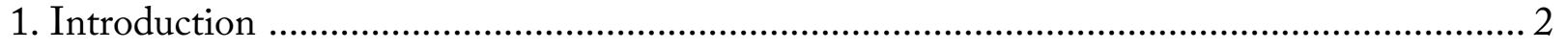

2. Background...1.n.

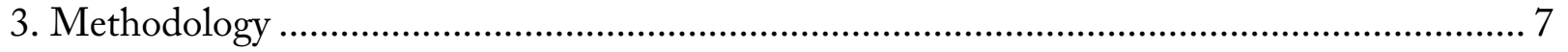

3.1 Roadside Transportation-Related Particulate Air Quality Data. .................................... 7

3.2 Roadside Air Quality Sensor Data Assimilation for Geospatial Analysis ....................... 9

3.3 Neighborhood Characteristic Data (Secondary data)....................................................... 10

3.4 Spatio-Temporal Analysis of Roadside Air Quality......................................................... 11

3.5 Evaluation of low-cost Sensors in Field application ......................................................... 12

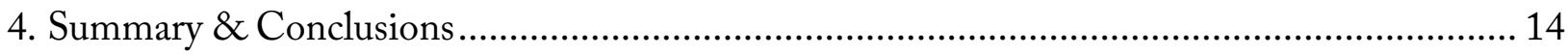

4.1 Roadside Transportation-Related Air Quality …………………................................ 14

4.2 Geospatial Descriptive Analyses of Roadside Air Quality Sensor Data ........................... 16

4.3 Parallel measurement data analyses ............................................................................ 18

4.4 Neighborhood Characteristic Analyses in zip codes .................................................... 20

4.5 Evaluation of low-cost Sensors in Collocation Sensor calibration ................................... 25

4.6 Spatio-Temporal Analysis of Roadside Air Quality ………………............................... 31

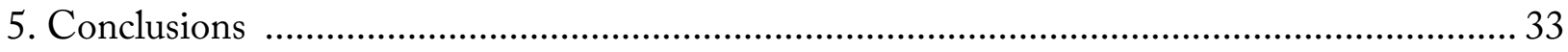

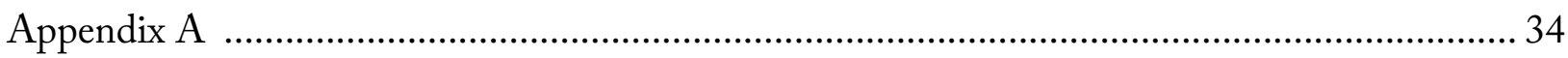

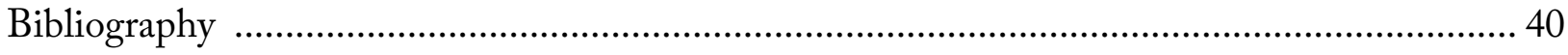

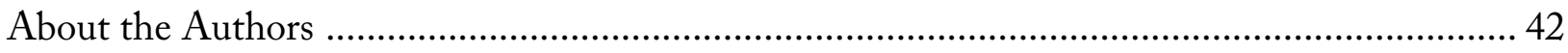




\section{LIST OF FIGURES}

Figure 1. Typical wind patterns in San Joaquin Valley air basin .............................................. 5

Figure 2. Map of Major Roadways and existing number of lanes in Fresno

(City of Fresno, 2014) .......................................................................................... 5

Figure 3. Daily PAHs in Fresno for 7 years (left), Spatial variability of PAHs in the

FACES - Fresno Asthmatic Children's Environment Study (right) ......................... 6

Figure 4. Relationship among the mode of transportation, built environment, and

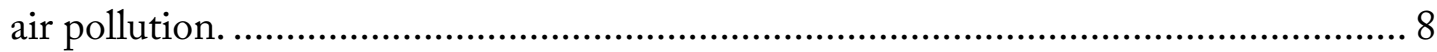

Figure 5. The concept of data synchronization.................................................................. 9

Figure 6. An example of time-synchronized data .............................................................. 9

Figure 7. (Left) Trajectory of black carbon concentration along local road, Fresno CA,

(Middle) black carbon concentration geocoded from the trajectory,

(Right) gridded black carbon concentration............................................................. 10

Figure 8. Spatio-temporal Data Analysis Workflow ……………………………………..... 11

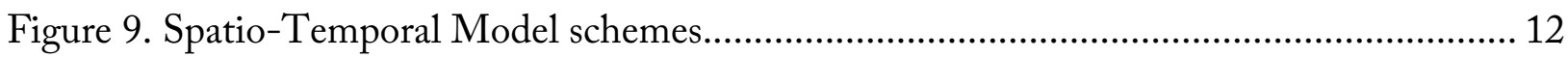

Figure 10. The real-time portable air quality monitoring sensors.............................................. 13

Figure 11. Trail heads of the transportation related air quality monitored walking routes and zip codes in Fresno Clovis area ........................................................................ 14

Figure 12. Time series plot example for black carbon (BC) and polycyclic aromatic hydrocarbons (PAHs) concentrations at a road-side walking route........................... 15

Figure 13. Distribution of average $\mathrm{PM}_{2.5}\left(\mu \mathrm{g} / \mathrm{m}^{3}\right)$ for walking route samples ............................. 17

Figure 14. Distribution of average Black Carbon $\left(\mu \mathrm{g} / \mathrm{m}^{3}\right)$ for walking route samples ................. 18

Figure 15. The parallel repeated measurements of PM2.5, black carbon, and PAHs at 8 walking routes on the same days and times..................................................... 19

Figure 16. PM2.5, BC, and PAHs concentrations and GPS waypoints measured

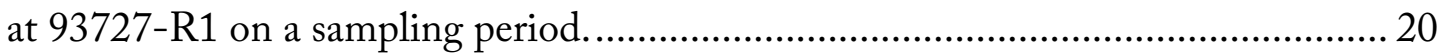

Figure 17. Gathered GIS Layers; Fresno City Boundary, Road Intersection (+ speed bump), Road segment, Previous CHAPS data, CalEnviroScreen data at census tracts ......... 21

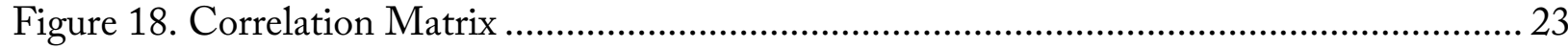

Figure 19. Map of BC/PM2.5 by zip code .......................................................................... 24

Figure 20. Low-cost particulate matter air sensors, Left: AtmoTube Pro, Right:

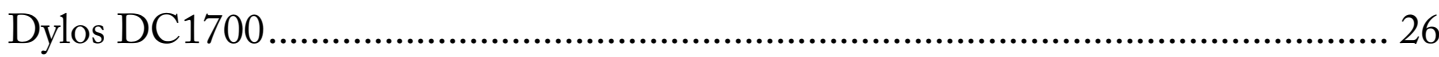

Figure 21. Collocation Measurement (Backyard) ..................................................................... 26 
Figure 22. Collocation PM2.5 mass concentrations from air quality monitor at a residential location from $10 / 30 / 20$ to $11 / 05 / 20$.

Figure 23. Box and whisker plots of PM2.5 mass concentrations from air quality monitors at the residential location from $10 / 30 / 20$ to $11 / 05 / 20$.

Figure 24. Inter-sensor analysis of DRX Dusttrack using PM2.5. Scatter plots of DRX Dusttrack D1 vs. DRX Dusttrack D2 (Left), Scatter plots of DRX Dusttrack D1 and H1 (Right). 28

Figure 25. Inter-sensor analysis of Dylos DC1700 using PM2.5. Scatter plots of Dylos DC1700 D1 vs. Dylos DC1700 D2. 28

Figure 26. Inter-sensor analysis of Atmotube Pro PM2.5. Scatter plots of Atmotube Pro D9 vs. Atmotube Pro DE (Left), Atmotube Pro D9 vs. Atmotube Pro FA (Right)........... 29 Figure 27. Scatter plots of PM2.5 mass concentrations from DRX Dusttracks D1 vs. Dusttracks $\mathrm{D} 2$ (correlation coefficient $\mathrm{R}=0.98$ ) and $\mathrm{H} 1$ (correlation coefficient $\mathrm{R}=0.96$ ). 29

Figure 28. Intra-sensor analysis of PM2.5. Scatter plots of PM2.5 mass concentrations from DRX Dusttracks D1 vs. Dylos DC1700 air sensors D1 and D2 $(\mathrm{R}=0.86, \mathrm{R}=0.83)$. 30

Figure 29. Scatter plots of PM2.5 mass concentrations from DRX Dusttracks D1 vs. Atmotube Pro air sensors, D9, DE, and FA ( $\mathrm{R}=0.92,0.92,0.83$ respectively)........................... 30

Figure A-1. Collocation Measurement near Clovis monitoring station ..................................... 39

Figure A-2. Mobile test near Clovis monitoring station ............................................................. 39 


\section{LIST OF TABLES}

Table 1. Summary of real-time mobile monitoring at structured social observation (SSO) route samples collected...................................................................................... 8

Table 2. Summary statistics of particle pollutant concentrations $\left(\mu \mathrm{g} / \mathrm{m}^{3}\right)$ and the compositional proportion of the particulate matter species......................................... 15

Table 3. Mean particle concentrations $\left(\mu \mathrm{g} / \mathrm{m}^{3}\right)$ by type of roadways ......................................... 16

Table 4. Particle Concentrations and compositional proportions by the immediate

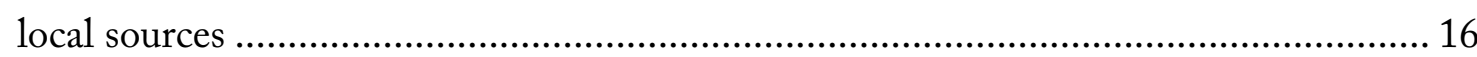

Table 5. Mean particulates concentration and the secondary neighborhoods' environmental and health characteristic indicators by zip codes ...................................................... 22

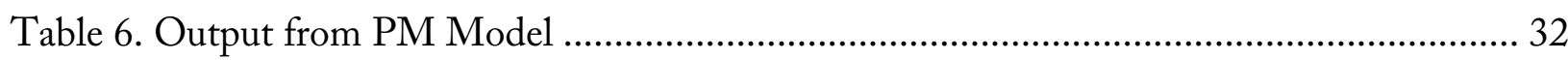

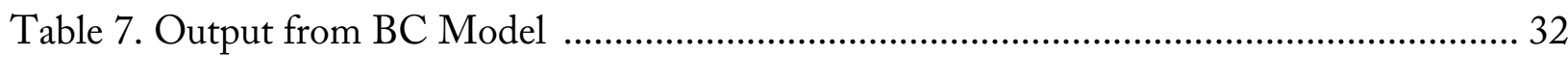

Table A-1. The average of particulate matter species and the coordinates of the trailhead

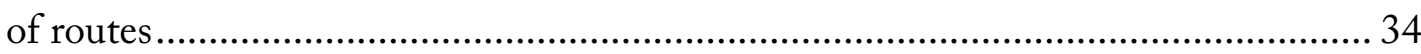

Table A-2 Correlation coefficients and p-values ...................................................................... 38 


\section{Executive Summary}

To promote active transportation modes (such as bike ride and walking), and to create safer communities for easier access to transit, it is essential to provide consolidated data-driven transportation information to the public. The relevant and timely information from data facilitates the improvement of decision-making processes for the establishment of public policy and urban planning for sustainable growth, and for promoting public health in the region. For the characterization of the spatial variation of transportation-emitted air pollution in the Fresno/Clovis neighborhood in California, various species of particulate matters emitted from traffic sources were measured using real-time monitors and GPS loggers at over 100 neighborhood walking routes within 58 census tracts from the previous research, Children's Health to Air Pollution Study - San Joaquin Valley (CHAPS-SJV).

Roadside air pollution data show that PM2.5, black carbon, and PAHs were significantly elevated in the neighborhood walking air samples compared to indoor air or the ambient monitoring station in the Central Fresno area due to the immediate source proximity. The simultaneous parallel measurements in two neighborhoods which are distinctively different areas (High diesel High poverty vs. Low diesel Low poverty) showed that the higher pollution levels were observed when more frequent vehicular activities were occurring around the neighborhoods. Elevated PM2.5 concentrations near the roadways were evident with a high volume of traffic and in regions with more unpaved areas. Neighborhood walking air samples were influenced by immediate roadway traffic conditions, such as encounters with diesel trucks, approaching in close proximity to freeways and/or busy roadways, passing cigarette smokers, and gardening activity. The elevated black carbon concentrations occur near the highway corridors and regions with high diesel traffic and high industry.

This project provides consolidated data-driven transportation information to the public including:

1. Transportation-related particle pollution data

2. Spatial analyses of geocoded vehicle emissions

3. Neighborhood characterization for the built environment such as cities, buildings, roads, parks, walkways, etc. 


\section{Introduction}

To promote active transportation modes, such as bike rides and walking, and to create safer communities for easier access to transit, it is essential to provide to the public the consolidated data-driven transportation information of the stakeholders and the public. The relevant and timely information from data facilitates the improvement of decision-making processes for the establishment of public policy and urban planning, and for sustainable growth and promoting public health in the region.

Among many transportation-related data, this study establishes:

1. Transportation-related particle pollution data

2. Spatial analyses of geocoded vehicle emissions

3. Neighborhood characterization for the built environment such as cities, buildings, roads, parks, walkways, etc.

Transportation Emitted Air Pollutant Data: The vehicle transportation-related air pollution was measured at 150 neighborhood walking routes within 22 zip codes including 58 census tracts in the Fresno/Clovis area for over four years from the previous NIEHS/USEPA funded research, Children's Health to Air Pollution Study - San Joaquin Valley (CHAPS-SJV) with PIs of UC Berkeley, Stanford University and Fresno State. To characterize the spatial variation of transportation-emitted air pollution in the Fresno/Clovis neighborhood, various species of particulate matter emitted from traffic sources were measured using real-time monitors and GPS loggers. The pollutants include particulate matter (PM10, PM2.5, PM1), black carbon (BC), ultrafine particles, and polycyclic aromatic hydrocarbons (PAHs).

Spatial Analyses of Geocoded Data: Vehicle transportation, especially diesel trucks, is known as a major emission source of fine particulate matter (PM2.5). Black carbon and polycyclic aromatic hydrocarbons (PAHs) are the toxic components of fine particulate matter and the trace of diesel emission. The real-time concentrations of particulate species varying in different transportation sources will provide a remarkable insight to analyze the dynamic temporal impact on transportation-related pollution patterns. For aligning various pollutant concentrations synchronously over the accurately geocoded neighborhood locations from the walking routes, quality assurance and quality control $(\mathrm{QA} / \mathrm{QC})$ from the pollution and positional data are necessary.

Neighborhood Characterization: Secondary data indicators characterizing built environment, transportation choices, and general health risks such as walkability and socioeconomic factors are available for each census tract where the neighborhood walking routes are contained (i.e., Walk score and CalEnvironScreen scores, etc.). Therefore, the geospatial analysis of the transportationrelated pollution by different roadway classes, land-use, meteorological conditions, and 
socioeconomic status of the neighborhoods will be possible as a result of the geospatial data consolidation.

The objectives of this study are to provide:

1. Pollution sensor calibration and evaluation of a low-cost pollution sensor

2. Spatial analysis of pollution data

a. Impact of transportation-related particulate matters on the roadside air quality in Fresno, CA

b. The relationship of particulate matter near roadways and zip code, taking into account spatial-temporal factors and analysis of health effects in Fresno, CA 


\section{Background}

The San Joaquin Valley, and Fresno in particular, are identified as areas for having high levels of particulate matter that go above federal and state clean air standards (EPA 2019). Many of the cities in the 8-county region, such as Fresno, are classified as the most polluted cities in the United States for both particulate matter and ozone pollution. (American Lung Association, 2021). Particulate matter, specifically those with a diameter of 2.5 micrometers (PM2.5), has been known to pose a risk to human health. While many PM2.5 particles vary in compositions, black carbon (BC) which occurs due to incomplete combustion from gas and diesel engines and other sources, make up a majority of particulate matter emitted worldwide (Bessagnet \& Allemand, 2020). As toxic components of particulate matters, black carbon, polycyclic aromatic hydrocarbons (Noth, et al., 2011) emitted from the fossil fuel combustion, mainly from transportation mobile sources, are associated with increased health effects including high levels of hospital admittance and emergency room visits linked to asthma complications, increased cardiovascular disease risks, and even premature death.

Contributors to high levels of air pollution in Fresno are partly due to the geography and weak winds present in the San Joaquin Valley; the valley is surrounded by mountains (the Sierra Nevada, Tehachapi Mountains, and Coastal Range mountains) that act as a barrier preventing air from leaving. Weak winds further prevent air from escaping the valley, thus increasing the concentration of pollutants as illustrated in Figure 1 (Noth et al., 2011). Local contributors to PM2.5 in Fresno include major roads such as California State Routes 41, 99, 168, \& 180 (City of Fresno, 2014) as well as other local sources. Figure 2 illustrates the roadways and bike and walking trails in the Fresno area. 
Figure 1. Typical Wind Patterns in San Joaquin Valley Air Basin (Noth et al 2011)

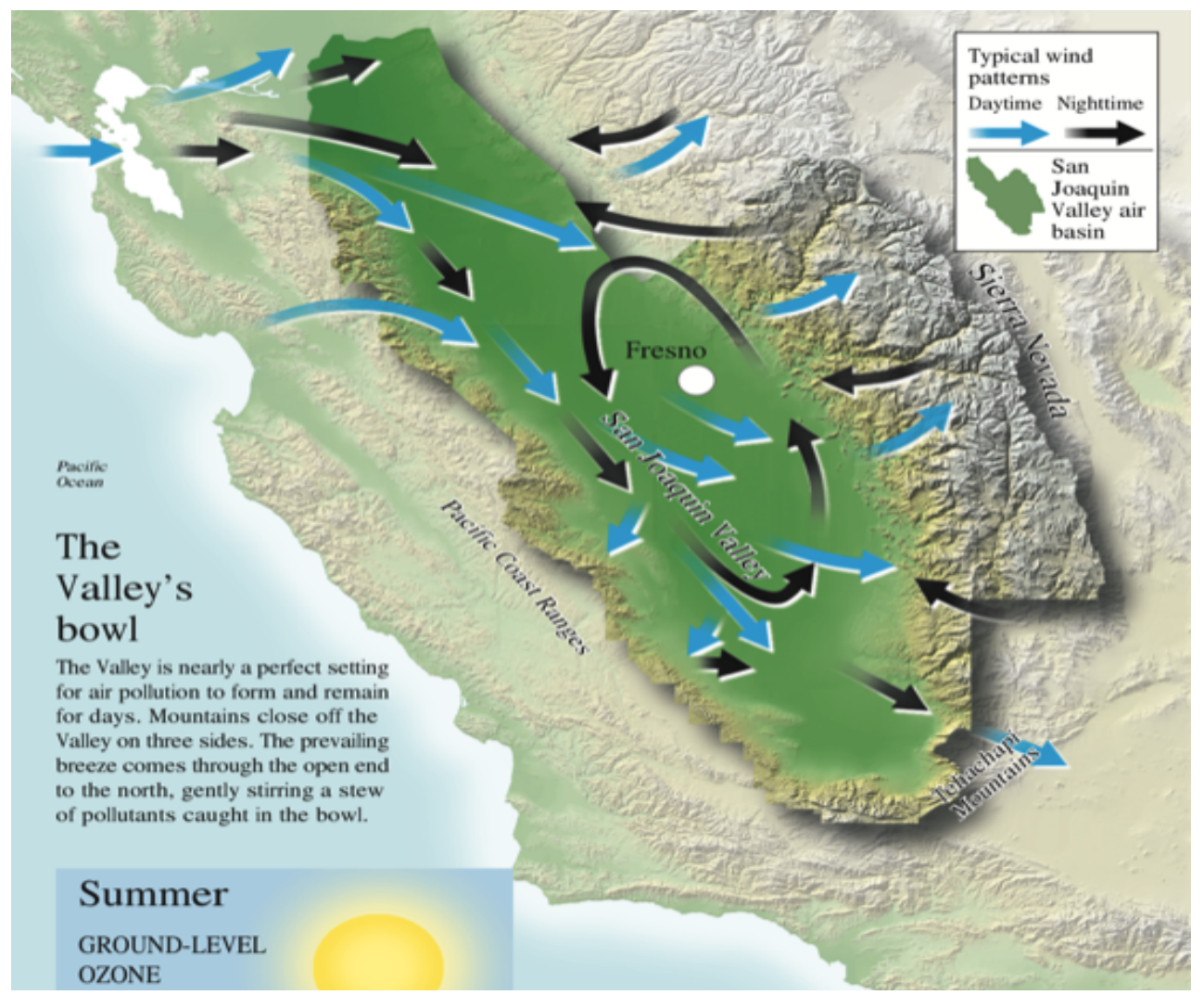

Figure 2. Map of Major Roadways and Existing Number of Lanes in Fresno (City of Fresno, 2014)

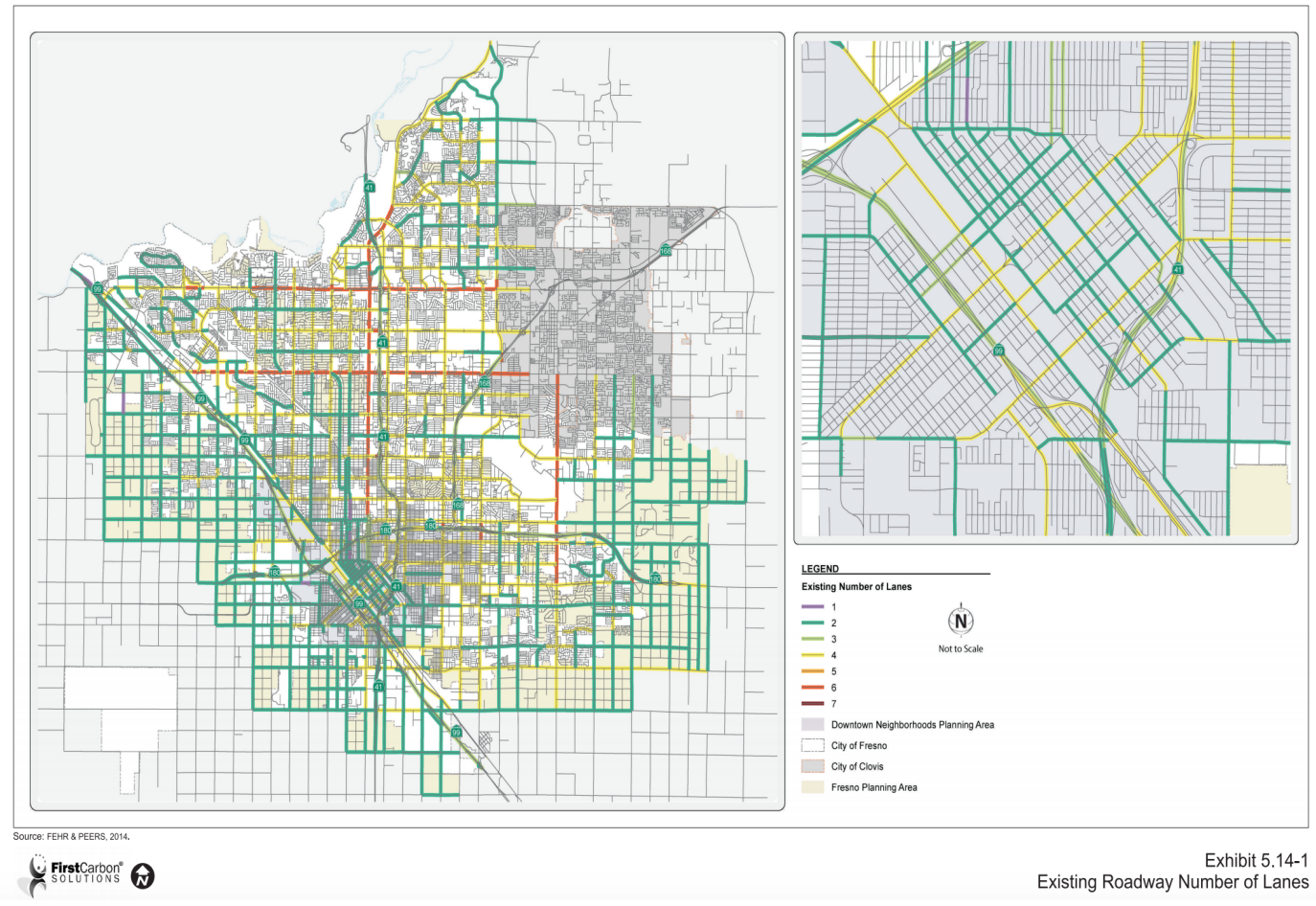


Previous studies have shown elevated levels of particulate matter occurring near roads due to emissions from cars and trucks. These particles are small enough to be inhaled and can cause irritation in the lungs and trouble breathing. Increased levels of particulate matter and exposure have shown an increase in levels of asthma and hospitalization as a result (Alcala et al., 2019). Padula et al. (2018) conducted in the San Joaquin Valley have also shown that mothers exposed to elevated levels of air pollutants, specifically particulate matter, were twice as likely to deliver a baby prematurely. In Fresno County alone, an estimated $12.1 \%$ of the population had increased levels of preterm birth, a statistic significantly higher than the state level of $9.6 \%$ (Padula et al., 2018). There has also been an association between pollutants emitted by road traffic and increased levels of hypertension (Weber et al., 2019) that can also decrease the quality of life for individuals exposed to elevated levels of air pollutants. The pollutants that occur near these roads are dependent on the level of traffic, temperature, and wind to further disperse pollutants to communities (Baldauf et al., 2009).

Figure 3. Daily PAHs in Fresno for 7 Years (left), Spatial Variability of PAHs in the FACES Fresno Asthmatic Children's Environment Study (right) (Noth et al., 2011)

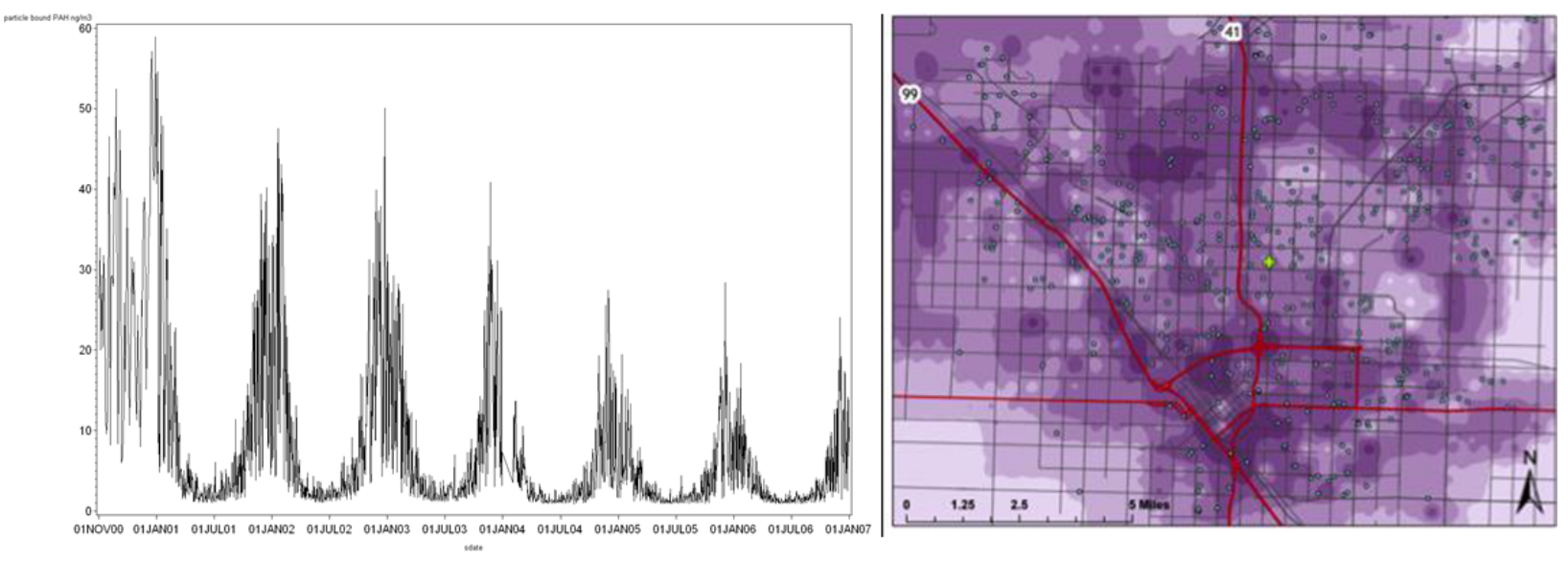




\section{Methodology}

\subsection{Roadside Transportation-Related Particulate Air Quality Data}

The roadside transportation-related air pollutant concentrations were measured using various realtime air quality monitors and Global Positioning System (GPS) loggers during the Children's Health to Air Pollution Study in San Joaquin Valley (CHAPS-SJV). One of the objectives of CHAPS-SJV was to examine neighborhood characteristics that have a direct and quantifiable relationship with an individual's transit patterns that in turn affect personal exposures to trafficrelated air pollution ( $\mathrm{PAHs}, \mathrm{PM}_{2.5}$, and $\mathrm{BC}$ ) (Figure 4). The transportation-emitted pollutants include particulate matter (PM10, PM2.5, PM1), black carbon (BC), ultrafine particles, and polycyclic aromatic hydrocarbons (PAHs). The pollution concentrations quantified by the multiple air monitors for specific particle pollutant of concern are as follow: DustTrack DRX Aerosol (8533, 8534, TSI Inc., Shoreview, MN) monitors for the particulate matter mass concentrations for PM10, PM2.5, and PM1; condensation particle counter (CPC 3007, TSI Inc., Shoreview, MN), microAeth AE51 personal exposure nephelometers (AethLabs, San Francisco, CA) for black carbon concentrations; and portable compact photoelectric aerosol sensors (PAS 2200CE, League City, TX) for PAHs. The GPS loggers (Trackstick, Telespial Systems, CA) recorded the GPS position data synchronously with the real-time air quality monitors during the air quality sampling. Because the zip codes in Fresno have a highly varying total area, area density, and area population, each zip code was divided into 3-5 sub-sections based on distances from the zip centroid and population density. The routes of 1.5-2 miles, representing 10 block faces (segments) were each selected for both neighborhood air pollution exposure and social structure observation (SSO) over the Fresno/Clovis area. Student assistants walked the route of the neighborhoods on each block carrying the real-time air pollutant measurement instruments on the strollers from January 2015 to June 2017. Overall, 96 route samples have been completed from 22 zip code areas (Table 1). In addition, three routes that had the highest PAHs levels at the first sampling were simultaneously sampled three times, along with the routes that had the lowest PAHs levels at the first sampling. Including the 54 repeated measures, 150 routes were sampled for the concentration of air pollutants. The starting location of the routes that were sampled is shown in Table A-1 (appendix). 
Figure 4. Relationship Among the Mode of Transportation, Built Environment, and Air Pollution.

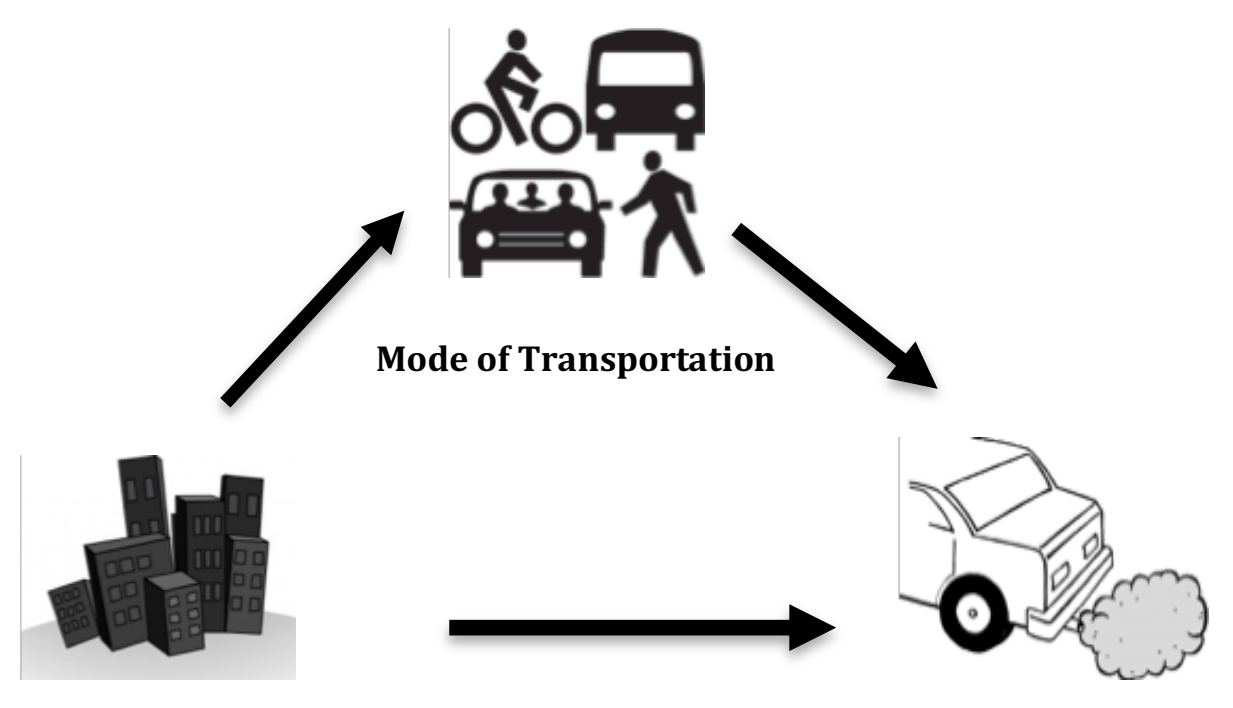

Built environment

Air Pollution

Table 1. Summary of Real-time Mobile Monitoring at Structured Social Observation (SSO) Route Samples Collected

\begin{tabular}{|c|c|c|r|r|r|c|}
\hline Batch ID & SSO & Air Pollution & New Zip Code & Routes & Pollution samples & Sample number \\
\hline Batch 1 & 2014 Fall & 2015 Spring & 3 & 10 & repeated & 20 \\
\hline Batch 2 & 2015 Spring & 2015 Spring & 3 & 10 & repeated & 20 \\
\hline Batch 3 & 2015 Fall & 2016 Spring & 3 & 13 & one time & 13 \\
\hline Batch 4 & 2016 Spring & 2016 Spring & 4 & 13 & one time & 13 \\
\hline $\begin{array}{l}\text { 2016 Spring, Two routes repeated 7 times } \\
\text { (High diesel High poverty vs. Low diesel Low poverty) }\end{array}$ & 14 \\
\hline Batch 5 & 2016 Summer & 2017 Spring & 8 & 27 & one time & 27 \\
\hline Batch 6 2017 Summer & 2017 Spring & 1 & 23 & one time & 23 \\
\hline 2017 Spring, two routes from Batch 4 were sampled again for CART students & 2 \\
\hline 2017 Spring, six routes from Batch 5 and 6 were sampled three times & 22 & 96 & 18 routes \\
\hline \multicolumn{7}{|c|}{ Total }
\end{tabular}




\subsection{Roadside Air Quality Sensor Data Assimilation for Geospatial Analysis}

Roadside transportation air quality was utilized for geospatial analysis and GPS positioned and polarized pollutant concentrations. The raw data were processed and organized in a way that positional data from GPS and quality-assured pollution concentrations are synchronized, followed by basic filtering (Figure $5 \& 6$ ). Roadside pollution changes in time and along the trajectories. Therefore, the relationship among the pollution levels with transportation and environmental factors such as speed, roadway classifications, and land use around the road can be produced by a 3D representation of results in Matlab and ArcGIS for each sampled location (Figure 7).

Figure 5. The Concept of Data Synchronization

\section{GPS Time \\ - Latitude \\ - Longitude}

\section{Pollution Time}

- BC

- PAH

- HOBO

- PM

- UFP
Pollution Data With Position

Most of the pollution sensors contain timestamps and pollution content such as PM2.5. In order to perform spatial analysis, GPS location information needs to be utilized in accordance with other pollution data. Based on GPS time, other pollution data time is searched if that data falls in the GPS 1-minute bin. The binned data are averaged to match GPS location data.

Figure 6. An Example of Time-Synchronized Data. A Single Position can have Multiple Pollution Data for Further Geospatial Analysis.

\begin{tabular}{|c|c|c|c|c|c|c|c|c|c|c|c|c|c|c|c|c|}
\hline & & & & & & $x$ & $Y$ & & & $c$ & & & 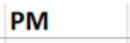 & T) & PM & \\
\hline 201 & 1 & 0 & 4 & 54 & 0 & 0 & $\epsilon$ & 9 & 5 & 513 & 50 & 2.83333 & 0.095 & 0. & & 5. \\
\hline 2015 & 1 & 30 & 4 & 56 & 0 & 4 & 6615 & 49 & .78673 & 1317 & .61767 & 33333 & 0945 & 24 & 3 & \\
\hline 2 & & 30 & & 57 & 0 & & & & 674 & 861 & & & 67 & & & \\
\hline 0 & & & & & 0 & & & & & & & & & & & \\
\hline 01 & 1 & 0 & & 5 & 0 & & & & & 1129 & 57 & 3333 & & & & \\
\hline 01 & & 30 & & & 0 & & & & & 3 & & & & & & \\
\hline ). & & & & 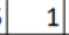 & 0 & & & & & & & & & & & \\
\hline 01 & 1 & 3 & & 8 & 0 & & & & & 1 & & 6 & & & & \\
\hline 0. & & & & & 0 & & & & & & & & & & & \\
\hline 1 & & & & 1 & 0 & & & & & 14 & & & & & & \\
\hline 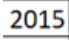 & & 3 & & 11 & 0 & & & & & 1604 & & & & & & \\
\hline 2 & & & & 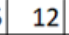 & 0 & & & & & 4 & & & & & & \\
\hline & & & & 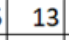 & 0 & & & & & 1185 & & 667 & & & & \\
\hline 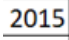 & & 30 & & 14 & 0 & & & & & 1359 & 283 & 667 & & 021 & & \\
\hline 2015 & 1 & 30 & 5 & 15 & 0 & 1933569 & 661173.9 & -119.744 & 36.78353 & 1670 & 2.342 & 26.16667 & 0.082833 & 0.021 & 0.084333 & 3371.25 \\
\hline
\end{tabular}


Figure 7. Example of Geo-Coded Pollution Data. (Left) The Trajectory of Black Carbon Concentration Along Local Roads, Fresno CA. (Middle) Black Carbon Concentration Geocoded from the Trajectory. (Right) Gridded Black Carbon Concentration.
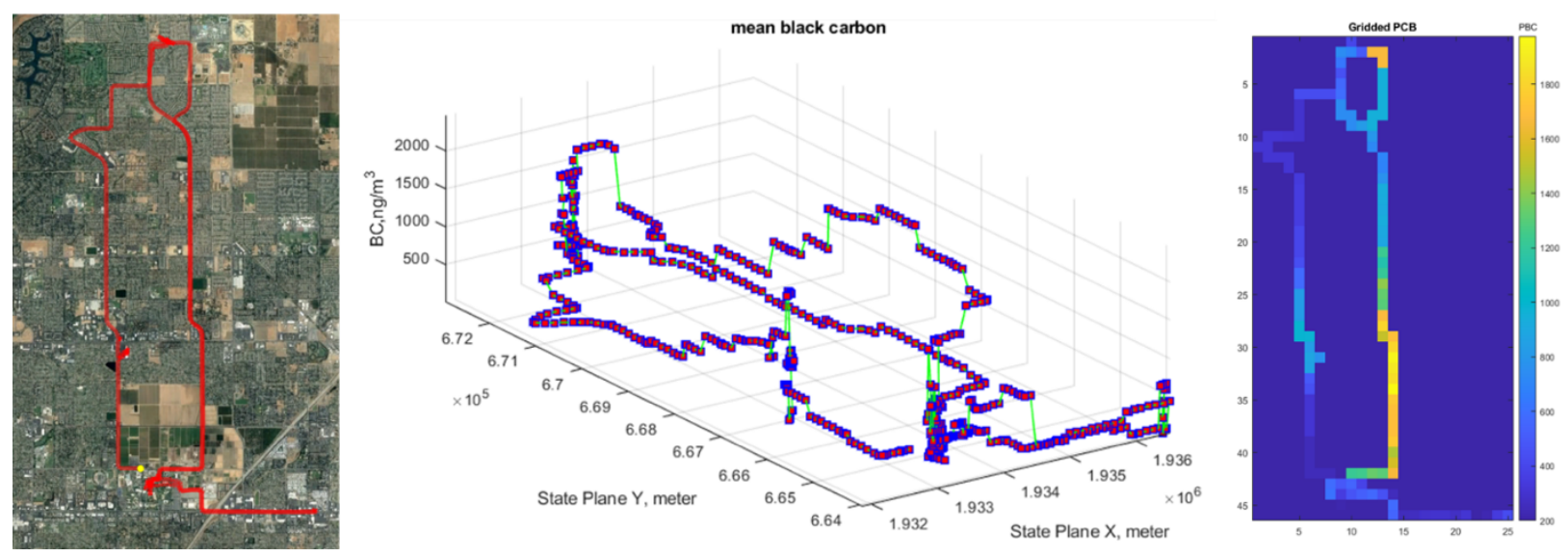

\subsection{Neighborhood Characteristic Data (Secondary data)}

The secondary environmental indicator data were collected to characterize assets (e.g., bus stops/routes, sidewalks, food outlets, etc.) and liabilities (e.g., neighborhood foreclosure rate, the density of condemned properties, Toxic Release Inventory sites, high-speed surface street traffic, etc.) of the local built environment using the structured social observation (SSO) tools and data from CalEnviroScreen (a mapping tool developed by California's Environmental Protection Agency in order to identify areas with high levels of pollution) during the CHAPS-SJV. The secondary indicators acquired and analyzed for this project are listed below.

- Walk Score ${ }^{\circledR}$ : uses GPS data to assess neighborhood walkability considering nearby amenities and transportation. The average for Fresno is 42 (and for comparison, Berkeley CA has an average score of 79). The data set prepared by https://www.walkscore.com is unique to this project and represented a new application for Walk Score. Range: 0 to 100.

- CES (CalEnviroScreen) Pollution Burden Score: Considers exposures and environmental effects. Range: 0.1 to 10 .

- CES (CalEnviroScreen) Population Characteristics Score: Considers sensitive populations and socioeconomic factors. Range: 0.1 to 10 .

- CalEnviroScreenScore: Pollution Burden X Population Characteristics. Score: up to 100.

- Disorder-Walking (SSO): considers 16 possible indicators of social disorder and barriers to walking, such as condoms and syringes on street, abandoned homes, adults being hostile, no safe place to walk, etc. 
- Order-Walking (SSO): considers 13 indicators of possible social order and supports for pedestrians such as streetlights, sidewalks, well-maintained empty lots, clearly marked crosswalks, etc.

- Environmental and Health Effect Data (CalEnviroScreen): to identify zip codes with high levels of traffic, diesel, asthma, and low birth rates in the Fresno/Clovis Area.

\subsection{Spatio-Temporal Analysis of Roadside Air Quality}

Time series analysis attempts to model the future in terms of previously observed values, and it has often been used to examine air pollution data. The particulate matters such as PM10, PM2.5, PM1, black carbon (BC), ultrafine particles, and polycyclic aromatic hydrocarbons (PAHs) are time-series data, and hence, understanding the time dependency is crucial for this project.

To characterize the spatial variation of air pollution in the Fresno/Clovis neighborhood, we will also employ a spatio-temporal framework to examine the variability through generalized additive models (GAM). GAM has been used in practice for many years in many different fields such as biology, engineering, health science, and business. Figures 8 and 9 illustrate the general concept of how the model is used.

Figure 8. Spatio-temporal Data Analysis Workflow

\section{- Spatio-temporal data analysis considers both temporal correlations and spatial correlations.}

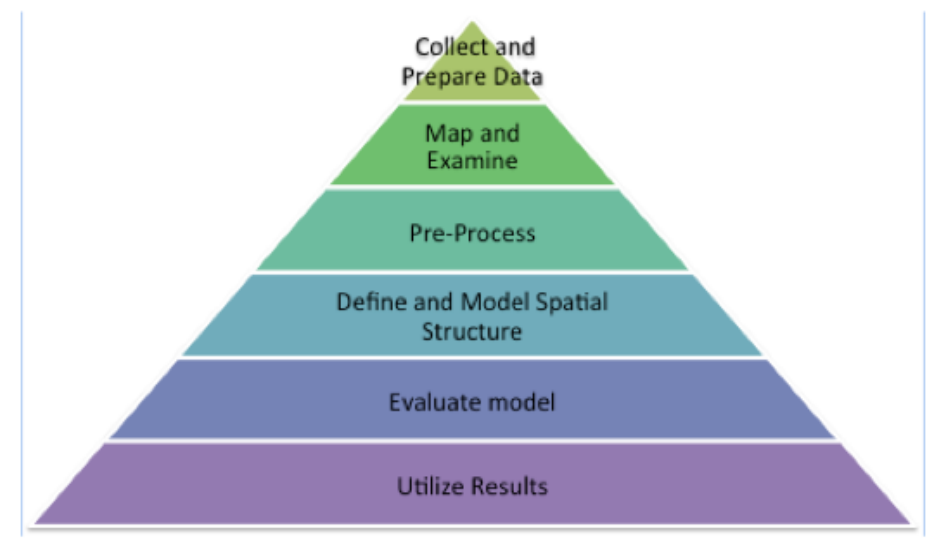

Spatio-temporal Data Analysis Workflow 
Figure 9. Spatio-temporal Model Schemes

$$
\begin{gathered}
\text { Spatio-Temporal Model: } \\
Y(s, t)=\mu(s, t)+v(s, t)+\varepsilon(s, t)
\end{gathered}
$$

$Y(s, t)$ : observations

$\mu(s, t):$ mean

$v(s, t)$ : zero-mean spatio-temporal process

$\varepsilon(s, t)$ : white noise (usually Gaussian distribution).

Example:

$$
\begin{gathered}
Y=X \theta+v+\varepsilon \\
\text { where } v \sim N\left(0, \sigma_{v}^{2} \Sigma_{v}\right) \text { and } \varepsilon \sim N\left(0, \sigma^{2} D\right)
\end{gathered}
$$

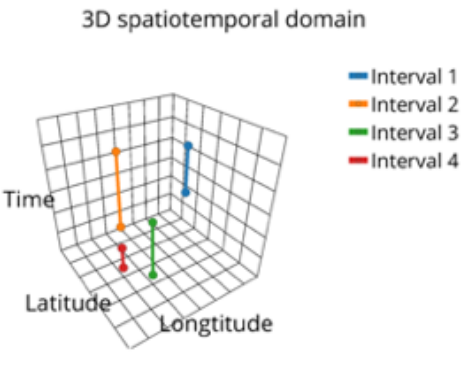

\subsection{Evaluation of low-cost Sensors in Field application}

Due to increasing public interest and awareness of air pollution, there are several low-cost portable air monitoring sensors available in the market. We tested the two different types of monitoring sensors, Dylos and AtmoTube Pro, which have been used not only by scientists but also by communities for citizen science projects collecting personal exposure to particulate matters. The low-cost particulate matter monitoring sensors evaluated are: Dylos DC1700 (Dylos Corp., Riverside, CA), and Atmotube Pro (Atmotech Inc., San Francisco, CA) (Figure 10). Dylos DC1700 is a laser particle counter with two size ranges of particulate matter, PM10, and PM2.5. Atmotube Pro is also an optical PM sensor, based on laser scattering for PM10, PM2.5, and PM1. Atmotube Pro has the TVOC (Total Volatile Organic Compounds) which can be useful to measure evaporative organic compounds such as benzene and toluene from gasoline and solvents. We validated the performance of low-cost sensors by the side-by-side comparison of the collected particulate concentrations with the conventional methodology we use for measuring roadside transportation air quality. 
Figure 10. The Real-Time Portable Air Quality Monitoring Sensors: DRX Dusttrack 8533 Aerosol Monitors (TSI Inc., Shoreview, MN); Dylos DC1700 (Dylos Corp., Riverside, CA); Atmotube Pro (Atmotech Inc., San Francisco, CA); And Tracksticks.

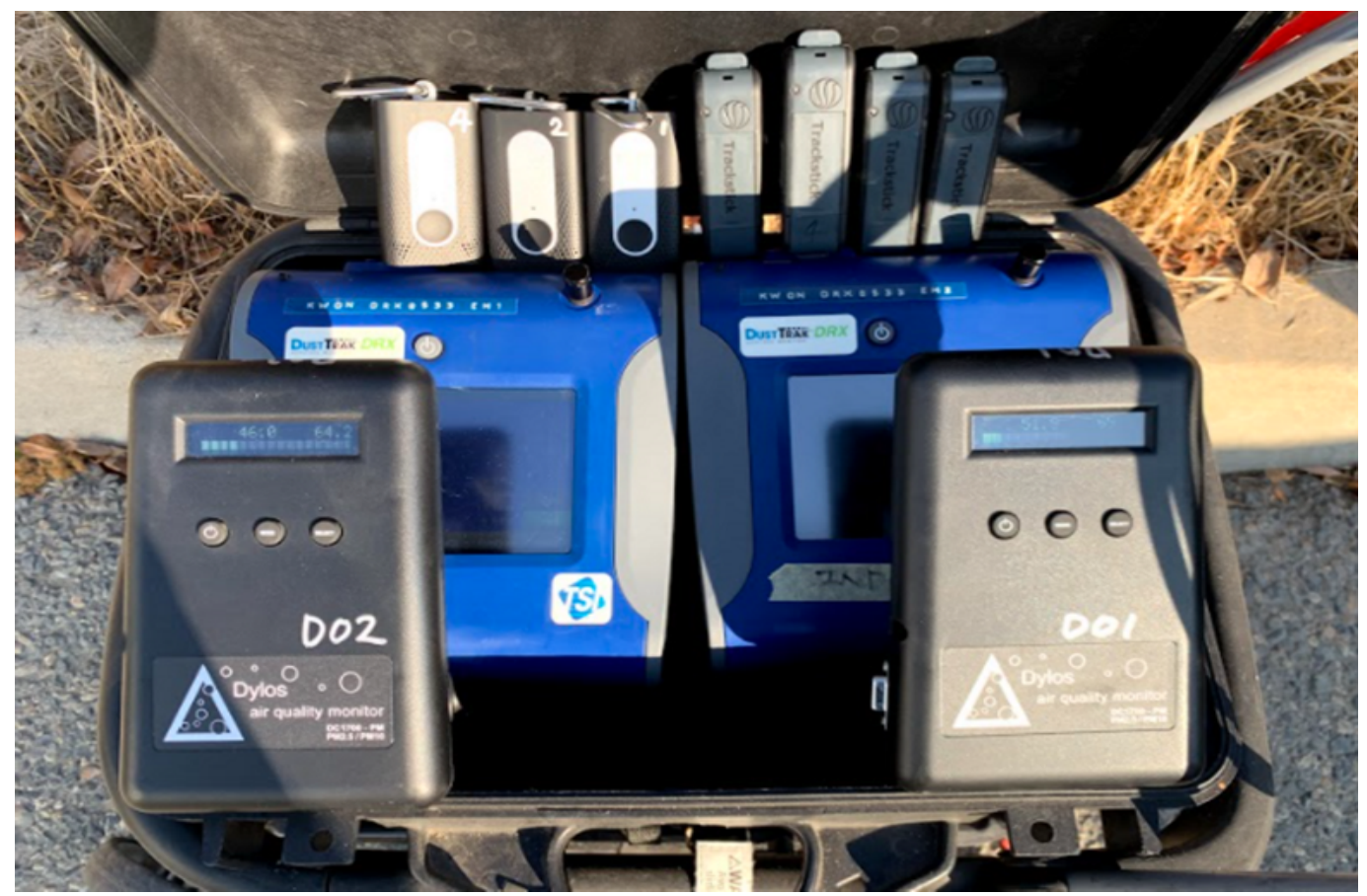




\section{Summary \& Conclusions}

\subsection{Roadside Transportation-Related Air Quality}

The distribution of the walking route trailheads in the Fresno/Clovis area by zip codes is illustrated in Figure 11. The descriptive statistics of the particle concentrations from the CHAPS-SJV project are summarized in Table 2. For accurate spatial data analysis, the algorithm of data consolidation was developed to combine multiple pollutants at accurate times and locations to represent the pollutant levels at the same log intervals. Then, the quality assurance and quality control (QA/QC) procedure to identify errors for review were developed. When pollution concentration data are aligned accurately within the same log interval, the levels of different particulate species and their compositional ratios between the particle species could be calculated by the roadways; this calculation was used to investigate the immediate potential emission sources from the roadside air quality data for corresponding sampling periods. Time series plot examples for black carbon (BC) and polycyclic aromatic hydrocarbons (PAHs) concentrations at a road-side walking route is a good example of this process (Figure 12).

Figure 11. Trailheads Of The Transportation-Related Air Quality Monitored Walking Routes And Zip Codes In The Fresno/Clovis Area.

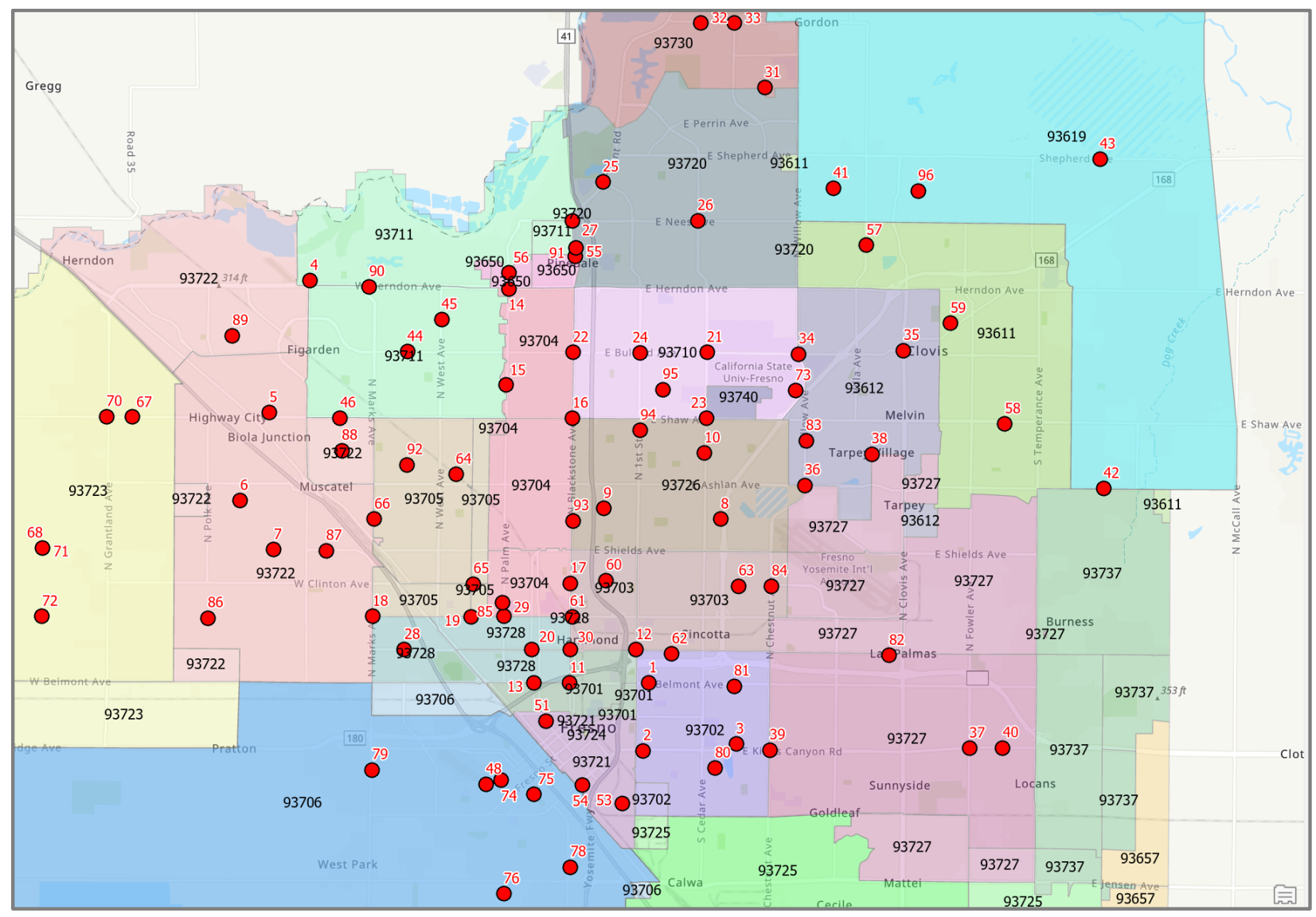


Table 2. Summary Statistics of Particle Pollutant Concentrations $\left(\mathrm{Mg} / \mathrm{M}^{3}\right)$ And the Compositional Proportion of the Particulate Matter Species

\begin{tabular}{|c|c|c|c|c|c|c|}
\hline Statistics & \multicolumn{1}{|c|}{$\mathrm{PM}_{2.5}$} & \multicolumn{1}{c|}{$\mathrm{BC}$} & \multicolumn{1}{c|}{$\mathrm{PAH}$} & \multicolumn{1}{c|}{$\mathrm{BC} / \mathrm{PM}_{2.5}$} & $\mathrm{PAH} / \mathrm{PM}_{2.5}$ & $\mathrm{PAH} / \mathrm{BC}$ \\
\hline Maximum & 64.9 & 4.00 & 0.329 & $41.38 \%$ & $5.00 \%$ & $344.08 \%$ \\
\hline $95 \%$ & 40.3 & 1.90 & 0.210 & $18.54 \%$ & $3.07 \%$ & $60.77 \%$ \\
\hline $75 \%$ & 19.8 & 0.91 & 0.138 & $9.88 \%$ & $1.40 \%$ & $25.14 \%$ \\
\hline Mean & 14.9 & 0.78 & 0.104 & $7.52 \%$ & $1.11 \%$ & $22.56 \%$ \\
\hline Median & 11.5 & 0.64 & 0.091 & $5.87 \%$ & $0.76 \%$ & $14.61 \%$ \\
\hline Geo Mean & 11.1 & 0.62 & 0.089 & $5.55 \%$ & $0.80 \%$ & $14.84 \%$ \\
\hline $25 \%$ & 6.4 & 0.40 & 0.059 & $3.22 \%$ & $0.47 \%$ & $8.44 \%$ \\
\hline Minimum & 1.3 & 0.10 & 0.012 & $0.29 \%$ & $0.06 \%$ & $1.65 \%$ \\
\hline $\mathrm{N}$ & 155 & 151 & 153 & 151 & 153 & 149 \\
\hline
\end{tabular}

Figure 12. Time Series Plot Example for Black Carbon (BC) and Polycyclic Aromatic Hydrocarbons (Pahs) Concentrations at a Roadside Walking Route. The Huge Concentration Peaks of Black Carbon and Pahs Were Observed Near an Old Lawnmower that was Starting.

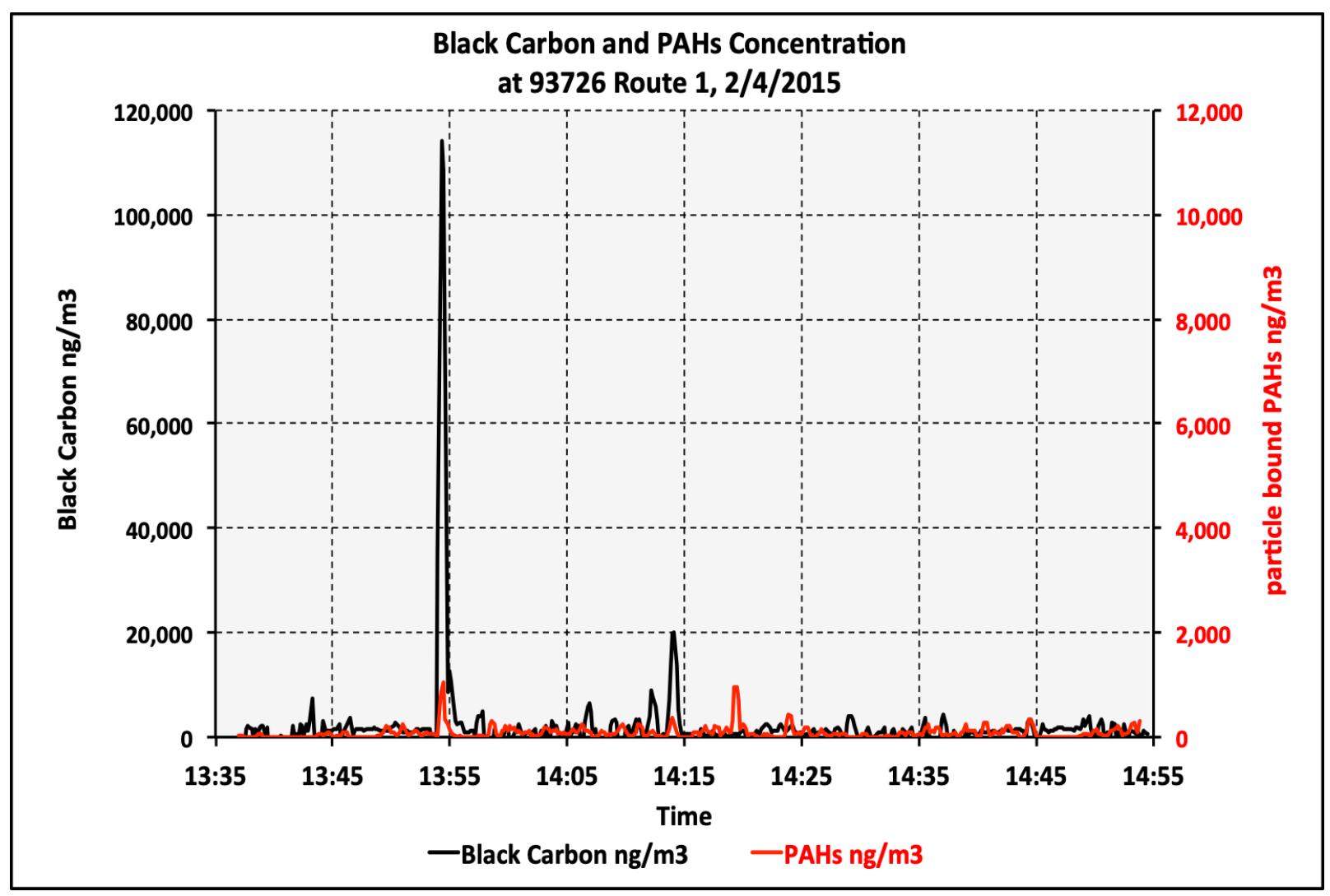




\subsection{Geospatial Descriptive Analyses of Roadside Air Quality Sensor Data}

The average PM2.5 concentration on routes was 3.8 times higher than PM2.5 at an indoor location. Particle concentrations were consistently higher than the concentrations measured at the ambient monitoring stations. Particle concentrations varied by the types of the roadways and immediate local sources encountered during sampling (Tables 3 and 4). PM2.5 was highest on roads over highways, while black carbons were highest on arterial roadways. The impact of sources such as passing buses, active smokers, motorcycles, and lawnmowers was greater for PM2.5, BC, and PAHs, while PAHs were also higher near schools and a factory. It is notable that black carbon and PAHs were minimal near the CNG school bus. Figures 13 and 14 illustrate the distribution of the PM2.5 and black carbon concentrations for overall walking routes respectively. The higher concentrations were observed near the highways for both PM2.5 and BC. However, the PM2.5 and $\mathrm{BC}$ concentrations did not align for every route. The ratios between the particle species would be useful to identify the local source profiles.

Table 3. Mean Particle Concentrations $\left(\mu \mathrm{g} / \mathrm{m}^{3}\right)$ by Type of Roadways (Partial Data, 2015-2016 Data)

\begin{tabular}{|c|c|c|c|}
\hline & $\mathrm{PM}_{2.5}$ & $\mathrm{BC}$ & PAHs \\
\hline Arterial / Collector over Highway & 13.1 & 0.313 & 0.064 \\
\hline Arterial / Collector & 8.5 & 0.811 & 0.055 \\
\hline Residential Street & 7.9 & 0.551 & 0.054 \\
\hline
\end{tabular}

Table 4. Particle Concentrations and Compositional Proportions by The Immediate Local Sources (Partial Data, 2015-2016 Data)

\begin{tabular}{|c|r|r|r|r|r|r|}
\hline & $\begin{array}{r}\mathrm{PM}_{2.5} \\
\left(\mu \mathrm{g} / \mathrm{m}^{3}\right)\end{array}$ & \multicolumn{1}{|c|}{$\begin{array}{c}\mathrm{BC} \\
\left(\mu \mathrm{g} / \mathrm{m}^{3}\right)\end{array}$} & \multicolumn{1}{|c|}{$\begin{array}{c}\mathrm{PAH} \\
\left(\mu \mathrm{g} / \mathrm{m}^{3}\right)\end{array}$} & $\begin{array}{c}\mathrm{BC} / \\
\mathrm{PM}_{2.5}(\%)\end{array}$ & $\begin{array}{c}\text { PAH/ } \\
\mathrm{PM}_{2.5}\end{array}$ & \multicolumn{1}{c|}{$\begin{array}{c}\text { PAH/ } \\
\mathrm{BC} \\
(\%)\end{array}$} \\
\hline Bus - Passing & 27.2 & 1.1 & 0.010 & 3.9 & 0.0 & 0.3 \\
\hline Bus stop & 6.4 & 0.9 & 0.045 & 15.0 & 1.0 & 7.6 \\
\hline Crossing street & 7.4 & 1.4 & 0.025 & 19.5 & 0.3 & 0.6 \\
\hline Factory & 2.6 & 0.5 & 0.072 & 19.1 & 2.8 & 14.7 \\
\hline Road over Highway & 13.1 & 0.3 & 0.064 & 1.7 & 0.4 & 61.8 \\
\hline Road under a highway overpass & 3.4 & 0.3 & 0.059 & 9.9 & 1.8 & 17.7 \\
\hline Old lawnmower & 17.8 & 66.4 & 0.049 & 374.0 & 0.3 & 0.1 \\
\hline Motorcycle & 19.6 & 1.6 & 0.097 & 8.2 & 0.5 & 7.4 \\
\hline School & 17.0 & 1.0 & 0.142 & 5.0 & 0.8 & 11.0 \\
\hline School Bus - CNG & 17.4 & 0.0 & 0.023 & 0.0 & 0.1 & 0.0 \\
\hline Active smoker & 26.2 & 1.2 & 0.091 & 4.4 & 0.3 & 2.9 \\
\hline Grand Total & 8.3 & 0.7 & 0.055 & 9.8 & 0.9 & 16.1 \\
\hline
\end{tabular}


Figure 13. Distribution of Average $\mathrm{PM}_{2.5}\left(\mu \mathrm{g} / \mathrm{m}^{3}\right)$ for Walking Route Samples

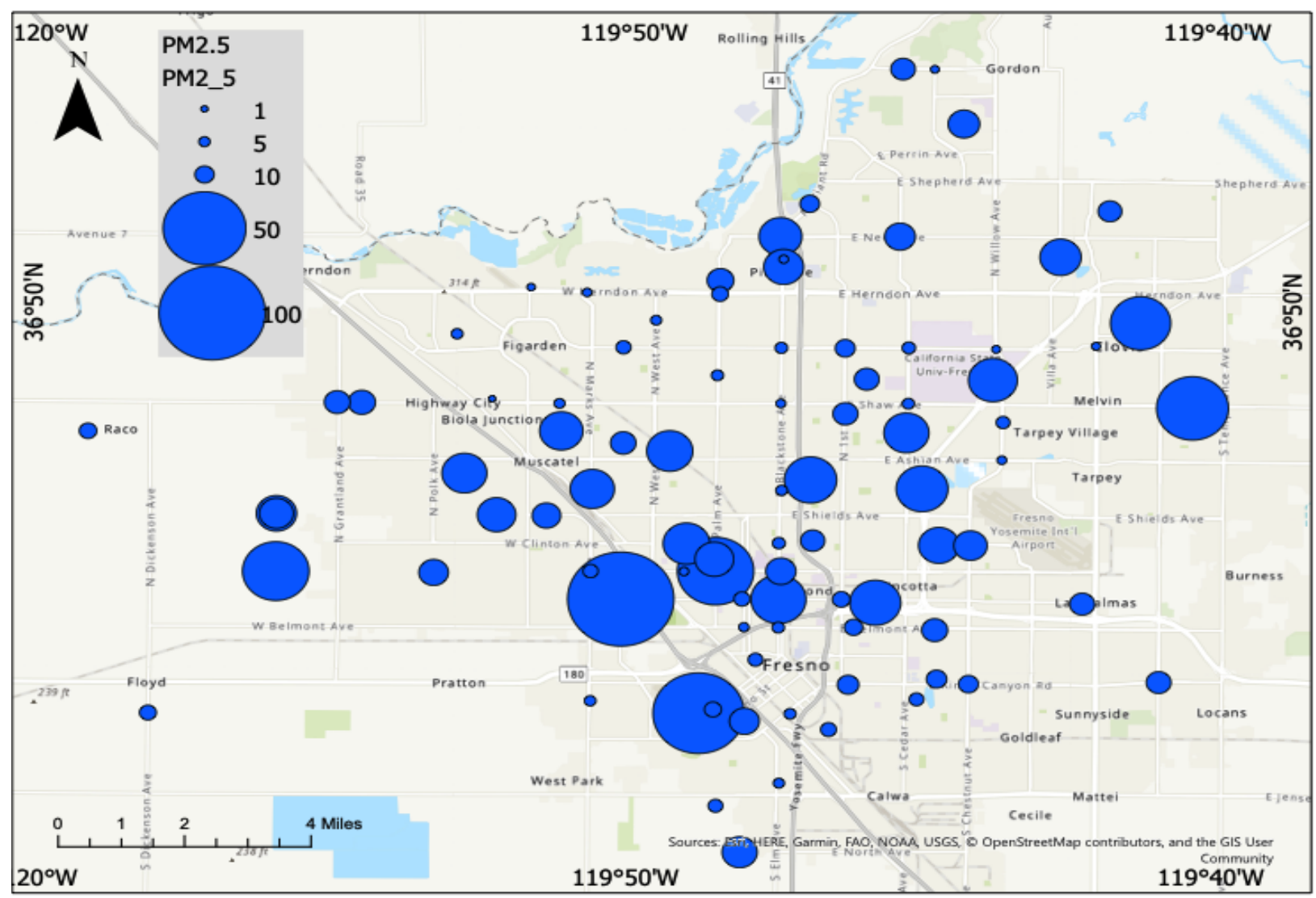


Figure 14. Distribution of Average Black Carbon $\left(\mu \mathrm{g} / \mathrm{m}^{3}\right)$ for Walking Route Samples

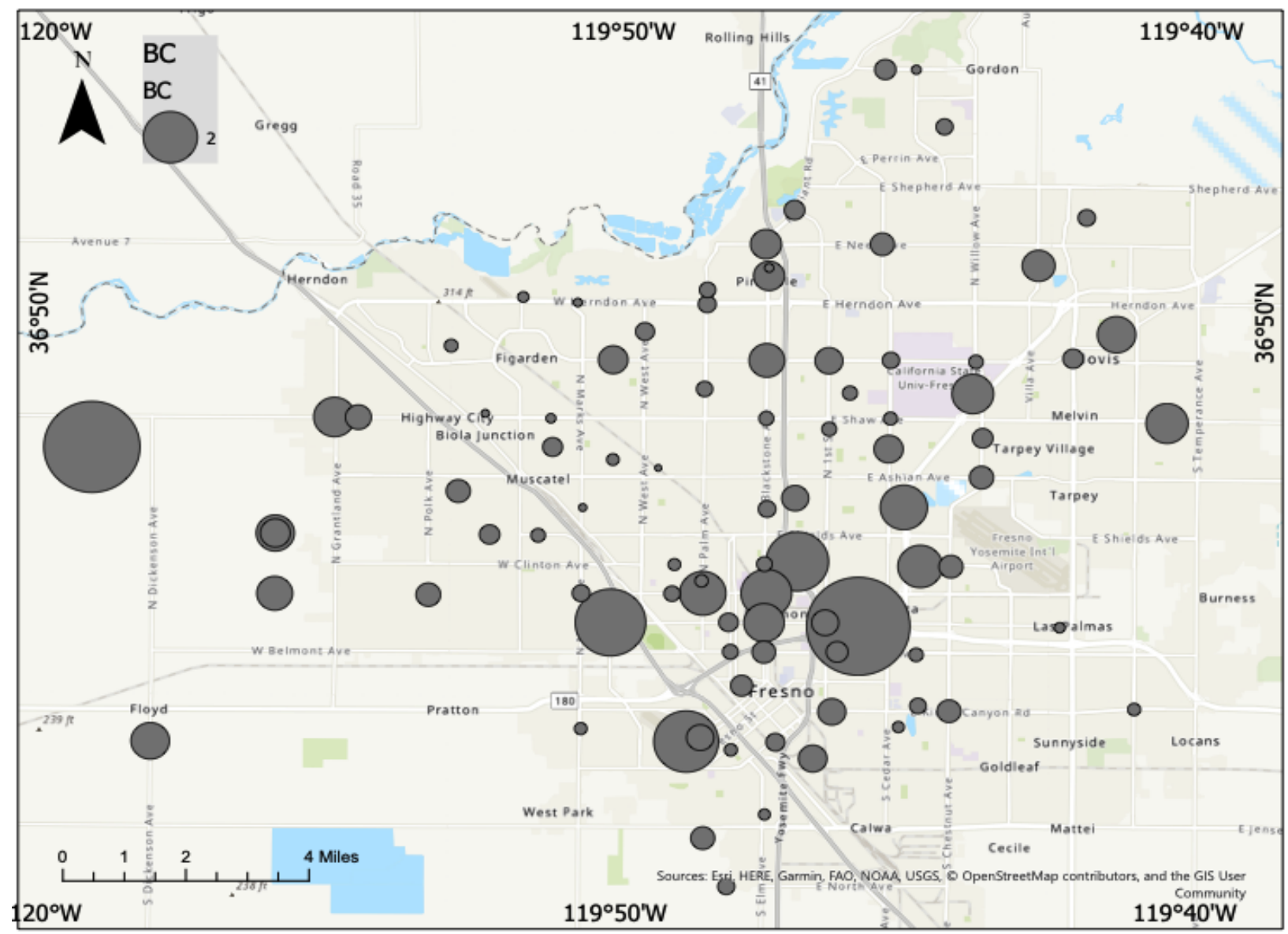

\subsection{Parallel measurement data analyses}

To minimize the impact of temporal variability on the particulate matter concentrations, the PM2.5, black carbon, and PAHs data from 8 walking routes were measured on the same day and time (parallel measurements). In Figure 15, the paired routes that were sampled parallelly are indicated by arrows. The GPS logged location points of the detailed routes (blue dots) illustrate each sampling location. As listed in each table, the particle compositions at the paired locations are distinctive from each other. For example, PM2.5 at 93704-R45 was more than 3 times higher than PM2.5 at 93721-R3. However, the concentrations of BC and PAHs at 93721-R3 were 2 to 3 times higher than those of 93704-R45. Similar trends of high BC and PAHs were observed at the routes near the highways (Hwy99, Hwy 41, Hwy 168) and high industrial areas (93704-R45, 93721-R3, 93702-R2, and 93612-R43). In contrast, the paired locations had elevated PM2.5, with more residential development, and unpaved grounds. It is interesting to note that the $93727-$ R1 had a newly built shopping mall that had a lot of traffic while 93702-R2 barely had any traffic in the early mornings. 
Figure 15. The Parallel Repeated Measurements of PM2.5, Black Carbon, and Pahs At 8 Walking Routes on the Same Days and Times. The Paired Routes are Indicated by Arrows. The Values are Averages of Overall Measurements Including Repeats.

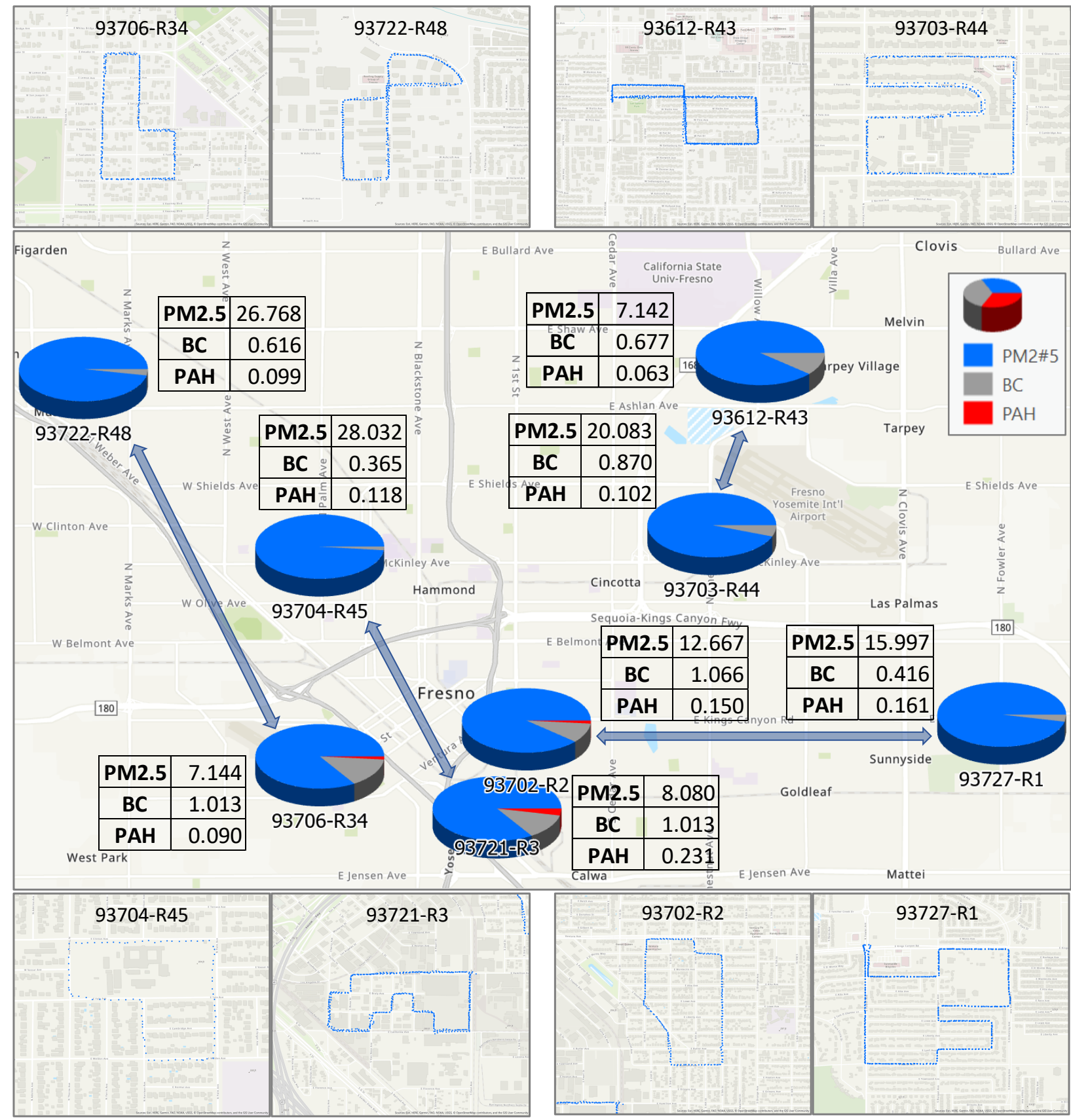

The walking route samples were immediately influenced by the crossing emissions or resuspended dust. To present the variability between different particulate matter species, PM2.5 (blue), BC (gray), and PAHs (red) concentrations and GPS waypoints measured at 93727-R1 on a sampling period are illustrated in Figure 16. For example, at 93727-R1 (one of the paired locations), elevated black carbon concentrations were observed in the middle of the residential area without any moving vehicles. PM2.5 and PAHs were not high at these locations. A pest control truck with an 
idling engine was the only suspicious emission source based on the sampler's observation at the location.

Figure 16. PM2.5, BC, and PAHs Concentrations and GPS Waypoints Measured at 93727-R1 on a Sampling Period.
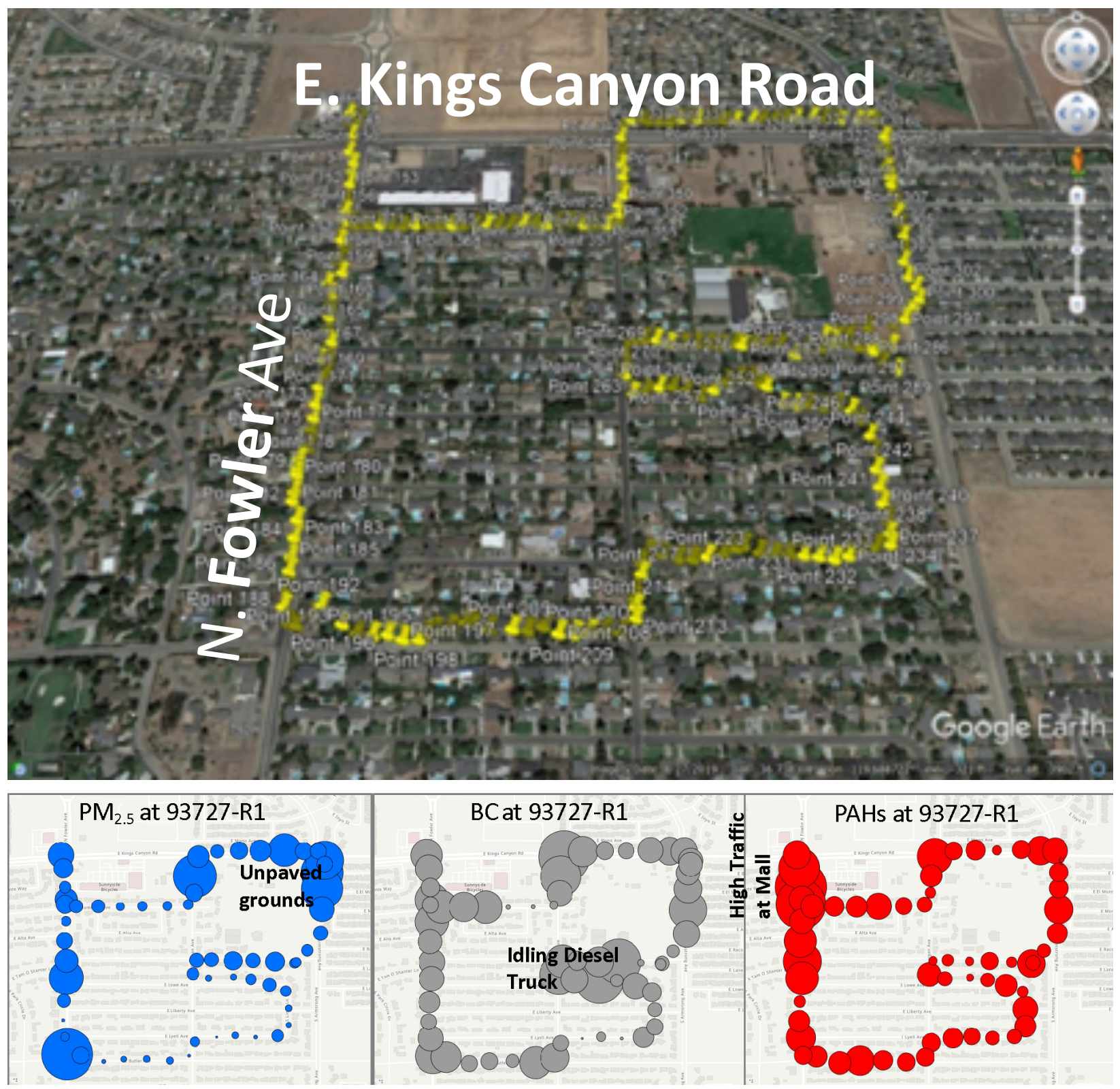

4.4 Neighborhood Characteristic Analyses in zip codes

The assimilated GPS layers are illustrated in Figure 17. The layers overlaid are Fresno City Boundary, Road Intersection (+ speed bump), Road segment (TIGER), CHAPS walking route air quality and location data, and CalEnviroScreen scores and variables. The average of the particle 
pollution and CalEnviroScreen scores and variables indicating health and environments (SSO disorder and order, asthma, and low birth weight summarized by zip codes) are listed in Table 5. Diesel PM emissions were highest near zip codes close to roads such as California state route 99 and 41 . Elevated levels of asthma were observed in zip codes such as 93706, 93701, \& 93721.

Figure 17. Gathered GIS Layers; Fresno City Boundary, Road Intersection (+ speed bump), Road segment, Previous CHAPS data, CalEnviroScreen Data at Census Tracts

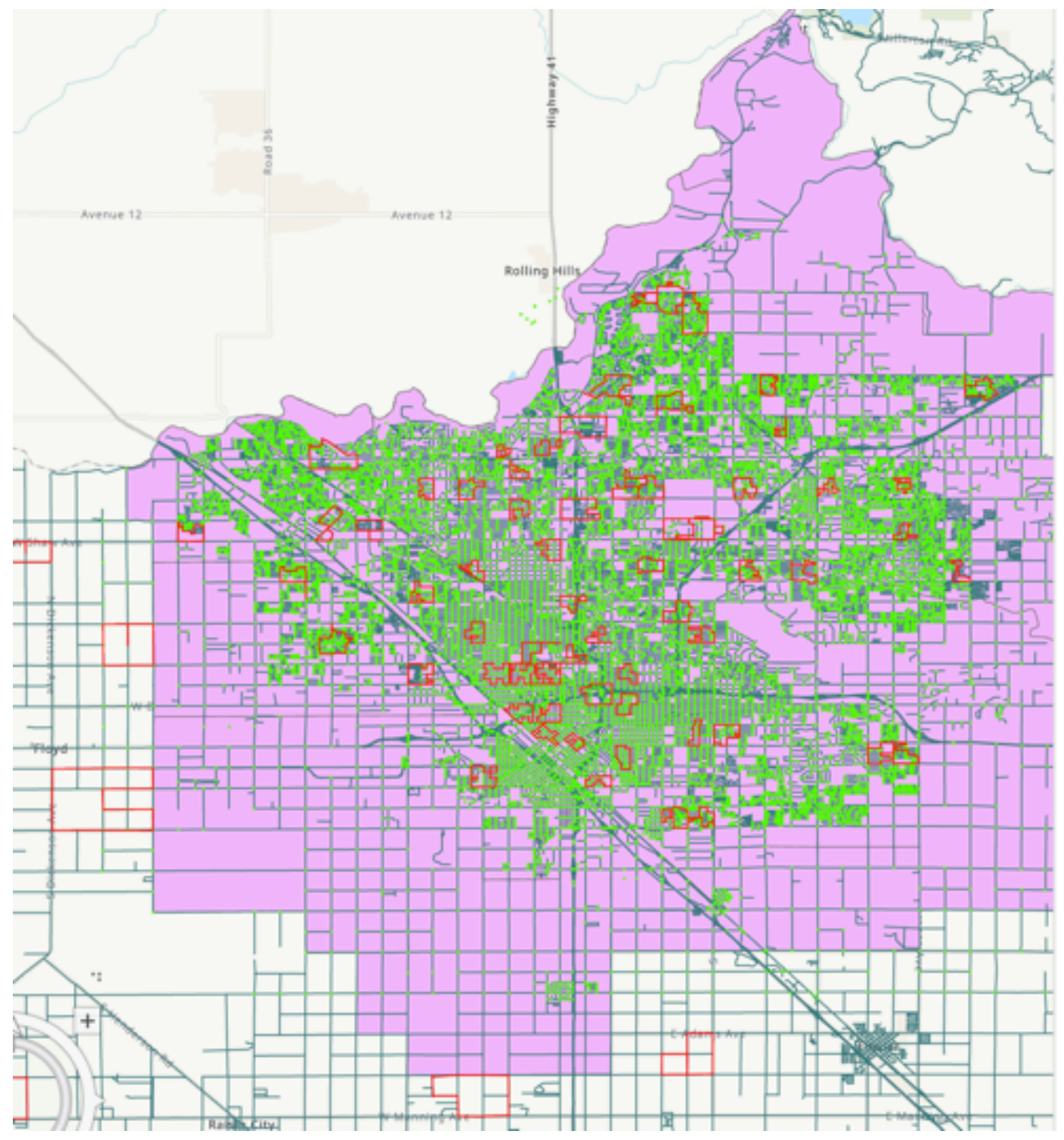


Table 5. Mean Particulates Concentration and the Secondary Neighborhoods' Environmental and Health Characteristic Indicators by Zip Codes

\begin{tabular}{|c|c|c|c|c|c|c|c|c|c|c|c|c|c|}
\hline $\begin{array}{c}\text { Zip } \\
\text { Code }\end{array}$ & $\begin{array}{c}\text { Average } \\
\text { BC } \\
(\mu \mathrm{g} / \mathrm{m} 3)\end{array}$ & $\begin{array}{c}\text { Average } \\
\text { PM } 2.5 \\
(\mu \mathrm{g} / \mathrm{m} 3)\end{array}$ & $\begin{array}{c}\mathrm{BC} / \mathrm{PM} \\
2.5(\%)\end{array}$ & $\begin{array}{c}\text { Traffic } \\
\text { (vehicle } \\
- \\
\text { kilomete } \\
\text { rs per } \\
\text { hour per } \\
\text { road } \\
\text { length) }\end{array}$ & $\begin{array}{c}\text { Diesel } \\
\text { PM } \\
\text { Emissio } \\
\mathrm{n} \\
\text { (kg/day) }\end{array}$ & $\begin{array}{l}\text { Walk } \\
\text { score }\end{array}$ & $\begin{array}{c}\text { CES } \\
\text { Pollution } \\
\text { Burden } \\
\text { Score }\end{array}$ & $\begin{array}{c}\text { CES } \\
\text { Populatio } \\
\mathbf{n} \\
\text { Characte } \\
\text { ristics } \\
\text { Score }\end{array}$ & $\begin{array}{l}\text { CES } \\
\text { Total } \\
\text { Score }\end{array}$ & $\begin{array}{c}\text { SSO } \\
\text { Disorder } \\
\text { Walking }\end{array}$ & $\begin{array}{c}\text { SSO } \\
\text { Order } \\
\text { Walking }\end{array}$ & $\begin{array}{c}\text { Asthma } \\
\text { (Rate } \\
\text { per } \\
10,000)\end{array}$ & $\begin{array}{c}\text { Low } \\
\text { Birth } \\
\text { Weight } \\
\text { (Rate per } \\
10,000)\end{array}$ \\
\hline 93723 & 2.00 & 15.8 & 12.7 & 85 & 8 & NA & 4.5 & 5.2 & 23.4 & 6.9 & .73 & 58 & 4.9 \\
\hline 93701 & 0.71 & 6.4 & 11.1 & 1468 & 59 & 56.5 & 4.8 & 9.2 & 44.16 & 39.8 & 22.9 & 116 & 6.0 \\
\hline 93612 & 0.63 & 6.3 & 10.0 & 556 & 28 & 34.9 & 6.4 & 6.2 & 39.68 & 3.89 & 6.76 & 63 & 5.0 \\
\hline 93711 & 0.50 & 5.2 & 9.6 & 966 & 18 & 29.3 & 6.0 & 4.4 & 26.4 & 3.04 & 11.05 & 30 & 5.1 \\
\hline 93710 & 0.65 & 7.9 & 8.2 & 1315 & 37 & 35.5 & 5.9 & 6.2 & 36.58 & 15.9 & 11.1 & 59 & 5.4 \\
\hline 93721 & 0.70 & 8.6 & 8.1 & 1623 & 57 & 61.5 & 6.8 & 7.7 & 52.36 & 12.5 & 9.5 & 103 & 5.7 \\
\hline 93703 & 1.50 & 19.7 & 7.6 & 1262 & 47 & 39.9 & 5.3 & 8.5 & 45.05 & 16.25 & 7 & 85 & 5.7 \\
\hline 93702 & 0.77 & 10.9 & 7.1 & 575 & 26 & 39.9 & 6.6 & 9.1 & 60.06 & 9.4 & 4.7 & 93 & 5.5 \\
\hline 93706 & 0.90 & 15.8 & 5.7 & 492 & 29 & 29.1 & 7.3 & 9.1 & 66.43 & 11.2 & 2.9 & 130 & 5.8 \\
\hline 93725 & 1.30 & 24.4 & 5.3 & 696 & 17 & 14.6 & 7.5 & 7.9 & 59.25 & 12.3 & 3.4 & 69 & 5.2 \\
\hline 93720 & 0.83 & 17.5 & 4.7 & 495 & 19 & 26.4 & 5.2 & 3.7 & 19.24 & 5.6 & 11.1 & 29 & 5.0 \\
\hline 93726 & 1.09 & 27.0 & 4.0 & 1006 & 45 & 35.4 & 4.8 & 7.2 & 34.56 & 66.6 & 7.8 & 81 & 5.1 \\
\hline 93730 & 0.46 & 11.5 & 4.0 & 329 & 9 & $\mathrm{NA}$ & 5.1 & 3.3 & 16.83 & 4.6 & 17.2 & 20 & 4.9 \\
\hline 93611 & 1.30 & 34.3 & 3.8 & 339 & 18 & 20.3 & 5.3 & 3.7 & 19.61 & 2.5 & 5.4 & 36 & 5.2 \\
\hline 93704 & 0.43 & 11.4 & 3.8 & 895 & 45 & 37.6 & 4.9 & 6.2 & 30.38 & 12.8 & 4.7 & 72 & 5.1 \\
\hline 93722 & 0.53 & 18.3 & 2.9 & 750 & 22 & 16.3 & 6.4 & 6.9 & 44.16 & 9.7 & 6.6 & 65 & 5.5 \\
\hline 93727 & 0.38 & 13.2 & 2.9 & 752 & 24 & 20.0 & 7.1 & 7.4 & 52.54 & 9.91 & 6.27 & 62 & 5.4 \\
\hline 93705 & 0.30 & 19.8 & 1.5 & 739 & 31 & 36.3 & 4.7 & 8.1 & 38.07 & 17.2 & 4.4 & 88 & 5.3 \\
\hline
\end{tabular}

From the correlation matrix (Figure 18), we can see that the pair (Asthma vs. CES Population Characteristics Score) has the highest positive correlation. Other pairs that have a fairly high correlation are the pairs (CES Total Score vs. CES Population Characteristics Score), (Asthma vs. CES Total Score), (Asthma vs. Low Birth Weight), (CES Population Characteristics Score vs. Low Birth Weight), (CES Pollution Burden Score vs. CES Total Score), (Walk score vs. Diesel PM Emission), and (Diesel PM Emission vs. Traffic). On the other hand, the pairs (Asthma vs. Average BC) and (BC/PM25 vs. Low Birth Weight) have a very weak correlation. The P-value table confirms that many pairs of variables have a population correlation significantly 
different from 0 . This result confirms that there exists a significant linear relationship among many pairs of variables (Table A-2 Appendix). The statistically significant correlations at $(\mathrm{p}<0.05)$ are highlighted.

Figure 18. Correlation Matrix

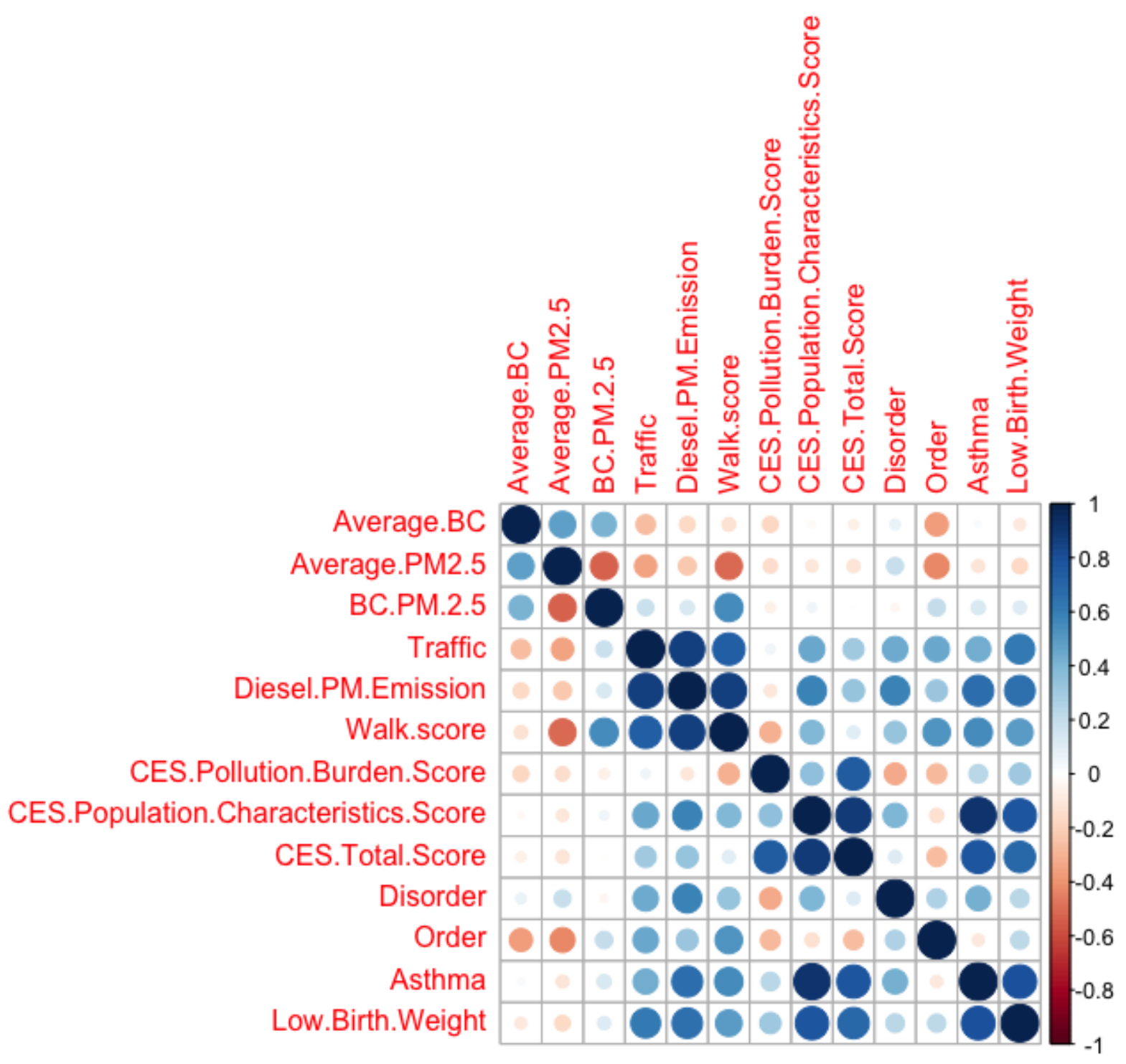


Figure 19. Map of BC/PM2.5 by Zip Code. High Level (red) of BC/PM2.5 Zip Code Areas were 93723, 93711, 93612, and 93701, Followed by Yellow Areas. The Green-colored Zip

Codes Show the Lowest BC Percentages in the PM2.5.
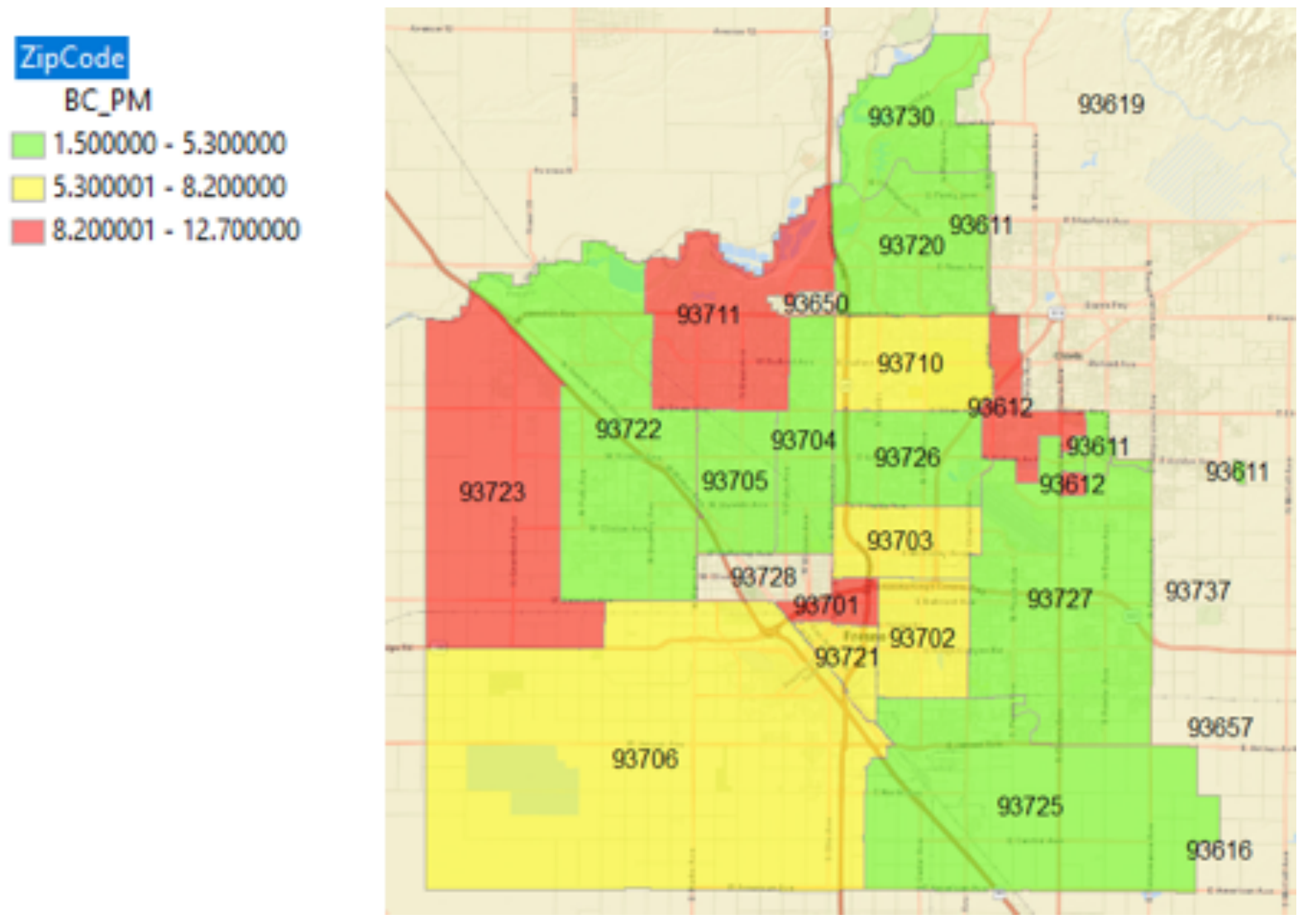

To investigate the relationship of particulate matter near roadways and by zip code, while also taking into account spatial-temporal factors and analyzing health effects in these identified areas, data taken at routes and CalEnviroScreen indicators were analyzed. BC percent of PM2.5 is mapped in three groups in Figure 19. The highest BC percent in PM2.5 areas (red) were 93723, 93711, 93612, and 93701. The yellow areas were 93706, 93721, 90702, 93703, and 93710. Compared to the lowest (green) BC contents zip code areas, red and yellow colored zip codes areas are closer to highway 99 or contain more highway networks within the area connected to higher volume arterial roadways. These results may be due to the fact that California State Highway 99 is mainly used by diesel trucks whereas California State Route $41 \& 180$ traffic is primarily occupied by light-duty vehicles, a distinction which can contribute to differences in particulate matter emitted and level of black carbon measured. It is necessary to further investigate by reducing temporal and meteorological factors that influenced the short-term air quality monitoring data. Further analyses characterizing the larger particles such as fugitive dust and PM10 in relation to the land use and the unpaved and uncovered lands in the areas where the high PM2.5 levels are necessary for future study. 
Previous studies have found a strong association between polycyclic aromatic hydrocarbons and rates of hospitalization and asthma near Highway 99 (Noth et al., 2011). The limitations of this research are greater variability in the zip code areas and the temporal trends of the particulate concentrations. Census tract-level examination and the standardization with particle concentrations measured at the central monitoring data would help further investigation of spatiotemporal analyses with health and built environmental indicators.

\subsection{Evaluation of low-cost Sensors in Collocation Sensor calibration}

The two different types of particulate monitoring air sensors (Dylos DC1700 and AtmoTube Pro) were tested for the relationship between number concentrations from low-cost sensors and mass concentrations from a more expensive and reliable DRX Dusttrak 8533 to collect particulate matters in urban air. Figures 20 and 21 illustrate the collocation measurement of three different air monitoring sensors. The side-by-side sample collection compared to the conventional methodology (DRX Dusttrack) results imply the low-cost sensors were reliable for measuring pollution levels. As shown in Figures 22 and 23, the time-series concentration increased and decreased in a similar and consistent manner by time, and the median concentrations were close. First, the sensors were calibrated at the same location in the residential setup. Second, the sensors were deployed for data collection at the selected roadside and residential locations, the central monitoring site at Clovis, and during the different modes of transportation such as on-road, invehicle, and on-bike riding. The sites were selected at our convenience of access rather than revisiting previously sampled routes, due to COVID-19 lockdown restrictions that affected personnel training. We plan, if possible, to continue to validate our results by revisiting the paired routes in order to compare hot spots with elevated pollution levels with relatively cleaner air quality areas. We will continue the evaluation of the sensors for a more accurate assessment of the personal exposure levels for the extended phase of the STARTRAQ study in 2021. We are developing research projects using commercially available low-cost sensors for future study. 
Figure 20. Low-cost Particulate Matter Air Sensors. (Left) AtmoTube Pro. (Right) Dylos DC1700
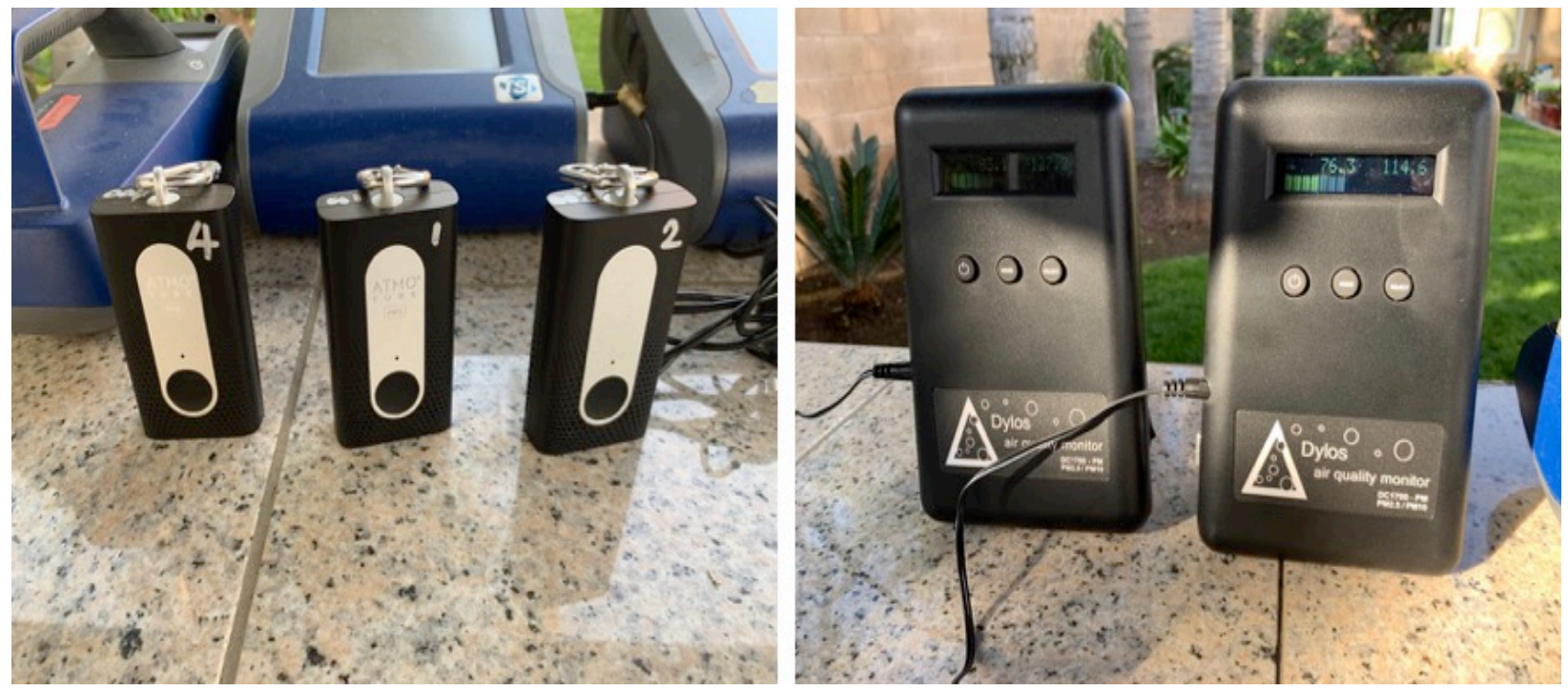

Figure 21. Collocation Measurement (Backyard)

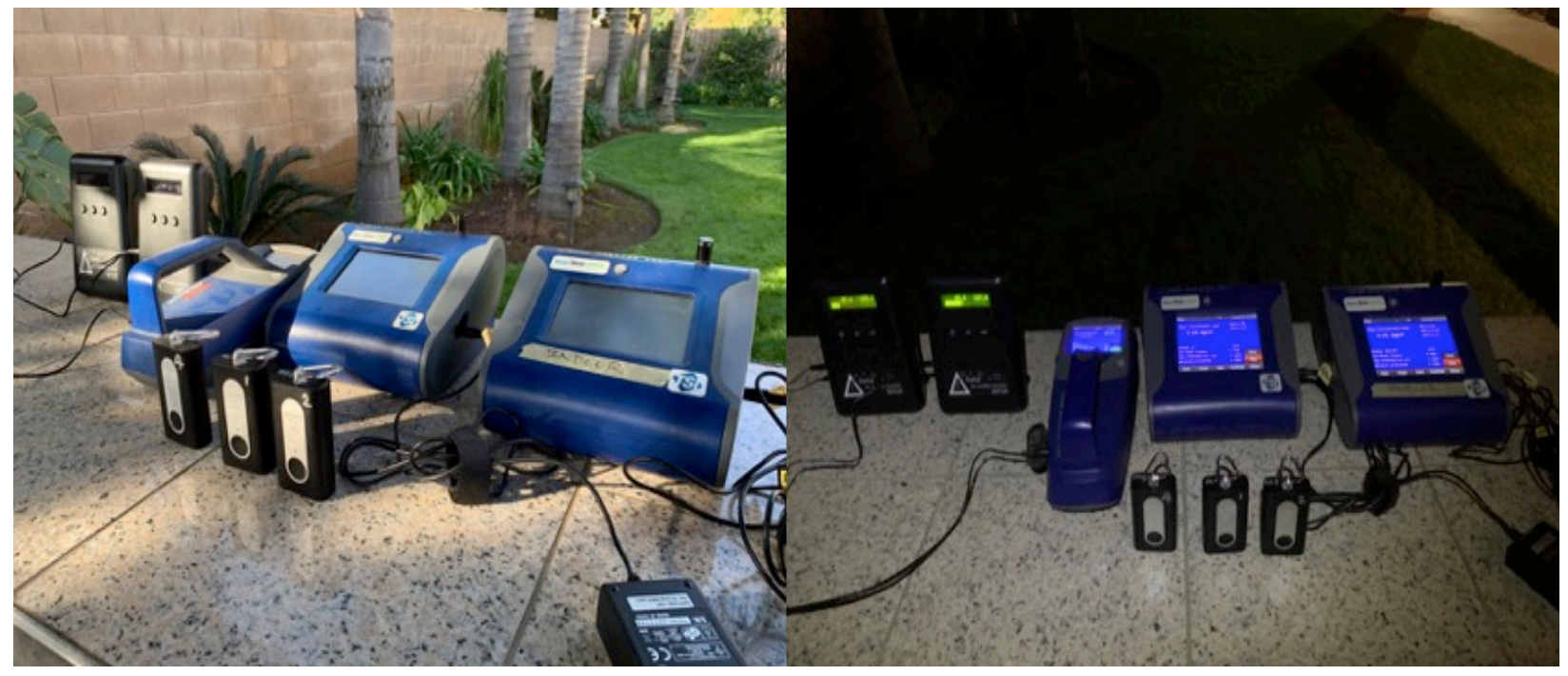


Figure 22. Collocation PM2.5 Mass Concentrations from Air Quality Monitor at a Residential Location from 10/30/20 to 11/05/20.

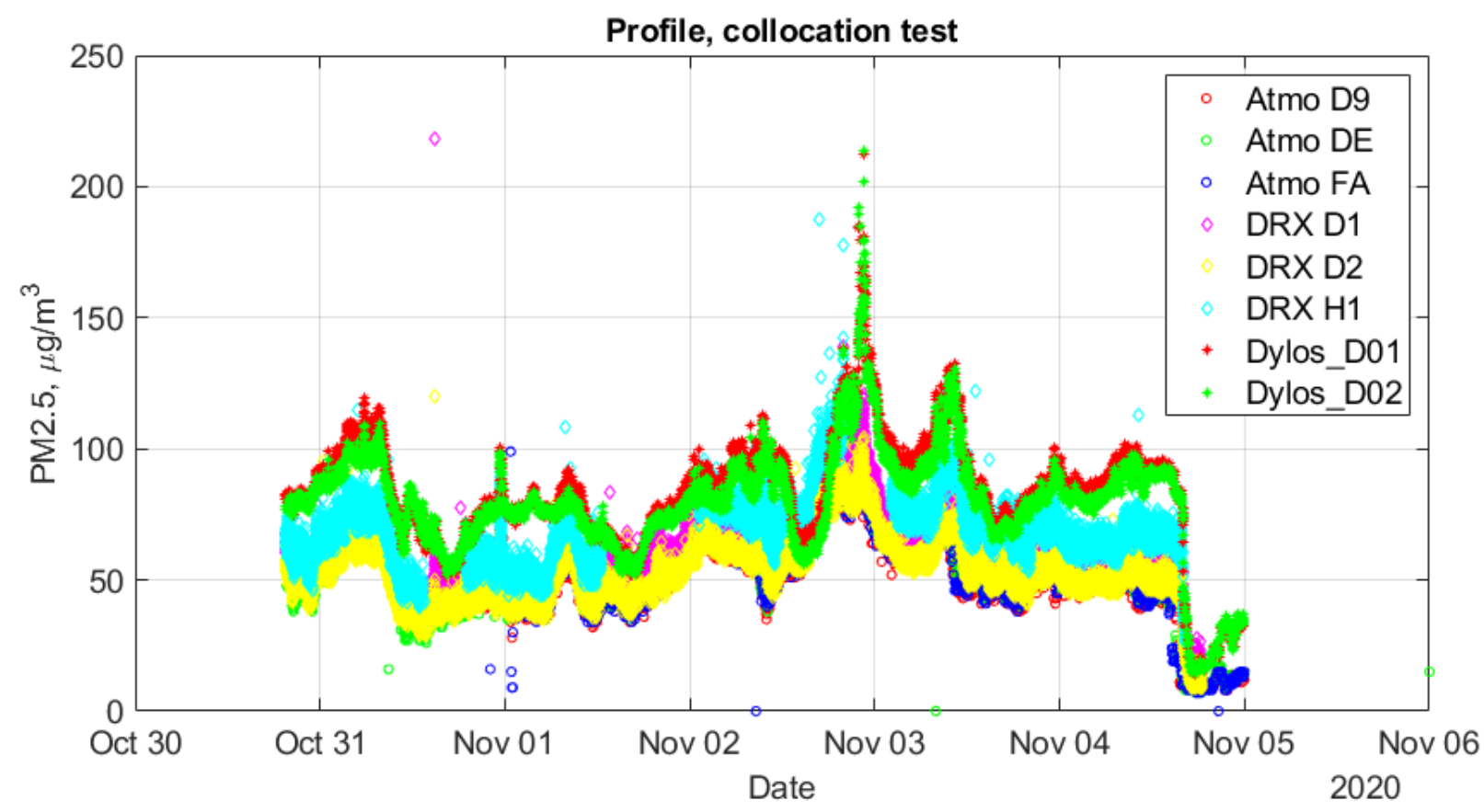

Figure 23. Box and Whisker plots of PM2.5 Mass Concentrations from Air Quality Monitors at the Residential Location from 10/30/20 to 11/05/20.

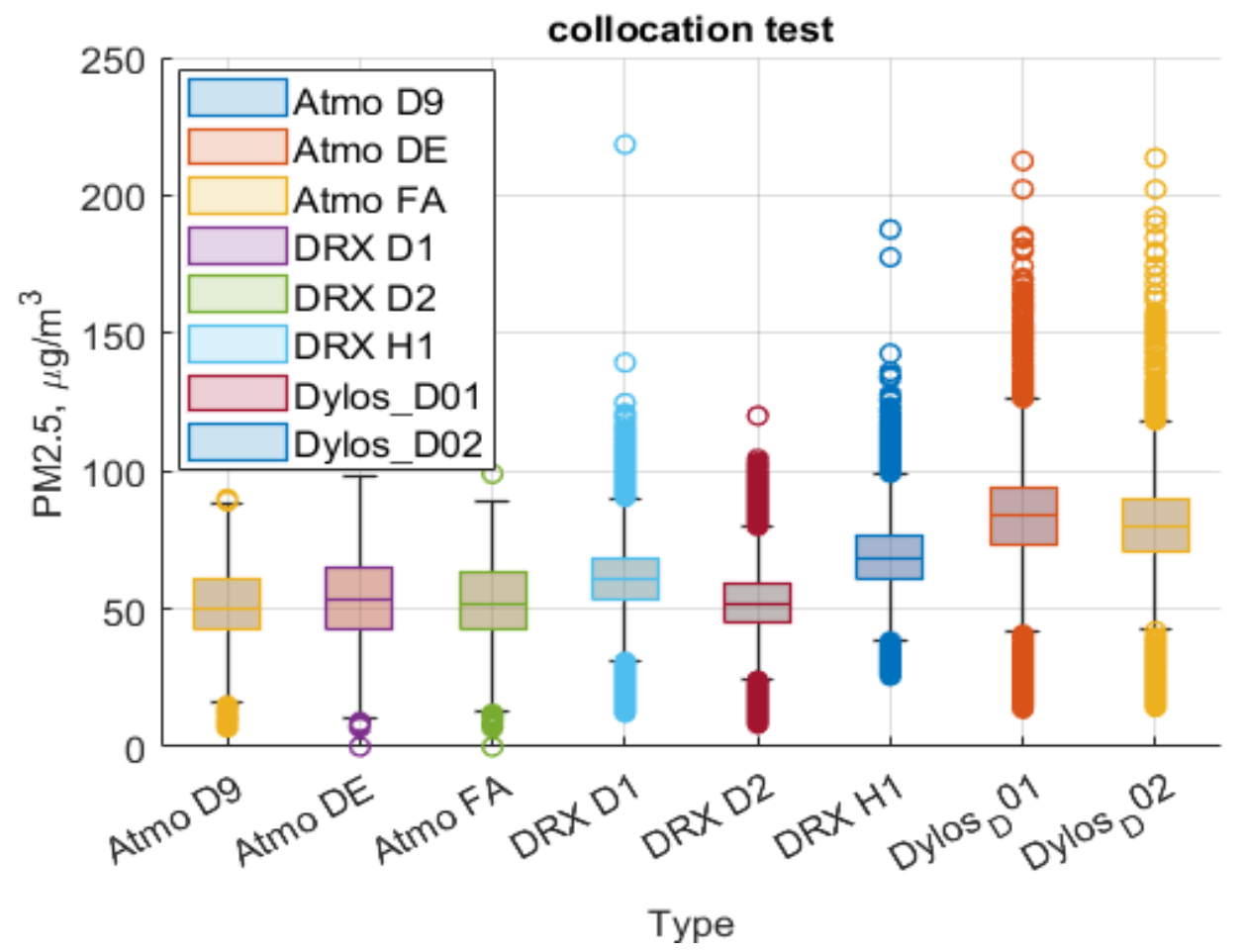


Figure 24. Inter-sensor analysis of DRX Dusttrack using PM2.5. Scatter plots of DRX Dusttrack D1 vs. DRX Dusttrack D2 (Left). Scatter plots of DRX Dusttrack D1 and H1 (Right).
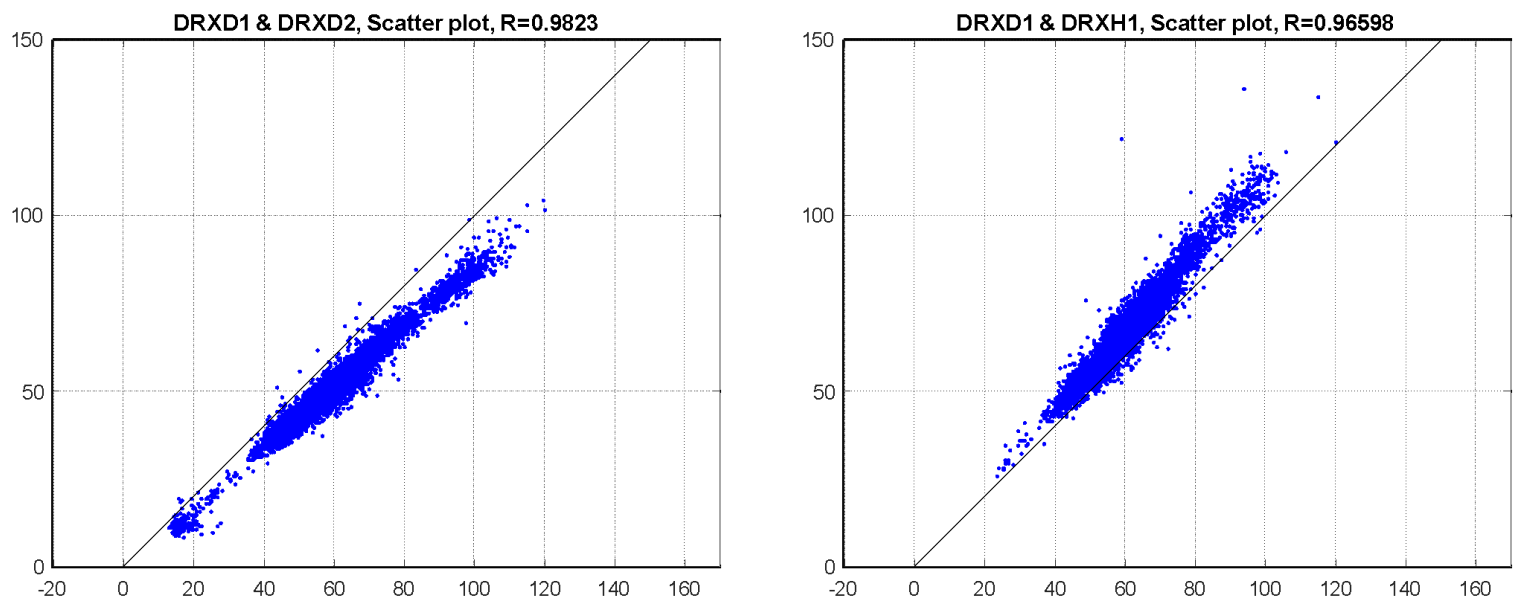

Figure 25. Inter-sensor Analysis of Dylos DC1700 Using PM2.5. Scatter Plots of Dylos DC1700 D1 vs. Dylos DC1700 D2.

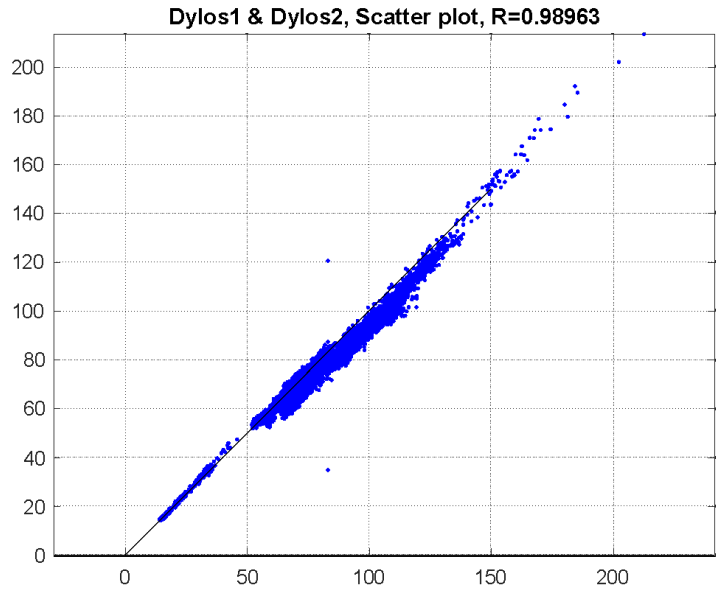


Figure 26. Inter-sensor analysis of Atmotube Pro PM2.5. Scatter plots of Atmotube Pro D9 vs. Atmotube Pro DE (Left). Atmotube Pro D9 vs. Atmotube Pro FA (Right).
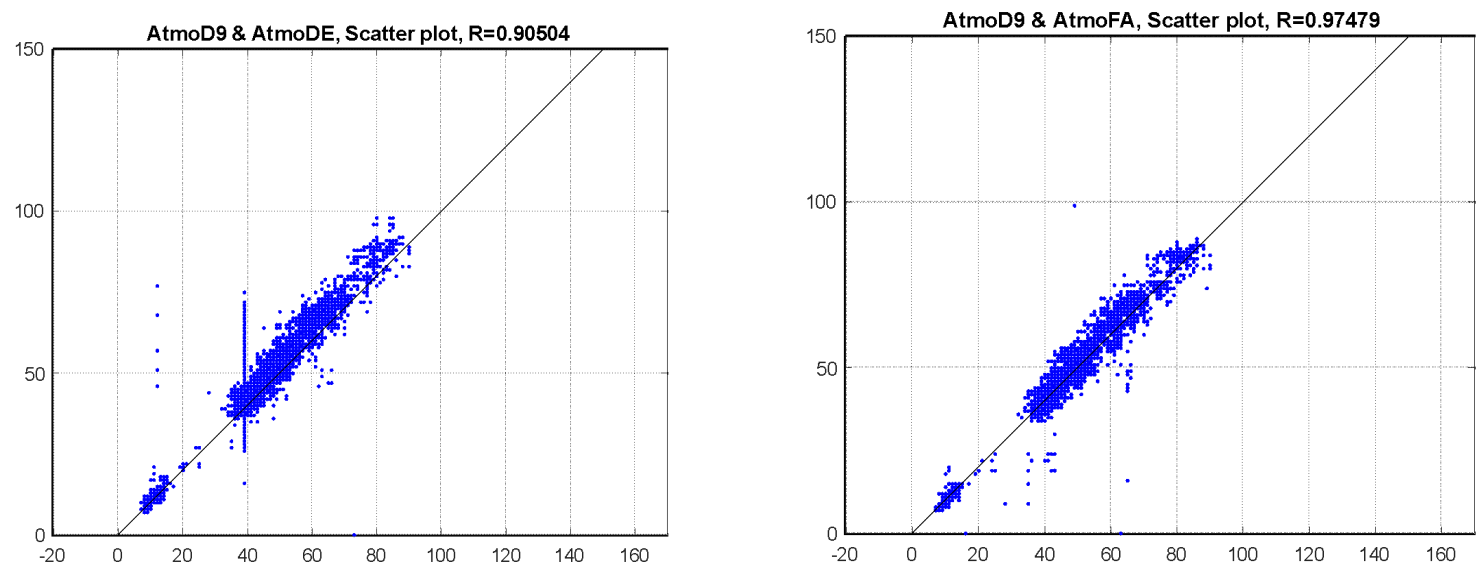

Figure 27. Scatter plots of PM2.5 Mass Concentrations from DRX Dusttracks D1 vs. Dusttracks D2 (correlation coefficient $\mathrm{R}=0.98$ ) and $\mathrm{H} 1$ (correlation coefficient $\mathrm{R}=0.96$ ).

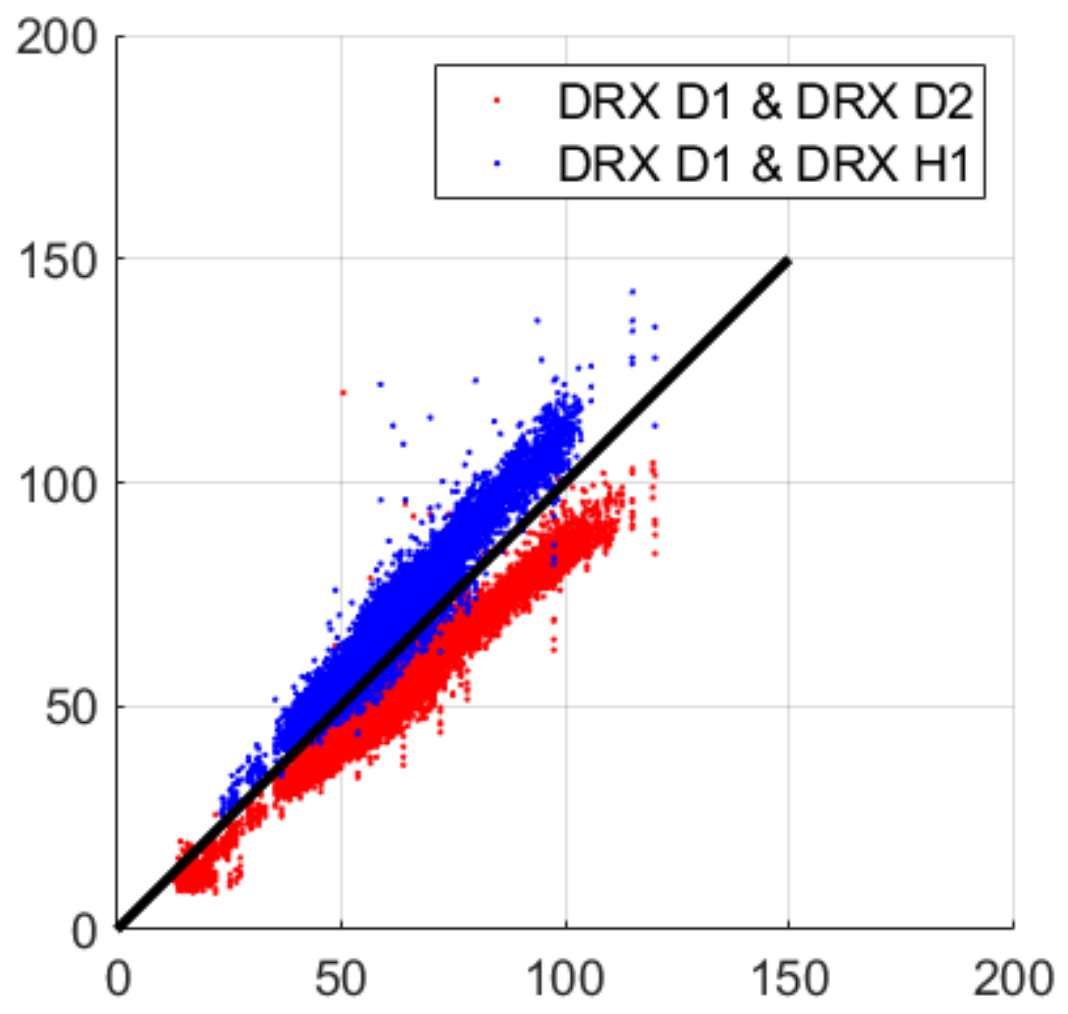


Figure 28. Intra-sensor Analysis of PM2.5. Scatter Plots of PM2.5 Mass Concentrations from DRX Dusttracks D1 vs. Dylos DC1700 Air Sensors D1 and D2 ( $R=0.86, R=0.83)$.

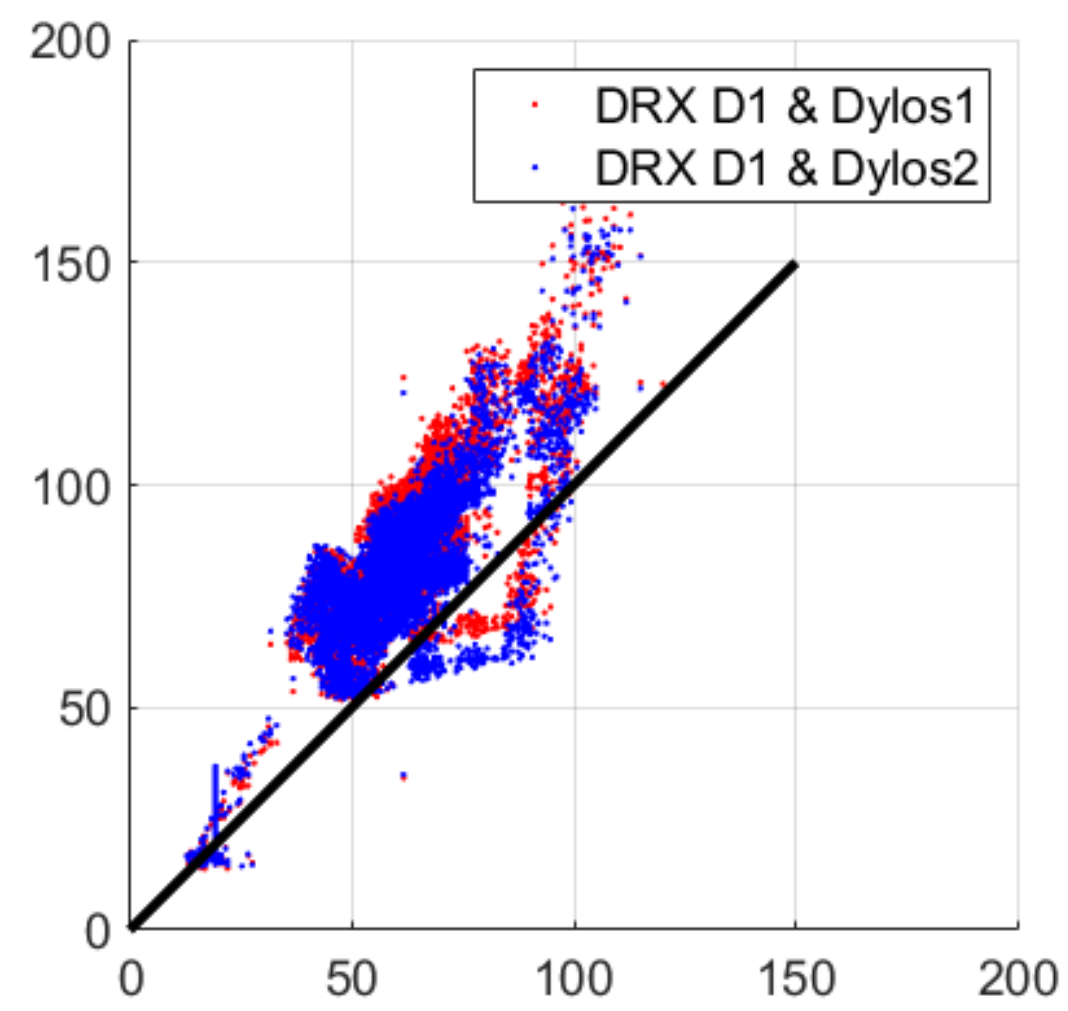

Figure 29. Scatter plots of PM2.5 Mass Concentrations from DRX Dusttracks D1 vs. Atmotube Pro Air Sensors, D9, DE, and FA ( $\mathrm{R}=0.92,0.92,0.83$ respectively).

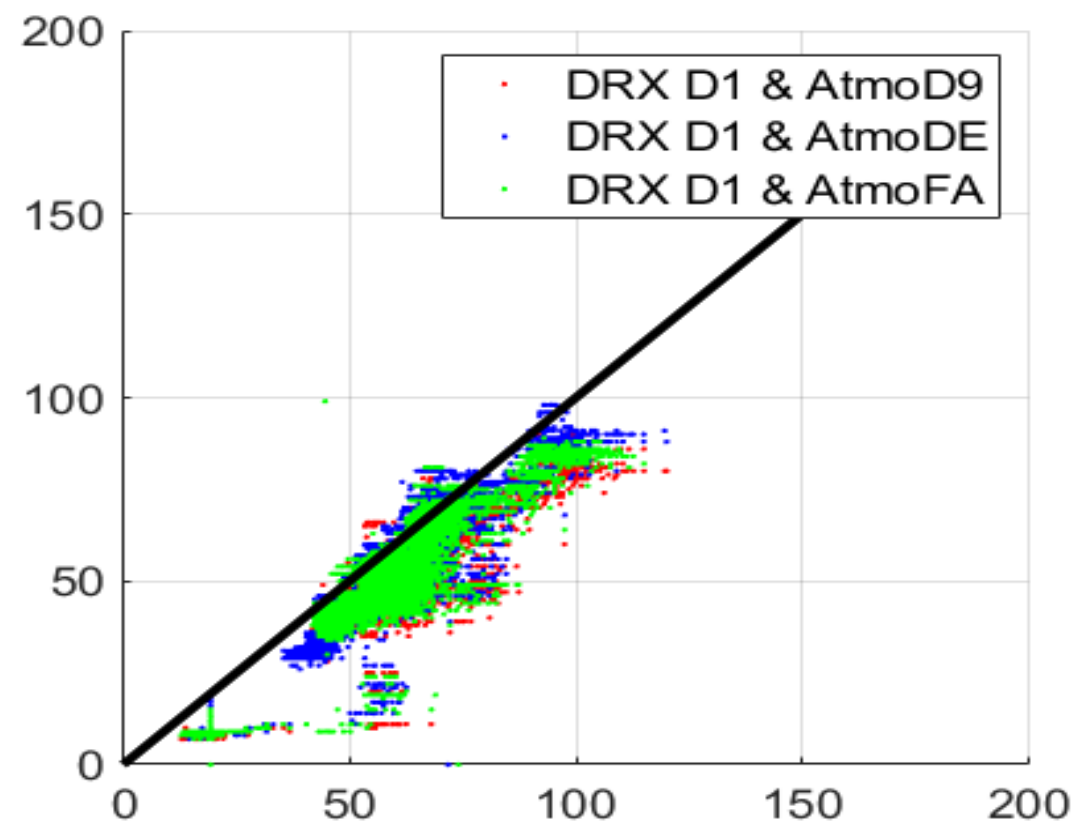


Figures 24-26 show the correlation coefficients from inter-sensor analyses and Figures 27-29 show the correlation coefficients from intra-sensor analyses. It is evident that inter-sensor analyses provide higher correlation coefficients than intra-sensor analyses.

\subsection{Spatio-Temporal Analysis of Roadside Air Quality}

Time series analysis attempts to model the future in terms of previously observed values, and it has often been used to examine air pollution data. The particulate matters such as PM10, PM2.5, PM1, black carbon (BC), ultrafine particles, and polycyclic aromatic hydrocarbons (PAHs) are time-series data, and hence understanding the time dependency is crucial for this project. However, due to incomplete and missing observations, time series analysis was limited in this project.

Some initial investigations suggest that simple models are sufficient for data. The data in Figure 6 and related data were fitted into the linear models given by

$$
y_{P M, t}=\alpha+\beta_{1} x_{y e a r, t}+\beta_{2} w_{l o n, t}+\beta_{2} w_{l a t, t}+\beta_{3} r_{2 t}+\beta_{4} r_{3 t}+\beta_{4} r_{3 t}+\beta_{6} z_{t}+e_{t} \text { (PM Model), }
$$

and

$$
y_{B C, t}=\alpha+\beta_{1} x_{\text {year }, t}+\beta_{2} w_{\text {lon }, t}+\beta_{2} w_{\text {lat }, t}+\beta_{3} r_{2 t}+\beta_{4} r_{3 t}+\beta_{4} r_{3 t}+\beta_{6} z_{t}+e_{t} \text { (BC Model). }
$$

where $\alpha$ is the intercept, $x_{\text {year, }}$ is 1 if the year is 2017 and 0 if the year is $2015, w_{\text {lon }, t}$ is the longitude, $w_{\text {lat, } t}$ is the latitude, $r_{2 t}$ is 1 if the route is $2, r_{3 t}$ is 1 if the route is $3, r_{3 t}$ is 1 if the route is 4 and 0 if the route is $1, z_{t}$ is 1 if the zip code is 93726 and 0 if the zip code is 93706 .

are assumed to follow $\mathrm{N}\left(0, \sigma^{2}\right) . y_{P M, t}$ and is the PM2.5 and black carbon (BC) measured at a minute level. Hence, these models render information about the spatio-temporal aspect of the data. 
Table 6. Output from PM Model

\begin{tabular}{|c|c|c|c|c|}
\hline & Estimate & Std. Error & t value & P-value \\
\hline Intercept & -297.47547 & 39.92625 & -7.451 & $3.33 e-13^{* * * *}$ \\
\hline Year2017 & 0.36606 & 0.04598 & 7.961 & $8.83 e-15^{\text {***k }}$ \\
\hline Longitude & -1.60168 & 0.19278 & $\mid-8.309$ & $6.69 \mathrm{e}-16^{\text {**** }}$ \\
\hline Latitude & 2.85952 & 0.48682 & 5.874 & $7.12 \mathrm{e}-09^{\text {**** }}$ \\
\hline Route2 & 0.31003 & 0.02392 & 12.959 & $<2 \mathrm{e}-16^{* * *}$ \\
\hline Route3 & 0.55878 & 0.07562 & 7.389 & $5.07 \mathrm{e}-13^{\text {**** }}$ \\
\hline Route4 & 0.46067 & 0.04730 & 9.739 & $<2 \mathrm{e}-16^{* * * *}$ \\
\hline Zipcode93726 & 0.57826 & 0.05111 & 11.315 & $<2 \mathrm{e}-16^{* * * *}$ \\
\hline
\end{tabular}

Table 7. Output from BC Model

\begin{tabular}{|l|l|l|l|l|}
\hline & Estimate & Std. Error & t value & P-value \\
\hline Intercept & -1087417.0 & 329660.6 & -3.299 & $0.00104^{* *}$ \\
\hline Year2017 & 1662.0 & 729.2 & 2.279 & $0.02305^{*}$ \\
\hline Longitude & -4695.2 & 2436.5 & -1.927 & 0.05451 \\
\hline Latitude & 14240.0 & 3605.1 & 3.950 & $7.12 \mathrm{e}-09^{\text {**** }}$ \\
\hline Route2 & 1084.9 & 261.5 & 4.150 & $8.87 \mathrm{e}-05^{\text {*** }}$ \\
\hline Route3 & 2162.2 & 521.8 & 4.143 & $3.88 \mathrm{e}-05^{\text {*** }}$ \\
\hline Route4 & 1746.3 & 408.8 & 4.272 & $3.98 \mathrm{e}-05^{* * * *}$ \\
\hline Zipcode93726 & 2720.3 & 369.7 & 7.358 & $7.08 \mathrm{e}-13^{* * * *}$ \\
\hline
\end{tabular}

Tables 6 and 7 show that all the variables are highly significant in both models. R2 values were 0.4765 and 0.3028 for PM and BC models, respectively. 


\section{CONCLUSIONS}

- Geo-coded pollution data enhances the ability to observe spatial variations of pollutants.

- Roadside concentrations of PM2.5, black carbons, and PAHs were significantly elevated compared to the concentrations at the ambient monitoring stations because of the immediate source proximity to the emission sources and because roadside readings were collected at the ground level.

- Persistent spatial patterns of higher concentrations of black carbon and PAHs as components of PM2.5 are evident from the parallel sampling comparisons.

- The elevated PM2.5 concentrations occur near roadways with a higher volume of traffic and regions with more unpaved areas.

- The elevated black carbon concentrations occur near highway corridors, and regions with high diesel traffic/high industry.

- From the correlation between the pollution, environmental variables, and health variables, we can see that the pair (Asthma vs. CES Population Characteristics Score) has the highest positive correlation.

- Other pairs that have a fairly high correlation are the pairs (CES Total Score vs. CES Population Characteristics Score), (Asthma vs. CES Total Score), (Asthma vs. Low Birth Weight), (CES Population Characteristics Score vs. Low Birth Weight), (CES Pollution Burden Score vs. CES Total Score), (Walk score vs. Diesel PM Emission), and (Diesel PM Emission vs. Traffic).

- The collocation test showed a high degree of agreement between inter-sensors whose correlation coefficients range 0.90 - 0.98. Variability of different sensors - DRX, Dylos, and AtmoTube - showed less correlation, suggesting that calibration of those sensors is required for pollution-sensitive regions, such as temporal or human-induced activities. 


\section{Appendix A}

Table A-1. The Average of Particulate Matter Species and the Coordinates of the Trailhead of Routes

\begin{tabular}{|c|c|c|c|c|c|c|c|c|c|c|c|}
\hline ID & zip & Repeat & Date & Latitude & Longitude & PM2.5 & $\mathrm{BC}$ & PAHs & \begin{tabular}{|c|} 
BC/ \\
PM2.5 \\
\end{tabular} & $\begin{array}{l}\text { PAHs/ } \\
\text { PM2.5 }\end{array}$ & $\begin{array}{c}\text { PAHs/ } \\
\text { BC }\end{array}$ \\
\hline B1-93702-R1 & 93702 & $1 \mathrm{st}$ & $2 / 5 / 2015$ & 36.751 & -119.769 & 11.9 & $\overline{\mathrm{NA}}$ & 0.043 & NA & $0.36 \%$ & $\overline{\mathrm{NA}}$ \\
\hline B1-93702-R2 & 93702 & $1 \mathrm{st}$ & $2 / 12 / 2015$ & 36.736 & -119.771 & 13.8 & 0.70 & 0.082 & $5 \%$ & $0.59 \%$ & $11.73 \%$ \\
\hline B1-93702-R3 & 93702 & $1 \mathrm{st}$ & $2 / 12 / 2015$ & 36.737 & -119.745 & 16.9 & 0.71 & 0.078 & $4 \%$ & $0.46 \%$ & $11.05 \%$ \\
\hline B1-93722-R1 & 93722 & $1 \mathrm{st}$ & $2 / 28 / 2015$ & 36.838 & -119.862 & 1.4 & 0.31 & 0.061 & $22 \%$ & $4.35 \%$ & $19.50 \%$ \\
\hline B1-93722-R2 & 93722 & $1 \mathrm{st}$ & $2 / 28 / 2015$ & 36.809 & -119.873 & 1.3 & 0.10 & 0.042 & $8 \%$ & $3.18 \%$ & $42.19 \%$ \\
\hline B1-93722-R3 & 93722 & $1 \mathrm{st}$ & $2 / 19 / 2015$ & 36.790 & -119.881 & 42.3 & 0.91 & 0.076 & $2 \%$ & $0.18 \%$ & $8.30 \%$ \\
\hline B1-93722-R4 & 93722 & $1 \mathrm{st}$ & $2 / 19 / 2015$ & 36.779 & -119.871 & 36.1 & NA & 0.078 & NA & $0.22 \%$ & $\mathrm{NA}$ \\
\hline B1-93726-R1 & 93726 & $1 \mathrm{st}$ & $1 / 30 / 2015$ & 36.787 & -119.750 & 41.4 & 1.26 & 0.041 & $3 \%$ & $0.10 \%$ & $3.25 \%$ \\
\hline B1-93726-R2 & 93726 & $1 \mathrm{st}$ & $2 / 3 / 2015$ & 36.789 & -119.782 & 51.7 & 1.65 & 0.033 & $3 \%$ & $0.06 \%$ & $1.98 \%$ \\
\hline B1-93702-R1 & 93702 & 2nd & $5 / 31 / 2015$ & 36.751 & -119.769 & 7.0 & 0.70 & 0.059 & $10 \%$ & $0.85 \%$ & $8.44 \%$ \\
\hline B1-93726-R3 & 93726 & $1 \mathrm{st}$ & $1 / 29 / 2015$ & 36.801 & -119.755 & 29.5 & 1.20 & 0.041 & $4 \%$ & $0.14 \%$ & $3.43 \%$ \\
\hline B1-93702-R2 & 93702 & 2nd & $5 / 31 / 2015$ & 36.736 & -119.771 & 6.5 & 0.51 & 0.063 & $8 \%$ & $0.96 \%$ & $12.35 \%$ \\
\hline B1-93702-R3 & 93702 & 2nd & $5 / 31 / 2015$ & 36.737 & 745 & 4.5 & 0.26 & 0.055 & $6 \%$ & $1.23 \%$ & $21.33 \%$ \\
\hline B1-93722-R1 & 93722 & 2nd & $6 / 1 / 2015$ & 36.838 & -119.862 & 5.0 & 0.23 & 0.056 & $5 \%$ & $1.13 \%$ & $24.71 \%$ \\
\hline B1-93722-R2 & 93722 & 2nd & $6 / 1 / 2015$ & 36.809 & -119.873 & 3.5 & 0.21 & 0.046 & $6 \%$ & $1.32 \%$ & $22.46 \%$ \\
\hline B1-93722-R3 & 93722 & 2nd & $3 / 29 / 2015$ & 36.790 & .881 & 10.1 & 68 & 0.045 & $7 \%$ & $0.45 \%$ & $6.71 \%$ \\
\hline B1-93722-R4 & 93722 & 2nd & $3 / 29 / 2015$ & 36.779 & -119.871 & 8.3 & 0.64 & 0.052 & $8 \%$ & $0.63 \%$ & $8.15 \%$ \\
\hline B1-93726-R1 & 93726 & 2nd & $2 / 4 / 2015$ & 36.787 & -119.750 & 19.6 & 2.17 & 0.093 & $11 \%$ & $0.48 \%$ & $4.29 \%$ \\
\hline B1-93726-R2 & 93726 & 2nd & $2 / 5 / 2015$ & 36.789 & -119.782 & 9.9 & 0.16 & 0.036 & $2 \%$ & $0.36 \%$ & $22.20^{\circ}$ \\
\hline B1-93726-R3 & 93726 & 2nd & $2 / 4 / 2015$ & 36.801 & -119.755 & 23.0 & 0.80 & 0.101 & $3 \%$ & $0.44 \%$ & $12.67 \%$ \\
\hline B2-93701-R1 & 93701 & $1 \mathrm{st}$ & $6 / 2 / 2015$ & 36.750 & -119.791 & 2.4 & 0.41 & 0.046 & $17 \%$ & $1.88 \%$ & $11.10 \%$ \\
\hline B2-93701-R2 & 93701 & $1 \mathrm{st}$ & $3 / 26 / 2015$ & 36.758 & -119.773 & 3.2 & 0.73 & 0.012 & $23 \%$ & $0.38 \%$ & $1.65 \%$ \\
\hline B2-93701-R3 & 93701 & $1 \mathrm{st}$ & $4 / 11 / 2015$ & 36.750 & -119.800 & 6.1 & 0.47 & 0.033 & $8 \%$ & $0.54 \%$ & $7.01 \%$ \\
\hline B2-93704-R1 & 93704 & $1 \mathrm{st}$ & $4 / 3 / 2015$ & 36.837 & -119.808 & 13.0 & 0.67 & 0.046 & $5 \%$ & $0.35 \%$ & $6.80 \%$ \\
\hline B2-93704-R2 & 93704 & $1 \mathrm{st}$ & $5 / 29 / 2015$ & 36.816 & -119.809 & 5.8 & 0.43 & 0.046 & $7 \%$ & $0.79 \%$ & $10.63 \%$ \\
\hline B2-93704-R3 & 93704 & $1 \mathrm{st}$ & $4 / 6 / 2015$ & 36.809 & -119.790 & 2.4 & 0.24 & 0.034 & $10 \%$ & $1.39 \%$ & $14.19 \%$ \\
\hline B2-93704-R4 & 93704 & $1 \mathrm{st}$ & $5 / 29 / 2015$ & 36.772 & -119.791 & 5.2 & 0.50 & 0.035 & $10 \%$ & $0.67 \%$ & $7.04 \%$ \\
\hline B2-93728-R1 & 93728 & $1 \mathrm{st}$ & $4 / 10 / 2015$ & 36.765 & -119.844 & 6.8 & NA & 0.035 & NA & $0.51 \%$ & NA \\
\hline B2-93728-R2 & 93728 & $1 \mathrm{st}$ & $6 / 3 / 2015$ & 36.765 & -119.818 & 3.3 & 0.51 & 0.037 & $15 \%$ & $1.12 \%$ & $7.32 \%$ \\
\hline B2-93728-R3 & 93728 & $1 \mathrm{st}$ & $4 / 9 / 2015$ & 36.758 & -119.801 & 12.8 & 0.78 & 0.024 & $6 \%$ & $0.19 \%$ & $3.06 \%$ \\
\hline B2-93701-R1 & 93701 & 2nd & $6 / 8 / 2015$ & 36.750 & -119.791 & 8.9 & 1.12 & 0.050 & $13 \%$ & $0.56 \%$ & $4.47 \%$ \\
\hline B2-93701-R2 & 93701 & 2nd & $6 / 8 / 2015$ & 36.758 & -119.773 & 15.0 & 1.10 & 0.055 & $7 \%$ & $0.37 \%$ & $5.02 \%$ \\
\hline B2-93701-R3 & 93701 & 2nd & $6 / 2 / 2015$ & 36.750 & -119.800 & 2.7 & 0.43 & 0.056 & $16 \%$ & $2.06 \%$ & $13.21 \%$ \\
\hline B2-93704-R1 & 93704 & 2nd & $6 / 5 / 2015$ & 36.837 & -119.808 & 3.7 & 0.41 & 0.074 & $11 \%$ & $2.02 \%$ & $18.09 \%$ \\
\hline B2-93704-R2 & 93704 & 2nd & $6 / 5 / 2015$ & 36.816 & -119.809 & 5.2 & 0.52 & 0.083 & $10 \%$ & $1.60 \%$ & $16.11 \%$ \\
\hline B2-93704-R3 & 93704 & 2nd & $6 / 7 / 2015$ & 36.809 & -119.790 & 5.8 & 0.60 & 0.036 & $10 \%$ & $0.62 \%$ & $6.07 \%$ \\
\hline B2-93704-R4 & 93704 & 2nd & 6/7/2015 & 36.772 & -119.791 & 6.9 & 0.40 & 0.051 & $6 \%$ & $0.75 \%$ & $12.79 \%$ \\
\hline B2-93728-R1 & 93728 & 2nd & $6 / 4 / 2015$ & 36.765 & -119.844 & 8.1 & 0.53 & 0.058 & $7 \%$ & $0.72 \%$ & $10.94 \%$ \\
\hline B2-93728-R2 & 93728 & 2nd & $6 / 4 / 2015$ & 36.765 & -119.818 & 4.6 & 0.45 & 0.064 & $10 \%$ & $1.41 \%$ & $14.31 \%$ \\
\hline
\end{tabular}




\begin{tabular}{|c|c|c|c|c|c|c|c|c|c|c|c|}
\hline ID & zip & $\mathrm{R}$ & Date & de & le & PM2.5 & $\mathrm{BC}$ & PAHs & $\begin{array}{c}\mathrm{BC} / \\
\mathrm{PM} 2.5\end{array}$ & $\begin{array}{l}\text { PAHs/ } \\
\text { PM2.5 }\end{array}$ & $\begin{array}{c}\text { PAHs/ } \\
\text { BC }\end{array}$ \\
\hline 2-93728-R3 & 3728 & 2nd & $6 / 3 / 2015$ & 36.758 & - & 3.3 & 0.43 & .041 & $13 \%$ & $.24 \%$ & $9.61 \%$ \\
\hline B3-93710-R1 & 3710 & $1 \mathrm{st}$ & $4 / 4 / 2016$ & .823 & 19.754 & 6.3 & 51 & 0.225 & $8 \%$ & $3.55 \%$ & $43.85 \%$ \\
\hline B3-93710-R2 & 93710 & $1 \mathrm{st}$ & $4 / 4 / 2016$ & 36.823 & 119.790 & 5.8 & 25 & 0.242 & $22 \%$ & $4.16 \%$ & $19.33 \%$ \\
\hline B3-93710-R3 & 93710 & $1 \mathrm{st}$ & $4 / 4 / 2016$ & 36.809 & -119.754 & 7.4 & .36 & 0.219 & $5 \%$ & $2.94 \%$ & $61.18 \%$ \\
\hline B3-93710-R4 & 93710 & $1 \mathrm{st}$ & $4 / 5 / 2016$ & 36.823 & 9.772 & 10.4 & 94 & 0.250 & $9 \%$ & $2.40 \%$ & $26.46 \%$ \\
\hline B3-93720-R1 & 93720 & $1 \mathrm{st}$ & $4 / 5 / 2016$ & 36.860 & -119.783 & 10.2 & 0.65 & 0.283 & $6 \%$ & $2.78 \%$ & $43.73 \%$ \\
\hline B3-93720-R2 & 93720 & $1 \mathrm{st}$ & $4 / 5 / 2016$ & 36.852 & .757 & 17.3 & 78 & .195 & $5 \%$ & $.13 \%$ & $24.85 \%$ \\
\hline B3-93720-R3 & 93720 & $1 \mathrm{st}$ & $4 / 6 / 2016$ & 36.852 & 791 & 24.9 & 07 & 0.189 & $4 \%$ & $0.76 \%$ & $17.62 \%$ \\
\hline B3-93728-R1 & 93728 & $1 \mathrm{st}$ & $4 / 7 / 2016$ & 36.757 & -119.836 & 64.9 & .66 & 0.206 & $4 \%$ & $0.32 \%$ & $7.74 \%$ \\
\hline B3-93728-R2 & 93728 & $1 \mathrm{st}$ & $4 / 7 / 2016$ & 36.765 & -119.809 & 46.0 & 68 & 0.192 & $4 \%$ & $0.42 \%$ & $11.42 \%$ \\
\hline B3-93728-R3 & 93728 & $1 \mathrm{st}$ & $4 / 7 / 2016$ & .758 & 91 & 32. & 45 & 0.100 & $4 \%$ & $31 \%$ & $6.93 \%$ \\
\hline B3-93730-R1 & 93730 & $1 \mathrm{st}$ & $4 / 6 / 2016$ & 36.881 & -119.739 & 17.8 & 51 & 0.206 & $3 \%$ & $1.15 \%$ & $40.68 \%$ \\
\hline B3-93730-R2 & 93730 & $1 \mathrm{st}$ & $4 / 6 / 2016$ & 36.896 & -119.756 & 13.3 & 68 & .138 & $5 \%$ & $1.03 \%$ & $20.30 \%$ \\
\hline B3-93730-R3 & 93730 & $1 \mathrm{st}$ & $4 / 15 / 2016$ & 36.896 & 747 & 3. & 1 & 0.172 & $6 \%$ & $5.00 \%$ & $83.33 \%$ \\
\hline B3-93710-R3 & 93710 & 2nd & $4 / 15 / 2016$ & 36.809 & -119.754 & 3.7 & 39 & 0.179 & $11 \%$ & $4.80 \%$ & $45.55 \%$ \\
\hline B4-93612-R1 & 93612 & $1 \mathrm{st}$ & \begin{tabular}{|c|}
$6 / 17 / 2016$ \\
\end{tabular} & 36.823 & .729 & 3.4 & 40 & .097 & $12 \%$ & $.85 \%$ & $24.36 \%$ \\
\hline B4-93612-R2 & 93612 & $1 \mathrm{st}$ & 6/17/2016 & 824 & -119.701 & 3.6 & 64 & 0.106 & $18 \%$ & $3.00 \%$ & $16.53 \%$ \\
\hline B4-93612-R3 & 93612 & $1 \mathrm{st}$ & 6/17/2016 & 36.794 & -119.727 & 3.9 & 79 & 0.109 & $20 \%$ & $2.78 \%$ & $13.79 \%$ \\
\hline B4-93727-R1 & 93727 & $1 \mathrm{st}$ & $5 / 2016$ & 36.737 & 682 & 7.2 & 9 & .097 & $3 \%$ & $1.36 \%$ & $52.57 \%$ \\
\hline B1-93702-R2 & 93702 & 4th & $5 / 26 / 2016$ & 36.736 & -119.771 & 7.8 & & 0.174 & $15 \%$ & $2.24 \%$ & $14.61 \%$ \\
\hline B1-93702-R2 & 93702 & 5 th & $5 / 27 / 2016$ & 36.736 & -119.771 & 10.6 & 0.94 & 0.148 & $9 \%$ & $1.40 \%$ & $15.80 \%$ \\
\hline B1-93702-R2 & 93702 & 6th & 16 & 36.736 & & 9.1 & & 109 & $14 \%$ & $19 \%$ & $8.43 \%$ \\
\hline B1-93702-R2 & 93702 & 7th & $6 / 2 / 2016$ & 36.736 & -119.771 & 12.4 & 8 & 0.061 & $8 \%$ & $0.49 \%$ & $6.18 \%$ \\
\hline B1-93702-R2 & 93702 & 8th & $6 / 3 / 2016$ & 36.736 & -119.771 & 12.3 & 11 & 0.221 & $9 \%$ & $1.79 \%$ & $19.95 \%$ \\
\hline B1-93 & 93702 & 9th & & & & & & 10 & $\%$ & $11 \%$ & $3.87 \%$ \\
\hline B4-93727-R1 & 93727 & $3 \mathrm{rd}$ & $5 / 26 / 2016$ & 36.737 & -119.682 & 7.1 & 6 & 0.153 & $4 \%$ & $2.15 \%$ & $58.06 \%$ \\
\hline B4-93727-R1 & 93727 & 4th & $5 / 27 / 2016$ & 36.737 & -119.682 & 13.5 & 31 & 0.171 & $2 \%$ & $1.27 \%$ & $55.56 \%$ \\
\hline B4-93727-R1 & 93727 & 5 th & $6 / 2 / 2016$ & 36.737 & 117.002 & (n) & & 0.105 & $2 \%$ & $1.60 \%$ & $82.61 \%$ \\
\hline B4-93727-R1 & 93727 & 6th & $6 / 2 / 2016$ & 36.737 & -119.682 & 13.3 & 0.34 & 0.211 & $3 \%$ & $1.59 \%$ & $61.68 \%$ \\
\hline B4-93727-R1 & 93727 & 7th & $6 / 3 / 2016$ & 36.737 & -119.682 & 19.0 & 64 & 0.131 & $3 \%$ & $0.69 \%$ & $20.54 \%$ \\
\hline B4-93727-R1 & 93727 & 8th & $6 / 3 / 2016$ & 36.737 & -119.682 & 23.0 & & 0.118 & $2 \%$ & $0.51 \%$ & $25.41 \%$ \\
\hline B4-93727-R3 & 93727 & $1 \mathrm{st}$ & $3 / 15 / 2016$ & 36.736 & -119.736 & 10.4 & 0.78 & 0.086 & $8 \%$ & $0.84 \%$ & $11.05 \%$ \\
\hline B4-93711-R1 & 93711 & $1 \mathrm{st}$ & 6/16/2016 & 36.823 & -119.835 & 7.3 & 1 & 0.141 & $14 \%$ & $1.92 \%$ & $13.93 \%$ \\
\hline B4-93711-R2 & 93711 & $1 \mathrm{st}$ & 6/16/2016 & 36.830 & -119.826 & 4.8 & & 0.134 & $12 \%$ & $.80 \%$ & $23.03 \%$ \\
\hline B4-93711-R3 & 93711 & $1 \mathrm{st}$ & $6 / 16 / 2016$ & 36.808 & -119.854 & 4.8 & 0.22 & 0.061 & $5 \%$ & $1.27 \%$ & $27.26 \%$ \\
\hline B5-93706-R1 & 93706 & 2nd & $5 / 30 / 2017$ & 36.727 & -119.97 & 8.4 & 1.9 & 0.078 & $23 \%$ & $0.93 \%$ & $4.08 \%$ \\
\hline B5-93706-R1 & 93706 & $1 \mathrm{st}$ & $5 / 26 / 2017$ & 36.727 & -119.97 & 8.64 & 0.8 & 0.081 & $10 \%$ & $0.94 \%$ & $9.81 \%$ \\
\hline B5-93706-R2 & 93706 & $1 \mathrm{st}$ & $3 / 10 / 2017$ & 36.728 & -119.8131 & 55.3 & 2.4 & 0.061 & $4 \%$ & $.11 \%$ & $2.53 \%$ \\
\hline B5-93706-R3 & 93706 & $1 \mathrm{st}$ & 5/30/2017 & 36.619 & -119.826 & 28.5 & 0.3 & 0.203 & $1 \%$ & $0.71 \%$ & $60.15 \%$ \\
\hline B5-93706-R4 & 93706 & $1 \mathrm{st}$ & $5 / 30 / 2017$ & 36.618 & -120.002 & 53.8 & 0.5 & 0.197 & $1 \%$ & $0.37 \%$ & $38.37 \%$ \\
\hline B5-93721-R1 & 93721 & $1 \mathrm{st}$ & $5 / 25 / 2017$ & 36.742 & -119.797 & 7.2 & 0.7 & $\mathrm{NA}$ & $10 \%$ & NA & NA \\
\hline B5-93721-R2 & 93721 & $1 \mathrm{st}$ & $5 / 27 / 2017$ & 36.47 & -119.5 & 19.5 & 0.1 & 0.195 & $0 \%$ & $1.00 \%$ & $344.08 \%$ \\
\hline B5-93721-R2 & 93721 & 2nd & $6 / 5 / 2017$ & 36.47 & -119.5 & 5.4 & 0.7 & NA & $13 \%$ & NA & NA \\
\hline B5-93721-R3 & 93721 & $1 \mathrm{st}$ & $5 / 26 / 2017$ & 36.724 & -119.776 & 7.1 & 0.8 & 0.112 & $12 \%$ & $1.58 \%$ & $13.15 \%$ \\
\hline B5-93721-R3 & 93721 & 2nd & $6 / 13 / 2017$ & 36.724 & -119.776 & 8.3 & 1.6 & 0.329 & $19 \%$ & $3.96 \%$ & $20.90 \%$ \\
\hline
\end{tabular}




\begin{tabular}{|c|c|c|c|c|c|c|c|c|c|c|c|}
\hline ID & zip & $\mathrm{R}$ & Date & de & de & $\mathrm{P}$ & $\mathrm{BC}$ & PAHs & \begin{tabular}{|c|}
$\mathrm{BC} /$ \\
$\mathrm{PM} 2.5$
\end{tabular} & $\begin{array}{l}\text { PAHs/ } \\
\text { PM2.5 }\end{array}$ & $\begin{array}{c}\text { PAHs/ } \\
\text { BC }\end{array}$ \\
\hline -93721-R3 & 3721 & $3 \mathrm{rd}$ & 7 & 36.724 & 76 & 8.9 & 0.9 & 0.166 & $10 \%$ & $1.86 \%$ & $18.90 \%$ \\
\hline B5-93721-R3 & 3721 & 4 th & $3 / 2017$ & .724 & 19.776 & 7.0 & 0.6 & 0.199 & $8 \%$ & $2.84 \%$ & $34.09 \%$ \\
\hline B5-93721-R4 & 93721 & $1 \mathrm{st}$ & /26/2017 & 36.728 & 119.787 & 5.5 & 0.6 & 0.079 & $11 \%$ & $1.44 \%$ & $13.66 \%$ \\
\hline B5-93650-R1 & 93650 & $1 \mathrm{st}$ & $3 / 18 / 2017$ & 36.844 & -119.79 & 23.0 & 1.1 & 0.057 & $5 \%$ & $0.25 \%$ & $5.32 \%$ \\
\hline B5-93650-R2 & 93650 & $3 \mathrm{rd}$ & 6/5/2017 & 36.8404 & -119.808 & 14.7 & 0.5 & 0.103 & $3 \%$ & $0.70 \%$ & $21.72 \%$ \\
\hline B5-93611-R1 & 93611 & $1 \mathrm{st}$ & $3 / 17 / 2017$ & 36.847 & -119.711 & 23.9 & 1.1 & 0.059 & $5 \%$ & $0.25 \%$ & $5.18 \%$ \\
\hline B5-93611-R2 & 93611 & $1 \mathrm{st}$ & $3 / 17 / 2017$ & 36.808 & -119.673 & 43.2 & 1.5 & .059 & $4 \%$ & $.14 \%$ & $3.89 \%$ \\
\hline B5-93611-R3 & 93611 & $1 \mathrm{st}$ & $3 / 17$ & 5.83 & 688 & 35.9 & .4 & 0.055 & $4 \%$ & $0.15 \%$ & $4.03 \%$ \\
\hline B5-93703-R1 & 93703 & $1 \mathrm{st}$ & $3 / 17 / 2017$ & 36.773 & -119.781 & 13.1 & 2.3 & 0.087 & $18 \%$ & $0.66 \%$ & $3.73 \%$ \\
\hline B5-93703-R2 & 93703 & $1 \mathrm{st}$ & $3 / 17 / 2017$ & 36.765 & -119.79 & 16.9 & 1.9 & 0.109 & $11 \%$ & $0.65 \%$ & $5.87 \%$ \\
\hline B5-93703-R3 & 93703 & $1 \mathrm{st}$ & $3 / 18$ & 36.757 & 19.763 & 30.0 & .0 & 0.139 & $13 \%$ & $0.46 \%$ & $3.48 \%$ \\
\hline B5-93703-R4 & 93703 & $1 \mathrm{st}$ & $3 / 18 / 2017$ & 36.772 & -119.745 & 23.5 & 1.6 & 0.168 & $7 \%$ & $0.71 \%$ & $10.32 \%$ \\
\hline B5-93705-R1 & 93705 & $1 \mathrm{st}$ & $5 / 25$ & 36.796 & -119.822 & 26.9 & 0.1 & 0.118 & $0 \%$ & $0.44 \%$ & $117.88 \%$ \\
\hline B5-93705-R2 & 93705 & $1 \mathrm{st}$ & $5 / 25 / 2017$ & 36.772 & -119.817 & 27. & 0.3 & 0.170 & $1 \%$ & $0.62 \%$ & $52.11 \%$ \\
\hline B5-93705-R3 & 93705 & $1 \mathrm{st}$ & $5 / 25 / 2017$ & 36.786 & -119.844 & 25.7 & 0.2 & 0.110 & $1 \%$ & $0.43 \%$ & $72.60 \%$ \\
\hline B5-93723-R1 & 93723 & $1 \mathrm{st}$ & $5 / 23 / 2017$ & 36.808 & -119.91 & 15.1 & 9 & .138 & $6 \%$ & $.91 \%$ & $15.88 \%$ \\
\hline B5-93723-R2 & 93723 & $1 \mathrm{st}$ & $5 / 23 / 2017$ & 36.779 & 19.934 & 23.3 & 1.4 & 0.176 & $6 \%$ & $0.76 \%$ & $12.95 \%$ \\
\hline B5-93723-R3 & 93723 & $1 \mathrm{st}$ & $5 / 25 / 2017$ & 36.8 & -119.988 & 8.9 & 3.7 & 0.092 & $41 \%$ & $1.04 \%$ & $2.50 \%$ \\
\hline B5-93725-R1 & 93725 & $1 \mathrm{st}$ & $5 / 23$ & .808 & 917 & 14.2 & 5 & 0.088 & $11 \%$ & $62 \%$ & $5.85 \%$ \\
\hline B5-93725-R2 & 93725 & $1 \mathrm{st}$ & $5 / 23 / 2017$ & 36.779 & -119.934 & 19.3 & 1.0 & 0.130 & $5 \%$ & $0.67 \%$ & $12.71 \%$ \\
\hline B5-93725-R3 & 93725 & $1 \mathrm{st}$ & $5 / 23 / 2017$ & 36.764 & -119.934 & 39.8 & 1.3 & 0.154 & $3 \%$ & $0.39 \%$ & $12.14 \%$ \\
\hline B5-93740-R1 & 93740 & $1 \mathrm{st}$ & $3 / 18$ & 36.815 & 9.73 & 28. & ${ }^{\circ}$ & 0.140 & $5 \%$ & $0.49 \%$ & $9.33 \%$ \\
\hline B6-93706-R34 & 93706 & $1 \mathrm{st}$ & $5 / 26 / 2017$ & 36.729 & -119.809 & 17.4 & 0.3 & 0.119 & $2 \%$ & $0.68 \%$ & $34.48 \%$ \\
\hline B6-93706-R34 & 93706 & 2nd & 6/8/2017 & 36.729 & -119.809 & 6.0 & 0.6 & 0.050 & $10 \%$ & $0.83 \%$ & $8.57 \%$ \\
\hline B6-93706-R34 & 93706 & 3rd & $6 / 8 / 2$ & 36.729 & -1 & 6.5 & .4 & 0.062 & $37 \%$ & $0.95 \%$ & $2.55 \%$ \\
\hline B6-93706-R34 & 93706 & 4 th & 6/8/2017 & 36.729 & -119.809 & 6.0 & 0.6 & 0.063 & $10 \%$ & $1.05 \%$ & $10.82 \%$ \\
\hline B6-93706-R34 & 93706 & 5 th & 6/15/2017 & 36.729 & -119.809 & 7.6 & .9 & 0.092 & $12 \%$ & $1.22 \%$ & $10.04 \%$ \\
\hline B6-93706-R34 & 93706 & 6th & $6 / 15 / 2017$ & 36.729 & -119.809 & 9.0 & 0.9 & 0.151 & $9 \%$ & $1.67 \%$ & $17.72 \%$ \\
\hline B6-93706-R34 & 93706 & 7 th & $6 / 15 / 2017$ & 36.729 & -119.809 & 7.7 & 0.7 & 0.120 & $9 \%$ & $1.55 \%$ & $16.81 \%$ \\
\hline B6-93706-R35 & 93706 & $1 \mathrm{st}$ & $5 / 26 / 2017$ & 36.726 & -119.8 & 16.8 & 0.3 & 0.091 & $2 \%$ & $0.54 \%$ & $26.49 \%$ \\
\hline B6-93706-R36 & 93706 & $1 \mathrm{st}$ & 6/5/2017 & 36.704 & -119.808 & 7.2 & 0.8 & 0.060 & $11 \%$ & $0.84 \%$ & $7.63 \%$ \\
\hline B6-93706-R37 & 93706 & $1 \mathrm{st}$ & $5 / 26 / 2017$ & 36.692 & -119.801 & 20.0 & 0.5 & 0.128 & $3 \%$ & $0.64 \%$ & $25.34 \%$ \\
\hline B6-93706-R38 & 93706 & $1 \mathrm{st}$ & $5 / 31 / 2017$ & 36.71 & -119.79 & 4.9 & 0.3 & 0.074 & $6 \%$ & $1.52 \%$ & $25.73 \%$ \\
\hline B6-93706-R39 & 93706 & $1 \mathrm{st}$ & $5 / 31 / 2017$ & 36.731 & -119.844 & 5.2 & 0.3 & 0.033 & $6 \%$ & $0.63 \%$ & $10.01 \%$ \\
\hline B6-93702-R40 & 93702 & $1 \mathrm{st}$ & $5 / 30 / 2017$ & 36.732 & -119.751 & 7.1 & 0.3 & 0.108 & $4 \%$ & $1.52 \%$ & $36.64 \%$ \\
\hline B6-93702-R41 & 93702 & $1 \mathrm{st}$ & $5 / 31 / 2017$ & 36.75 & -119.746 & 14.2 & 0.4 & 0.105 & $3 \%$ & $0.74 \%$ & $26.66 \%$ \\
\hline B6-93727-R42 & 93727 & $1 \mathrm{st}$ & $5 / 31 / 2017$ & 36.757 & -119.704 & 13.6 & 0.3 & 0.116 & $2 \%$ & $0.85 \%$ & $44.69 \%$ \\
\hline B6-93612-R43 & 93612 & $1 \mathrm{st}$ & 6/2/2017 & 36.804 & -119.727 & 3.8 & .5 & 0.059 & $14 \%$ & $1.56 \%$ & $11.38 \%$ \\
\hline B6-93612-R43 & 93612 & 2nd & 6/7/2017 & 36.804 & -119.727 & 6.9 & 0.7 & 0.046 & $11 \%$ & $0.66 \%$ & $6.27 \%$ \\
\hline B6-93612-R43 & 93612 & $3 \mathrm{rd}$ & 6/7/2017 & 36.804 & -119.727 & 6.9 & 0.6 & 0.057 & $8 \%$ & $0.83 \%$ & $9.75 \%$ \\
\hline B6-93612-R43 & 93612 & 4th & 6/7/2017 & 36.804 & -119.727 & 6.7 & 0.6 & 0.080 & $9 \%$ & $1.18 \%$ & $12.77 \%$ \\
\hline B6-93612-R43 & 93612 & 5 th & $6 / 7 / 2017$ & 36.804 & -119.727 & 7.4 & 0.7 & 0.059 & $10 \%$ & $0.79 \%$ & $8.31 \%$ \\
\hline B6-93612-R43 & 93612 & 6th & 6/7/2017 & 36.804 & -119.727 & 7.8 & 0.7 & 0.074 & $10 \%$ & $0.95 \%$ & $9.97 \%$ \\
\hline B6-93703-R44 & 93703 & 1 st & $5 / 31 / 2017$ & 36.772 & -119.736 & 13.4 & 0.4 & 0.086 & $3 \%$ & $0.64 \%$ & $23.06 \%$ \\
\hline B6-93703-R44 & 93703 & 2nd & $6 / 7 / 2017$ & 36.772 & -119.736 & 17.0 & 0.7 & 0.073 & $4 \%$ & $0.43 \%$ & $10.80 \%$ \\
\hline
\end{tabular}




\begin{tabular}{|c|c|c|c|c|c|c|c|c|c|c|c|}
\hline ID & zip & Repeat & Date & Latitude & tude & PM2.5 & $\mathrm{BC}$ & PAHs & \begin{tabular}{|c|} 
BC/ \\
PM2.5
\end{tabular} & $\begin{array}{l}\text { PAHs/ } \\
\text { PM2.5 }\end{array}$ & $\begin{array}{c}\text { PAHs/ } \\
\text { BC }\end{array}$ \\
\hline$-93703-\mathrm{R} 44$ & 93703 & $3 \mathrm{rd}$ & 6/7/2017 & 36.772 & 19.736 & 19. & 1.3 & .103 & $7 \%$ & $0.53 \%$ & $7.95 \%$ \\
\hline B6-93703-R44 & 93703 & 4 th & $6 / 7 / 2$ & .772 & & & .9 & 083 & $4 \%$ & $37 \%$ & $8.91 \%$ \\
\hline B6-93703-R44 & 93703 & 5 th & 6/7/2017 & .772 & 9.736 & 14.4 & .6 & 0.108 & $4 \%$ & $.75 \%$ & $18.59 \%$ \\
\hline B6-93703-R44 & 93703 & 6th & 6/7/2017 & 36.772 & 19.736 & 2 & 0.9 & 0.144 & $3 \%$ & $53 \%$ & $16.50 \%$ \\
\hline B6-93704-R45 & 93704 & $1 \mathrm{st}$ & $5 / 31 / 2017$ & .768 & .809 & 5.2 & .3 & .073 & $6 \%$ & $40 \%$ & $23.82 \%$ \\
\hline B6-93704-R45 & 93704 & 2nd & $6 / 13 / 2017$ & 768 & 99 & 28. & .4 & 0.097 & $1 \%$ & $34 \%$ & $27.41 \%$ \\
\hline B6-93704-R45 & 93704 & $3 \mathrm{rd}$ & $6 / 13 / 2017$ & 36.768 & -119.809 & 27.7 & 0.3 & 0.114 & $1 \%$ & $0.41 \%$ & $41.07 \%$ \\
\hline B6-93704-R45 & 93704 & 4th & $6 / 13 / 2017$ & 36.768 & -119.809 & 27. & 0.5 & 0.143 & $2 \%$ & $0.52 \%$ & $30.91 \%$ \\
\hline B6-93722-R46 & 93722 & 1 st & 7 & 764 & 89 & & 8 & .049 & $5 \%$ & $30 \%$ & $5.99 \%$ \\
\hline B6-93722-R47 & 93722 & $1 \mathrm{st}$ & 6/1/2017 & 36.779 & -119.857 & 15.9 & 0.4 & 0.080 & $3 \%$ & $0.50 \%$ & $19.78 \%$ \\
\hline B6-93722-R48 & 93722 & $1 \mathrm{st}$ & 6/1/2017 & 36.801 & -119.853 & 13.1 & NA & 0.062 & NA & $0.47 \%$ & NA \\
\hline B6-93722-R48 & 93722 & 2nd & 6/8/2017 & 36.801 & -119.853 & & 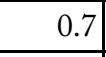 & 0.067 & $2 \%$ & $0.24 \%$ & $9.75 \%$ \\
\hline B6-93722-R48 & 93722 & 3rd & 6/8/2017 & 36.801 & -119.853 & 25.2 & 0.4 & 0.068 & $2 \%$ & $0.27 \%$ & $15.25 \%$ \\
\hline B6-93722-R48 & 93722 & 4 th & 6/8/2017 & 36.801 & -119.853 & 23.2 & 0.4 & 0.071 & $2 \%$ & $0.31 \%$ & $19.65 \%$ \\
\hline B6-93722-R48 & 93722 & 5 th & $6 / 15 / 2017$ & 36.801 & -119.853 & & 0.0 & 0.130 & $3 \%$ & $0.45 \%$ & $15.63 \%$ \\
\hline B6-93722-R48 & 93722 & 6th & $6 / 15 / 2017$ & 36.801 & -119.853 & 28 & 0.7 & 0.126 & $2 \%$ & $0.45 \%$ & $18.81 \%$ \\
\hline B6-93722-R48 & 93722 & 7th & $6 / 15 / 2017$ & 36.801 & -119.853 & 27.8 & 0.7 & 0.131 & $2 \%$ & $0.47 \%$ & $18.95 \%$ \\
\hline B6-93722-R48 & 93722 & 8th & $6 / 15 / 2017$ & 36.801 & -119.853 & 27.0 & 0.1 & 0.116 & $2 \%$ & $0.42 \%$ & $17.58 \%$ \\
\hline B6-93722-R49 & 93722 & $1 \mathrm{st}$ & 6/1/2017 & 36.826 & -119.883 & 5.2 & 0.4 & 0.117 & $7 \%$ & $2.23 \%$ & $31.74 \%$ \\
\hline B6-93711-R50 & 93711 & $1 \mathrm{st}$ & $6 / 1 / 2017$ & 36.837 & -119.846 & 3.9 & .2 & 0.069 & $5 \%$ & $1.76 \%$ & $38.41 \%$ \\
\hline B6-93650-R51 & 93650 & 1 st & 6/1/2017 & 36.846 & -119.79 & 3.8 & 0.2 & 0.149 & $5 \%$ & $3.87 \%$ & $77.56 \%$ \\
\hline B6-93705-R52 & 93705 & $1 \mathrm{st}$ & $6 / 5 / 2017$ & 36.798 & -119.8353 & 13.9 & 0.3 & 0.094 & $2 \%$ & $0.68 \%$ & $29.71 \%$ \\
\hline B6-93705-R53 & 93705 & $1 \mathrm{st}$ & $6 / 2 / 2017$ & 36.786 & -119.79 & 5.2 & 0.5 & 0.054 & $10 \%$ & $1.03 \%$ & $10.27 \%$ \\
\hline B6-93726-R54 & 93726 & $1 \mathrm{st}$ & $6 / 2 / 2017$ & 36.806 & -119.772 & 13.7 & 0.4 & 0.119 & $3 \%$ & $0.87 \%$ & $28.90 \%$ \\
\hline B6-93710-R55 & 93710 & $1 \mathrm{st}$ & $6 / 2 / 2017$ & 36.815 & -119.766 & 13.6 & 0.4 & 0.106 & $3 \%$ & $0.78 \%$ & $25.14 \%$ \\
\hline B6-93612-R56 & 93612 & $1 \mathrm{st}$ & $6 / 2 / 2017$ & 36.859 & -119.697 & 12.8 & 0.5 & 0.090 & $4 \%$ & $0.70 \%$ & $17.26 \%$ \\
\hline
\end{tabular}


Table A-2 Correlation Coefficients and p-values

\begin{tabular}{|c|c|c|c|c|c|c|c|c|c|c|c|c|c|}
\hline & $\begin{array}{c}\text { Black } \\
\text { Carbon }\end{array}$ & $\begin{array}{c}\mathrm{PM} 2 . \\
5\end{array}$ & $\begin{array}{c}\mathrm{BC} / \\
\mathrm{PM} 2 . \\
5\end{array}$ & Traffic & $\begin{array}{c}\text { Diesel.P } \\
\text { M } \\
\text { Emission }\end{array}$ & $\begin{array}{c}\text { Walk } \\
\cdot \cdot \\
\text { score }\end{array}$ & $\begin{array}{c}\text { CES. } \\
\text { Pollution } \\
\dot{ } \\
\text { Burden. } \\
\text { Score } \\
\end{array}$ & $\begin{array}{c}\text { CES. } \\
\text { Population. } \\
\text { Characteristic } \\
s \\
\text {.Score } \\
\end{array}$ & $\begin{array}{l}\text { CES. } \\
\text { Total. } \\
\text { Score }\end{array}$ & $\begin{array}{c}\text { Disorde } \\
\mathrm{r}\end{array}$ & $\begin{array}{c}\text { Orde } \\
\mathrm{r}\end{array}$ & $\begin{array}{c}\text { Asthm } \\
\text { a }\end{array}$ & $\begin{array}{c}\text { Low.Birth.Weig } \\
\text { ht }\end{array}$ \\
\hline Black Carbon & 1 & & & & & & & & & & & & \\
\hline $\mathrm{P}$-value & $\mathrm{NA}$ & & & & & & & & & & & & \\
\hline PM2.5 & 0.49 & 1 & & & & & & & & & & & \\
\hline $\mathrm{P}$-value & 0.041 & $\mathrm{NA}$ & & & & & & & & & & & \\
\hline BC/PM2.5 & 0.41 & -0.53 & 1 & & & & & & & & & & \\
\hline $\mathrm{P}$-value & 0.09 & 0.024 & $\mathrm{NA}$ & & & & & & & & & & \\
\hline Traffic & -0.26 & -0.34 & 0.18 & 1 & & & & & & & & & \\
\hline $\mathrm{P}$-value & 0.30 & 0.16 & 0.47 & NA & & & & & & & & & \\
\hline $\begin{array}{l}\text { Diesel.PM. } \\
\text { Emission }\end{array}$ & -0.17 & -0.22 & 0.14 & $\begin{array}{l}0.87 \\
0.00000\end{array}$ & 1 & & & & & & & & \\
\hline P-value & 0.51 & 0.38 & 0.59 & 3 & $\mathrm{NA}$ & & & & & & & & \\
\hline Walk.score & -0.13 & -0.51 & 0.56 & 0.73 & 0.87 & 1 & & & & & & & \\
\hline $\mathrm{P}$-value & 0.64 & 0.044 & 0.025 & 0.00124 & 0.00001 & $\mathrm{NA}$ & & & & & & & \\
\hline $\begin{array}{l}\text { CES.Pollution. } \\
\text { Burden.Score }\end{array}$ & -0.17 & -0.14 & -0.07 & 0.06 & -0.10 & -0.30 & 1 & & & & & & \\
\hline $\mathrm{P}$-value & 0.50 & 0.58 & 0.78 & 0.82 & 0.68 & 0.25 & NA & & & & & & \\
\hline $\begin{array}{l}\text { CES.Population. } \\
\text { Characteristics. } \\
\text { Score }\end{array}$ & -0.03 & -0.10 & 0.06 & 0.46 & 0.59 & 0.39 & 0.35 & 1 & & & & & \\
\hline P-value & 0.92 & 0.69 & 0.83 & 0.055 & 0.010 & 0.13 & 0.15 & $\mathrm{NA}$ & & & & & \\
\hline CES.Total.Score & -0.07 & -0.12 & 0.00 & 0.31 & 0.34 & 0.11 & 0.75 & 0.88 & 1 & & & & \\
\hline P-value & 0.79 & 0.64 & 0.99 & 0.22 & 0.17 & 0.69 & 0.00036 & 0.000001 & $\mathrm{NA}$ & & & & \\
\hline Disorder & 0.07 & 0.20 & -0.04 & 0.45 & 0.59 & 0.34 & -0.32 & 0.40 & 0.11 & 1 & & & \\
\hline $\mathrm{P}$-value & 0.78 & 0.43 & 0.88 & 0.063 & 0.010 & 0.20 & 0.19 & 0.10 & 0.65 & $\mathrm{NA}$ & & & \\
\hline Order & -0.37 & -0.43 & 0.21 & 0.45 & 0.32 & $\begin{array}{l}0.53 \\
0.03\end{array}$ & -0.27 & -0.13 & -0.26 & 0.26 & 1 & & \\
\hline $\mathrm{P}$-value & 0.13 & 0.08 & 0.41 & 0.060 & 0.19 & 6 & 0.27 & 0.60 & 0.29 & 0.30 & NA & & \\
\hline Asthma & 0.02 & -0.11 & 0.14 & 0.44 & 0.67 & $\begin{array}{l}0.56 \\
0.02\end{array}$ & 0.24 & 0.92 & $\begin{array}{l}0.78 \\
0.0001\end{array}$ & 0.43 & -0.10 & 1 & \\
\hline $\mathrm{P}$-value & 0.93 & 0.66 & 0.59 & 0.07 & 0.0024 & 4 & 0.34 & 0.00000 & 4 & 0.08 & 0.70 & NA & \\
\hline $\begin{array}{l}\text { Low.Birth.Weig } \\
\text { ht }\end{array}$ & -0.09 & -0.16 & 0.12 & 0.62 & 0.65 & $\begin{array}{l}0.49 \\
0.05\end{array}$ & 0.31 & 0.77 & $\begin{array}{l}0.69 \\
0.0014\end{array}$ & 0.24 & 0.23 & 0.79 & 1 \\
\hline $\mathrm{P}$-value & 0.72 & 0.52 & 0.65 & 0.0061 & 0.0033 & 3 & 0.21 & 0.00017 & 8 & 0.35 & 0.36 & 0.0001 & NA \\
\hline
\end{tabular}


Figure A-1. Collocation Measurement near Clovis monitoring station
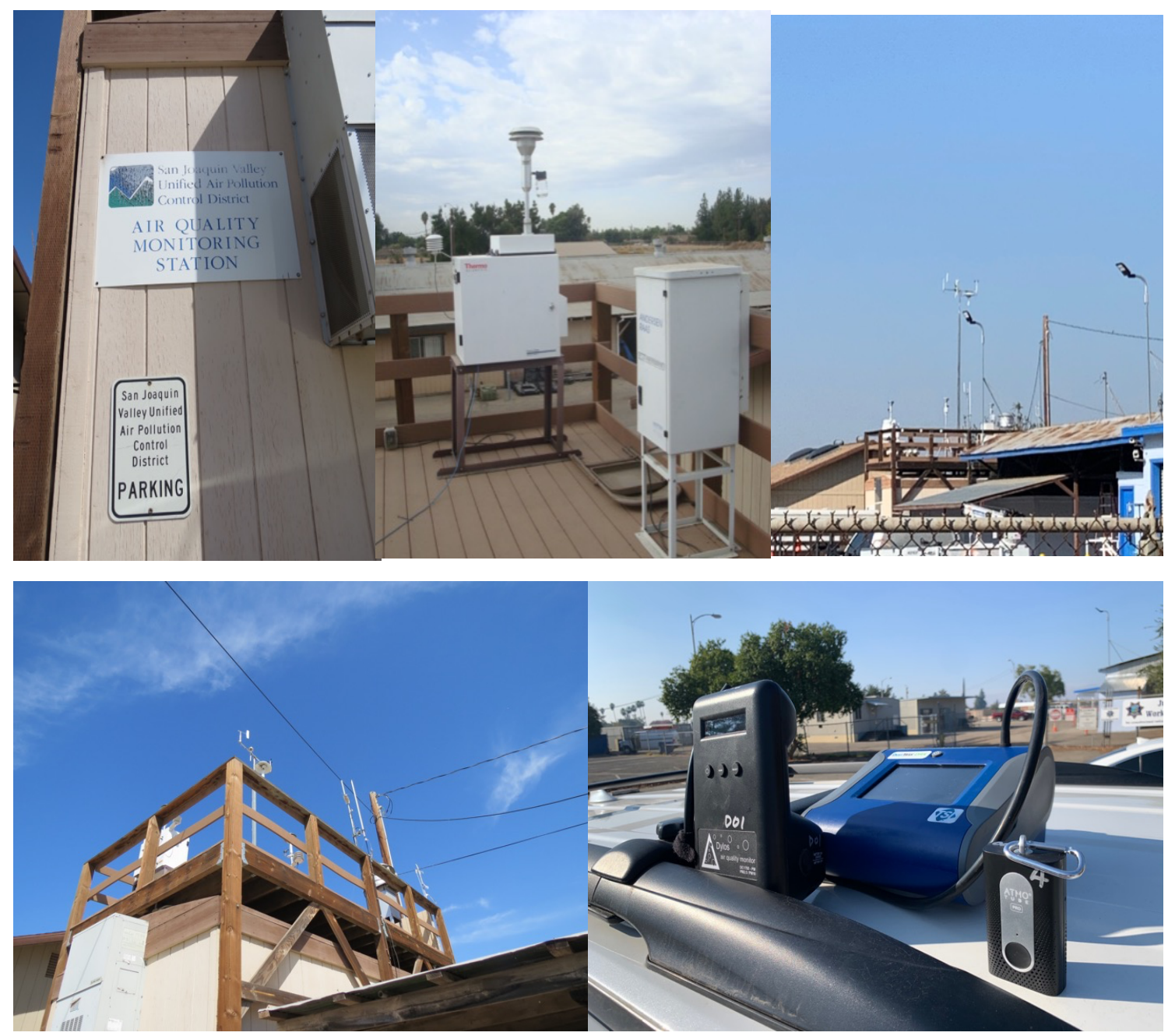

Figure A-2. Mobile Test Near Clovis Monitoring Station

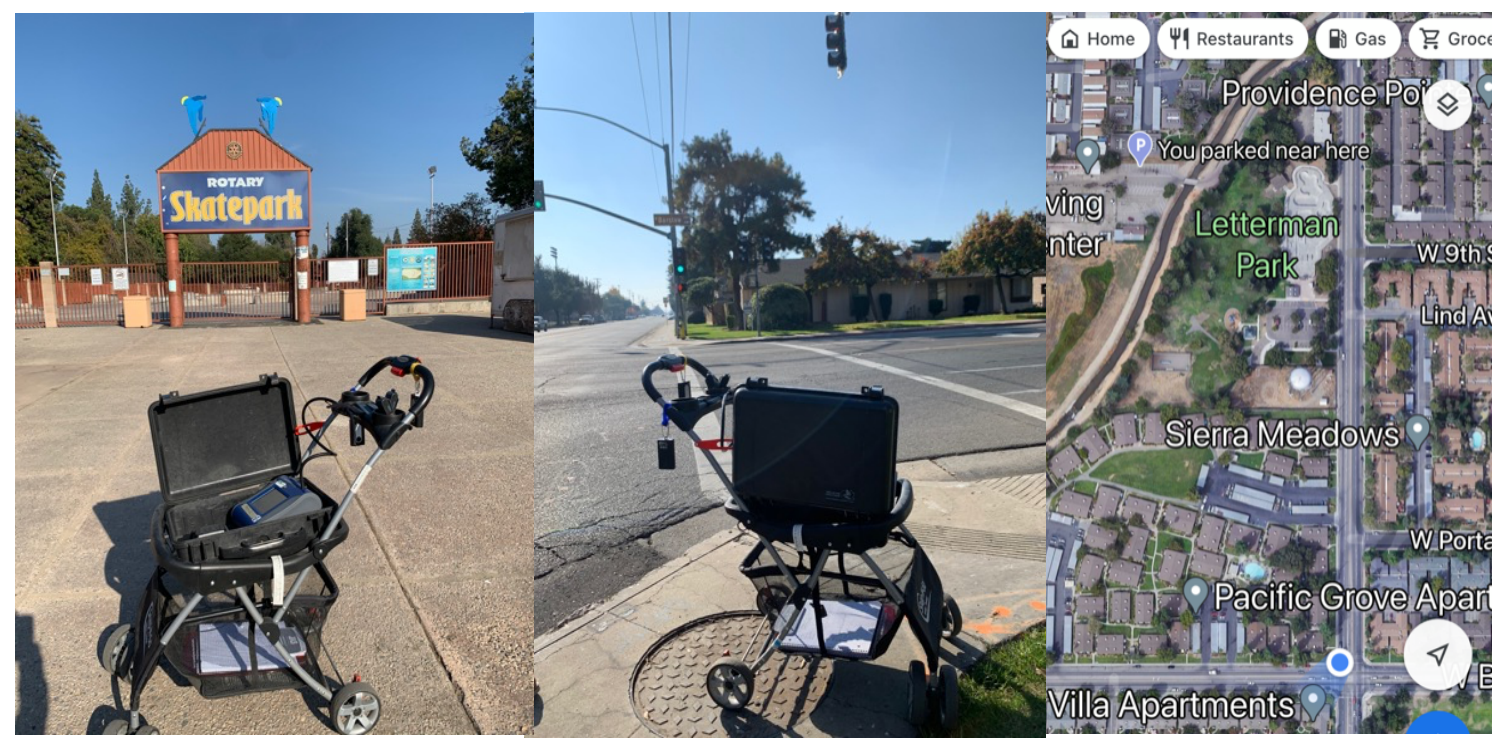




\section{Bibliography}

Alcala, E., Brown, P., Capitman, J. A., Gonzalez, M., \& Cisneros, R. (27 July 2019). Cumulative Impact of Environmental Pollution and Population Vulnerability on Pediatric Asthma Hospitalizations: A Multilevel Analysis of CalEnviroScreen. Int J Environ Res Public Health. 16(15), 2683. doi: 10.3390/ijerph16152683. PMID: 31357578; PMCID: PMC6696276.

American Lung Association. (2021). Most Polluted Cities: State of the Air. American Lung Association. https://www.stateoftheair.org/city-rankings/most-polluted-cities.html.

Baldauf, R., Watkins, N., Heist, D., Bailey, C., Rowley, P., \& Shores, R. (12 March 2009). Near-road air quality monitoring: Factors affecting network design and interpretation of data. Air Quality, Atmosphere \& Health. https://link.springer.com/article/10.1007/s11869009-0028-0\#citeas.

Bessagnet, B., \& Allemand, N. (December 2020). Review on Black Carbon (BC) and Polycyclic Aromatic Hydrocarbons (PAHs) emission reductions induced by PM emission abatement techniques. unece.org, https://unece.org/sites/default/files/202012/Review\%20on\%20BC\%20and\%20PAH\%20emission\%20reductions\%20.pdf.

City of Fresno. (22 July 2014). Transportation and Traffic. Fresno.Gov. https://www.fresno.gov/darm/wp-content/uploads/sites/10/2016/11/Sec-05-14Transportation-MEIR.pdf.

EPA. (6 March 2019). EPA activities for cleaner air. https://www.epa.gov/sanjoaquinvalley/epaactivities-cleaner-air.

Noth, E. M., Hammond, S. K., Biging, G. S., \& Tager, I. B. (2011). A spatial-temporal regression model to predict daily outdoor residential PAH concentrations in an epidemiologic study in Fresno, CA. Atmospheric Environment (1994), 45(14), 2394-2403. https://doi.org/10.1016/j.atmosenv.2011.02.014

Padula, A. M., Huang, H., Baer, R. J., August, L. M., Jankowska, M. M., Jellife-Pawlowski, L. L., Sirota, M., \& Woodruff, T. J. (2018). Environmental pollution and social factors as contributors to preterm birth in Fresno County. Environmental Healtb: A Global Access Science Source, 17(1), 70. https://doi.org/10.1186/s12940-018-0414-x 
Weber, K. A., Yang, W., Lurmann, F., Hammond, S. K., Shaw, G. M., \& Padula, A. M. (2019). Air Pollution, Maternal Hypertensive Disorders, and Preterm Birth.

Environmental epidemiology (Philadelphia, Pa.), 3(5), e062.

https://doi.org/10.1097/ee9.0000000000000062 


\section{About the Authors}

\section{Jaymin Kwon}

Dr. Jaymin Kwon is an associate professor in the Department of Public Health and Environmental/Occupational Health and Safety option coordinator. He obtained his B.S. and M.S. in Food Engineering and Biotechnology at Yonsei University, Korea and M.S. and Ph.D. in Environmental Sciences at Rutgers University. He joined Fresno State in 2011. His research focuses on the epidemiological human exposure assessment to traffic emissions and adverse health effects, the development of sensors for air pollution monitoring, and the impact of traffic emission in under-represented microenvironments. His previous research assesses the exposure to trafficemitted air pollutants on the different populations in Fresno, depending on their mode of transportation and the built environment of their community. His work characterizes the concentration of air pollutants, including particulate matters, polycyclic aromatic hydrocarbons, black carbon, and nitrous oxides near roadways and various commuting activities and microenvironments.

\section{Yushin Ahn}

Yushin Ahn is an assistant professor of the Department of Civil and Geomatics Engineering, California State University at Fresno, CA. He received a B. Eng. Degree in civil engineering and a M.S. degree in surveying and digital photogrammetry from Inha University, Korea in 1998 and 2000, and the M.S. and Ph.D. degree in geodetic science from the Ohio State University, Columbus, in 2005 and 2008 respectively.

His research interests include digital photogrammetry, feature tracking, and sensor calibration and integration. Dr. Ahn received the Robert E. Altenhofen Memorial Scholarship from the American Society of Photogrammetry and Remote Sensing. He has been a certified Photogrammetrist since 2014.

\section{Steve Chung}

Dr. Steve Chung is an associate professor in the Department of Mathematics at California State University, Fresno. He received his BS in Applied Mathematics at CalPoly Pomona and Ph.D. in Statistics from Florida State University. His research focuses on time series analysis and applied statistics. 
Founder, Honorable

Norman Mineta*

Secretary (ret.),

US Department of Transportation

Chair,

Will Kempton

Retired Transportation Executive

Vice Chair,

Jeff Morales

Managing Principal

InfraStrategies, LLC

Executive Director,

Karen Philbrick, PhD*

Mineta Transportation Institute

San José State University

Winsome Bowen

Vice President, Project Development

Strategy

WSP

David Castagnetti

Co-Founder

Mehlman Castagnetti Rosen \&

Thomas

Maria Cino

Vice President, America \& U.S.

Government Relations

Hewlett-Packard Enterprise

Grace Crunican**

Owner

Crunican LLC

Donna DeMartino

Managing Director

Los Angeles-San Diego-San Luis

Obispo Rail Corridor Agency
John Flaherty

Senior Fellow

Silicon Valley American Leadership

Forum

William Flynn *

President \& CEO

Amtrak

Rose Guilbault

Board Member

Peninsula Corridor Joint Power

Board

Ian Jefferies*

President \& CEO

Association of American Railroads

Diane Woodend Jones

Principal \& Chair of Board

Lea \& Elliott, Inc.

David S. Kim*

Secretary

California State Transportation

Agency (CALSTA)

Therese McMillan

Executive Director

Metropolitan Transportation

Commission (MTC)

Abbas Mohaddes

President \& COO

Econolite Group Inc.

Stephen Morrissey

Vice President - Regulatory and

Policy

United Airlines
Dan Moshavi, $\mathrm{PhD}^{*}$

Dean

Lucas College and GraduateSchool

of Business, San José State

University

Toks Omishakin*

Director

California Department of

Transportation (Caltrans)

Takayoshi Oshima

Chairman \& CEO

Allied Telesis, Inc.

Greg Regan

President

Transportation Trades Department, AFL-CIO

Paul Skoutelas*

President \& CEO

American Public Transportation

Association (APTA)

Kimberly Slaughter

CEO

Systra USA

Beverley Swaim-Staley

President

Union Station Redevelopment

Corporation

Jim Tymon*

Executive Director

American Association of State

Highway and Transportation

Officials (AASHTO)

$*$ Ex-Officio

** = Past Chair, Board of Trustees

\section{Directors}

Karen Philbrick, PhD

Executive Director

Hilary Nixon, PhD

Deputy Executive Director

Asha Weinstein Agrawal, PhD

Education Director

National Transportation Finance Center Director

Brian Michael Jenkins National Transportation Security Center Director

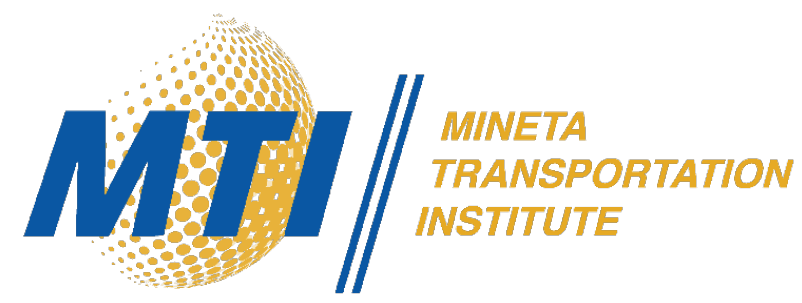

